\title{
Pharmacological interventions for promoting smoking cessation during pregnancy (Review)
}

Coleman T, Chamberlain C, Davey MA, Cooper SE, Leonardi-Bee J

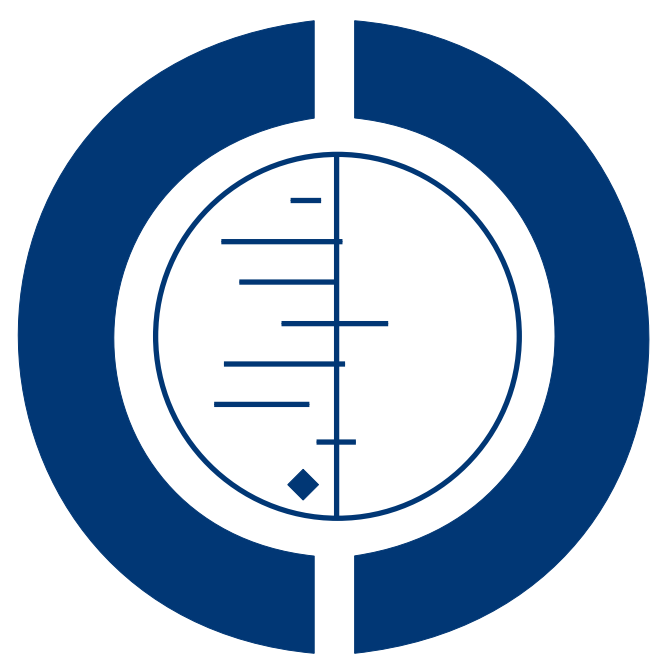

\section{THE COCHRANE COLLABORATION $^{\circledR}$}

This is a reprint of a Cochrane review, prepared and maintained by The Cochrane Collaboration and published in The Cochrane Library 2015, Issue 12

http://www.thecochranelibrary.com

\section{WILEY}

Pharmacological interventions for promoting smoking cessation during pregnancy (Review)

Copyright $\odot 2015$ The Cochrane Collaboration. Published by John Wiley \& Sons, Ltd. 
TABLE OF CONTENTS

HEADER

ABSTRACT

PLAIN LANGUAGE SUMMARY

BACKGROUND

OBJECTIVES

METHODS

RESULTS

Figure 1

Figure 2.

AUTHORS' CONCLUSIONS

ACKNOWLEDGEMENTS

REFERENCES

CHARACTERISTICS OF STUDIES

DATA AND ANALYSES

Analysis 1.1. Comparison 1 Nicotine replacement therapy versus control (Primary outcome - efficacy), Outcome 1 Validated cessation in later pregnancy.

Analysis 1.2. Comparison 1 Nicotine replacement therapy versus control (Primary outcome - efficacy), Outcome 2 Selfreport cessation at 3 or 6 months after childbirth.

Analysis 1.3. Comparison 1 Nicotine replacement therapy versus control (Primary outcome - efficacy), Outcome 3 Selfreport cessation at 12 months after childbirth.

Analysis 2.1. Comparison 2 Nicotine replacement therapy versus control (Secondary outcomes - safety), Outcome 1 Miscarriage and spontaneous abortion.

Analysis 2.2. Comparison 2 Nicotine replacement therapy versus control (Secondary outcomes - safety), Outcome 2 Stillbirth.

Analysis 2.3. Comparison 2 Nicotine replacement therapy versus control (Secondary outcomes - safety), Outcome 3 Mean birthweight $(\mathrm{g})$.

Analysis 2.4. Comparison 2 Nicotine replacement therapy versus control (Secondary outcomes - safety), Outcome 4 Low birthweight $(<2500 \mathrm{~g})$.

Analysis 2.5. Comparison 2 Nicotine replacement therapy versus control (Secondary outcomes - safety), Outcome 5 Preterm birth (birth < 37 weeks).

Analysis 2.6. Comparison 2 Nicotine replacement therapy versus control (Secondary outcomes - safety), Outcome 6 Neonatal intensive care unit admissions.

Analysis 2.7. Comparison 2 Nicotine replacement therapy versus control (Secondary outcomes - safety), Outcome 7 Neonatal death.

Analysis 2.8. Comparison 2 Nicotine replacement therapy versus control (Secondary outcomes - safety), Outcome 8 Congenital abnormalities.

Analysis 2.9. Comparison 2 Nicotine replacement therapy versus control (Secondary outcomes - safety), Outcome 9 Caesarean section.

ADDITIONAL TABLES . . . . . . . . . . . . . . . . . . . . . . . . . . . . . . . . . . . 57

WHAT'S NEW . . . . . . . . . . . . . . . . . . . . . . . . . . . . . . . . . . . . . . . . 59

CONTRIBUTIONS OF AUTHORS . . . . . . . . . . . . . . . . . . . . . . . . . . . . . . . . . . 60

DECLARATIONS OF INTEREST . . . . . . . . . . . . . . . . . . . . . . . . . . . . . . . . . . . . 60

SOURCES OF SUPPORT . . . . . . . . . . . . . . . . . . . . . . . . . . . . . . . . . . . . . . . . . . . . . 60

DIFFERENCES BETWEEN PROTOCOL AND REVIEW . . . . . . . . . . . . . . . . . . . . . . . . . . . . 61

INDEX TERMS . . . . . . . . . . . . . . . . . . . . . . . . . . . . . . . . . . . . . 62

Pharmacological interventions for promoting smoking cessation during pregnancy (Review)

Copyright $\odot 2015$ The Cochrane Collaboration. Published by John Wiley \& Sons, Ltd. 


\title{
[Intervention Review] \\ Pharmacological interventions for promoting smoking cessation during pregnancy
}

\author{
Tim Coleman $^{1}$, Catherine Chamberlain ${ }^{2}$, Mary-Ann Davey $^{3}$, Sue E Cooper ${ }^{1}$, Jo Leonardi-Bee ${ }^{4}$ \\ ${ }^{1}$ Division of Primary Care, University of Nottingham, Nottingham, UK. ${ }^{2}$ Indigenous Health Equity Unit, Centre for Health Equity, \\ Melbourne School of Population and Global Health, University of Melbourne, Melbourne, Australia. ${ }^{3}$ Judith Lumley Centre, La Trobe \\ University, Melbourne, Australia. ${ }^{4}$ Division of Epidemiology and Public Health, The University of Nottingham, Nottingham, UK \\ Contact address: Tim Coleman, Division of Primary Care, University of Nottingham, D1411, Medical School, Queen's Medical Centre, \\ Nottingham, NG7 2UH, UK. tim.coleman@nottingham.ac.uk.
}

Editorial group: Cochrane Pregnancy and Childbirth Group.

Publication status and date: New search for studies and content updated (no change to conclusions), published in Issue 12, 2015.

Review content assessed as up-to-date: 11 July 2015.

Citation: Coleman T, Chamberlain C, Davey MA, Cooper SE, Leonardi-Bee J. Pharmacological interventions for promoting smoking cessation during pregnancy. Cochrane Database of Systematic Reviews 2015, Issue 12. Art. No.: CD010078. DOI: 10.1002/14651858.CD010078.pub2.

Copyright (C) 2015 The Cochrane Collaboration. Published by John Wiley \& Sons, Ltd.

\begin{abstract}
A B S T R A C T
Background

Smoking in pregnancy is a public health problem. When used by non-pregnant smokers, pharmacotherapies (nicotine replacement therapy (NRT), bupropion and varenicline) are effective for smoking cessation, however, their efficacy and safety in pregnancy remains unknown. Electronic Nicotine Delivery Systems (ENDS), or e-cigarettes, are becoming widely used but their efficacy and safety when used for smoking cessation in pregnancy are also unknown.
\end{abstract}

\section{Objectives}

To determine the efficacy and safety of smoking cessation pharmacotherapies (including NRT, varenicline and bupropion), other medications, or ENDS when used for smoking cessation in pregnancy.

\section{Search methods}

We searched the Pregnancy and Childbirth Group's Trials Register (11 July 2015), checked references of retrieved studies, and contacted authors.

\section{Selection criteria}

Randomised controlled trials (RCTs) conducted in pregnant women with designs that permit the independent effects of any type of pharmacotherapy or ENDS on smoking cessation to be ascertained were eligible for inclusion.

The following RCT designs are included.

Placebo-RCTs: any form of NRT, other pharmacotherapy, or ENDS, with or without behavioural support/cognitive behaviour therapy (CBT), or brief advice, compared with an identical placebo and behavioural support of similar intensity.

RCTs providing a comparison between i) any form of NRT, other pharmacotherapy, or ENDS added to behavioural support/CBT, or brief advice and ii) behavioural support of similar (ideally identical) intensity.

Parallel- or cluster-randomised trials were eligible for inclusion. Quasi-randomised, cross-over and within-participant designs were not, due to the potential biases associated with these designs.

Pharmacological interventions for promoting smoking cessation during pregnancy (Review)

Copyright $\odot 2015$ The Cochrane Collaboration. Published by John Wiley \& Sons, Ltd. 


\section{Data collection and analysis}

Two review authors independently assessed trials for inclusion and risk of bias and also independently extracted data and cross checked individual outcomes of this process to ensure accuracy. The primary efficacy outcome was smoking cessation in later pregnancy (in all but one trial, at or around delivery); safety was assessed by 11 outcomes (principally birth outcomes) that indicated neonatal and infant well-being; and we also collated data on adherence with trial treatments.

\section{Main results}

This review includes a total of nine trials which enrolled 2210 pregnant smokers: eight trials of NRT and one trial of bupropion as adjuncts to behavioural support/CBT. The risk of bias was generally low across trials with virtually all domains of the 'Risk of bias' assessment tool being satisfied for the majority of studies. We found no trials investigating varenicline or ENDS. Compared to placebo and non-placebo controls, there was a difference in smoking rates observed in later pregnancy favouring use of NRT (risk ratio (RR) $1.41,95 \%$ confidence interval (CI) 1.03 to 1.93 , eight studies, 2199 women). However, subgroup analysis of placebo-RCTs provided a lower RR in favour of NRT (RR 1.28, 95\% CI 0.99 to 1.66 , five studies, 1926 women), whereas within the two non-placebo RCTs there was a strong positive effect of NRT, (RR 8.51, 95\% CI 2.05 to 35.28, three studies, 273 women; P value for randomeffects subgroup interaction test $=0.01$ ). There were no differences between NRT and control groups in rates of miscarriage, stillbirth, premature birth, birthweight, low birthweight, admissions to neonatal intensive care, caesarean section, congenital abnormalities or neonatal death. Compared to placebo group infants, at two years of age, infants born to women who had been randomised to NRT had higher rates of 'survival without developmental impairment' (one trial). Generally, adherence with trial NRT regimens was low. Non-serious side effects observed with NRT included headache, nausea and local reactions (e.g. skin irritation from patches or foul taste from gum), but these data could not be pooled.

\section{Authors' conclusions}

NRT used in pregnancy for smoking cessation increases smoking cessation rates measured in late pregnancy by approximately $40 \%$. There is evidence, suggesting that when potentially-biased, non-placebo RCTs are excluded from analyses, NRT is no more effective than placebo. There is no evidence that NRT used for smoking cessation in pregnancy has either positive or negative impacts on birth outcomes. However, evidence from the only trial to have followed up infants after birth, suggests use of NRT promotes healthy developmental outcomes in infants. Further research evidence on NRT efficacy and safety is needed, ideally from placebo-controlled RCTs which achieve higher adherence rates and which monitor infants' outcomes into childhood. Accruing data suggests that it would be ethical for future RCTs to investigate higher doses of NRT than those tested in the included studies.

\section{PLAIN LANGUAGE SUMMARY}

\section{Drug treatments for stopping smoking in pregnancy}

Smoking during pregnancy harms women and infants. Women who continue to smoke during pregnancy generally are poorer and more poorly educated and are more likely to have no partner or have a partner who smokes.

Medications to help stop smoking include nicotine replacement therapy (NRT), bupropion and varenicline. E-cigarettes contain nicotine and are used by some smokers to help avoid smoking. The safety and effectiveness of smoking cessation drugs and e-cigarettes is not known. This updated review sought evidence for the efficacy and safety of any smoking cessation drugs or e-cigarettes when these are used in pregnancy and found nine randomised studies that enrolled a total of 2210 women. Studies tested NRT used with behavioural support (counselling) apart from a small bupropion trial which enrolled only 11 women. Together, these showed borderline evidence to suggest that NRT combined with behavioural support, might help women to stop smoking in later pregnancy. However, when just the higher-quality, placebo-controlled trials were analysed, NRT was found to be no more effective than a placebo.

There was insufficient evidence to conclude whether or not NRT had either positive or negative impacts on rates of miscarriage, stillbirth, preterm birth (less than 37 weeks'), low birthweight (less than $2500 \mathrm{~g}$ ), admissions of babies to neonatal intensive care or neonatal deaths or whether this affected mean birthweights amongst infants. However, in one trial in which infants were followed to two years of age, those born to women who had been randomised to NRT were more likely to have healthy development.

Side effects observed with NRT included headache, nausea and local reactions (e.g. skin irritation from patches or foul taste from gum).

Studies that reported adherence to medication found that this was generally low and the majority of participants did not use a large proportion of the NRT that was offered or prescribed to them.

Pharmacological interventions for promoting smoking cessation during pregnancy (Review)

Copyright ( 2015 The Cochrane Collaboration. Published by John Wiley \& Sons, Ltd. 
More research evidence is needed; in particular, placebo-controlled trials that test higher doses of NRT, encourage high adherence rates and follow infants into childhood are now warranted.

\section{B A C K G ROU N D}

\section{Description of the condition}

\section{Risks associated with smoking in pregnancy}

Tobacco smoking during pregnancy is the most important, potentially-preventable cause of a range of adverse pregnancy outcomes, including placental abruption, miscarriage, preterm birth (less than 37 weeks' gestation) and low birthweight (less than 2500 g) (Hammoud 2005; Salihu 2007; US DHHS 2004). Cigarette smoking causes intrauterine growth restriction, probably through a reduction in the supply of oxygen and other essential fetal nutrients (Crawford 2008); it is also associated with poorer fetal neurodevelopment (Herrmann 2008). Preterm birth is the leading cause of neonatal mortality (Hammoud 2005; Kramer 1987) and morbidity, with up to half of all paediatric neurodevelopmental problems ascribed to preterm birth (Green 2005). Low birthweight is a surrogate measure of the harmful impact of tobacco smoking on fetal development, and there is growing evidence of the association between low birthweight and adult morbidities, including coronary heart disease, type 2 diabetes mellitus, and adiposity (Gluckman 2008).

Tobacco smoking also has many long-term health impacts for women and their children, and is a major risk factor for six of the eight leading causes of death globally (WHO 2008).

Tobacco addiction is caused by the nicotine in tobacco, which produces a cascade of actions, including release of "pleasure enhancing" dopamine, which strengthens associations of positive feelings with smoking behaviour and appears to be involved in all addictive behaviours (Schmidt 2004).

\section{Epidemiology of smoking in pregnancy}

Tobacco smoking is associated with low socioeconomic status and has been cited as one of the principal causes of health inequality between rich and poor (Wanless 2004).

In high-income countries, such as the United States (US), Denmark and Sweden, the prevalence of smoking in pregnancy has declined from between $20 \%$ and $35 \%$ in the 1980 s to between $10 \%$ to 20\% in 2000s (Al-Sahab 2010; Cnattingius 2004; Dixon 2009; Giovino 2007; Tappin 2010; Tong 2009; US DHHS 2004), and below $10 \%$ by 2010 (Lanting 2012). However, the decline has not been consistent across all sectors of society, with lower rates of decline in lower socioeconomic groups (Graham 2010; Lanting 2012; Pickett 2009; US DHHS 2004). There are marked socioeconomic differences between women who continue to smoke in pregnancy and those who do not. Compared to women in appropriate reference groups, those who continue to smoke in pregnancy generally have lower incomes; higher parity; lower levels of social support; more limited education; are younger; receive publicly-funded or deficient maternity care; are without a partner or with a partner who smokes and are more likely to feel criticised by society (Ebert 2007; Frost 1994; Graham 1976; Graham 1996; Schneider 2008; Tappin 1996; US DHHS 2004). There is a significantly higher prevalence of smoking in pregnancy in several indigenous and ethnic minority groups, which is in accord with their social and material deprivation (Chan 2001; Hunt 2003; Kaplan 1997; US DHHS 2004; Wiemann 1994). Despite the high prevalence, there is a paucity of evidence-based literature into interventions to reduce antenatal smoking in indigenous groups (Gilligan 2007). In some migrant groups, cultural differences may cut across this social gradient. Women who are migrants or refugees to the United Kingdom, Northern Europe, North America or Australia and who originate from South East Asia retain a lower prevalence of smoking, despite major social disadvantage (Bush 2003; Potter 1996; Small 2000). However, second generation migrant women are more likely to smoke during pregnancy (Troe 2008). In the US, African American, Hispanic, and Pacific-Islander women have a lower prevalence of smoking in pregnancy than white women (Andreski 1995; US DHHS 2004; Wiemann 1994).

The global tobacco smoking epidemic is shifting from high-income countries to low- and middle-income ones, with predictions that $80 \%$ of the eight million annual tobacco-related deaths will be occurring in low-middle income countries within 30 years (Oncken 2010). World wide, the prevalence of tobacco smoking and smokeless tobacco use among women is increasing, not decreasing, and is expected to rise to $20 \%$ by 2025 (Oncken 2010; Richmond 2003; Samet 2001). The World Health Organization (WHO) has identified this rise of tobacco use in young females in low-income, high-population countries as one of the most ominous developments of the tobacco epidemic (WHO 2008). National rates of smoking in pregnancy appear to be associated with economic development; for example, in Poland the prevalence is estimated at 30\% (Polanska 2005), while the prevalence in coun-

Pharmacological interventions for promoting smoking cessation during pregnancy (Review) 
tries such as the Democratic Republic of Congo is still very low (Richmond 2003). However, given the aggressive nature of tobacco marketing, there is concern that prevalence of smoking in pregnancy will increase with economic development (WHO 2008), with subsequent health impacts on countries with already high disease burdens and limited resources to provide health care and in particular, neonatal care (Cnattingius 2004).

In addition to the socioeconomic factors associated with continued smoking, there is a growing understanding of psychological associations, especially depression and stress (Aveyard 2007; Blalock 2005; Crittenden, 2007). Depressed women are up to four times more likely to smoke during pregnancy than non depressed women (Blalock 2005), but there is limited information available about the effects of smoking and interventions in pregnant women with psychological symptoms as they are often excluded from trials (Blalock 2005). Two reviews in the general population (Stead 2013; Tsoi 2013), and several trials of smoking cessation interventions conducted in pregnant women, report higher levels of stress and depression among women who continue to smoke during pregnancy (Aveyard 2007; Blalock 2005; Crittenden, 2007). A higher proportion of women stop smoking during pregnancy than at other times in their lives. Up to $45 \%$ of women who smoke before pregnancy "spontaneously quit" or stop before their first antenatal visit (Quinn 1991; The NHS Information Centre 2011; Woodby 1999); this 'quit rate' is substantially higher than reported in the general population (McBride 2003). 'Spontaneous quitters' usually smoke less and are more likely to have temporarily stopped smoking previously; have a non-smoking partner; have more support and encouragement at home for quitting; have stronger beliefs about the dangers of smoking, or be less seriously addicted (Baric 1977; Ryan 1980). Consequently, women who are eligible for smoking cessation assistance in pregnancy are likely to find it more difficult to quit than those in other populations. However, only a third of women who stop smoking spontaneously remain abstinent after one year (CDCP 2002). McBride 2003 hypothesises that pregnancy may be a "teachable moment" at which women perceive increased risk from smoking and become more motivated to attempt smoking cessation. These factors highlight some of the major differences between the non-pregnant population included in trials of pharmacotherapy for smoking cessation and pregnant women who continue to smoke after they become pregnant (Oncken 2009b).

\section{Smoking cessation in pregnancy}

In addition to acknowledged benefits for maternal health, stopping smoking in pregnancy has positive impacts on infants' outcomes. Research studies show that smoking cessation interventions delivered in pregnancy reduce the prevalences of low birthweight and preterm births, both of which are accompanied by substantial infant morbidity and mortality (Chamberlain 2013: Lumley 2009). Similar findings have been observed in women who stop smoking after receiving standard antenatal care, suggesting that trial findings are probably generalisable to all women who stop smoking in early pregnancy whether or not they participate in research studies (McCowan 2009).

Some non-pharmacological (psychosocial) interventions are effective in reducing the proportion of women who smoke during pregnancy and the evidence for these can be obtained from an associated review (Chamberlain 2013), and a previous version of this review (Lumley 2009). For example, compared to usual care, a range of counselling or behavioural support interventions, were demonstrated as effective (risk ratio $1.44,95 \%$ confidence interval 1.19 to $1.75,27$ studies) (Chamberlain 2013). Financial incentives also appear to be effective, but this finding was based on only four small US trials that compared incentives to a range of control conditions (Chamberlain 2013); incentives used in addition to routine care in other countries may have different effects.

Before reviews for pharmacological (Coleman 2012) and psychosocial (Chamberlain 2013) interventions against smoking in pregnancy were divided, the overall review of pregnancy cessation interventions classified multimodal intervention strategies for combining in meta-analyses by their predominant intervention strategy (Lumley 2009). This analysis approach permitted synthesis of multi-component interventions and the review's meta-analysis for studies, which were categorised as having nicotine replacement therapy (NRT) as the predominant intervention strategy included a quasi-randomised controlled trial (RCT) that compared NRT with intensive behavioural smoking cessation support (an effective cessation treatment) with normal antenatal care only (i.e. no behavioural support) (Hegaard 2003). Consequently, this analysis (Lumley 2009), investigated the effectiveness of multi-component intervention strategies which included NRT rather than the efficacy of NRT for cessation in pregnancy. Splitting reviews was intended to alter this situation, such that multi-modal interventions are included in the psychosocial review, and this review provides evidence on the independent efficacy and safety effects of pharmacological interventions in pregnancy.

\section{Description of the intervention}

Any pharmacological intervention, including electronic nicotine delivery systems (ENDS, (e-cigarettes)), used by pregnant women for the purposes of stopping smoking, with or without additional behavioural support or cognitive behaviour therapy (CBT).

\section{How the intervention might work}

One would expect NRT, bupropion and varenicline, which are all frequently-used, effective, pharmaceutical smoking cessation interventions to have the same mechanisms of action in pregnant women as they do in non-pregnant smokers. NRT works by substituting 'clean' nicotine in medicinal forms (e.g. transdermal patches 
or lozenges) for nicotine which would have been inhaled with tobacco smoke. The NRT dose is gradually reduced so that smokers' intake of medicinal nicotine decreases until they can comfortably stop NRT without experiencing excessive withdrawal symptoms. Additionally, when nicotine is provided via NRT, the user avoids roughly 4000 other toxins that are inhaled with nicotine in tobacco smoke (Stedman 1968); consequently medicinal nicotine is likely to be safer than tobacco smoke nicotine. Bupropion is an antidepressant which has both dopaminergic and adrenergic actions (Ascher 1995; Cooper 1994), whilst also appearing to antagonise the nicotinic acetyl cholinergic receptor (Slemmer 2000); its mechanism of action for smoking cessation remains uncertain. Varenicline is an alpha 4 beta 2 nicotinic acetylcholine receptor partial agonist. It attaches to the nicotinic acetylcholine receptor and is believed to mimic the pleasurable dopaminergic (dopaminereleasing) effect of nicotine. Varenicline binds more easily to receptors than nicotine, so when abstinent smokers use this drug, receptors become blocked with varenicline. Should varenicline users choose to smoke, varenicline then prevents nicotine from attaching to receptors so this cannot cause any pleasurable effects for smokers (Coe 2005). Consequently, smoking whilst using varenicline is less enjoyable and attractive for smokers who also experience fewer cravings or withdrawal symptoms and so, are better able to remain abstinent.

The metabolism of many drugs, including of nicotine, is increased in pregnancy and any medications that are metabolised more swiftly can become less effective at standard doses. Cotinine, the primary metabolite of nicotine, is metabolised much more quickly in pregnancy (Dempsey 2001), so nicotine replacement therapies used by pregnant women would be expected to generate lower blood levels of nicotine and these might not adequately substitute for nicotine received from smoking. Consequently, one might expect NRT to be less effective for smoking cessation in pregnancy than it is when used outside of pregnancy. The metabolism of bupropion and varenicline is not known to be altered in pregnancy.

A caveat to the use of pharmaceutical treatments for smoking cessation in pregnancy is that of potential fetal harm caused by their use. There are insufficient studies investigating the fetal impacts of either bupropion or varenicline use in pregnancy to draw any conclusions about the safety of using either. There are, however, more studies demonstrating the effects of nicotine on the fetus and these suggest that nicotine is a fetal toxin (Dempsey 2001). Also, nicotine crosses the placenta and accumulates in the developing fetus (Maritz 2009; Rore 2008) causing concerns about both short-term effects on newborns (Gaither 2009) and longer-term impacts on infants (Bruin 2010). However, as tobacco smoke contains nicotine plus many other toxins and NRT delivers nicotine alone, there is a consensus amongst experts that maternal use of NRT in pregnancy should be safer for the fetus than continued smoking (Benowitz 2000); though currently, there is insufficient research evidence to support this view. The first version of this review investigated the impact of pharmacological interventions on birth outcomes; however, as at least one trial known to the authorship team is known to be following up infants after use of pharmacological interventions in pregnancy, this review also seeks information on childhood outcomes after use of these interventions in pregnancy.

Since the last version of this review was published, ENDS or ecigarettes have been used with increasing frequency; these are devices that do not burn tobacco leaves, instead by heating a solution that contains nicotine, a nicotine-containing aerosol that the user inhales is released (Cobb 2010). The awareness and use of ENDS is increasing (Regan 2013), with over 400 brands now on the market (Zhu 2014), and 2.1 million current users in the UK in 2014 (Action on Smoking and Health 2014). There is vigorous debate about the public health impact, regulation, and role of ENDS in smoking cessation (Auf 2014; Benowitz 2014; Bialous 2014; Doyle 2014; Hitchman 2014). A recent review by the WHO (WHO 2013), which is also controversial (McNeill 2014), suggests there is a lack of evidence for three main concerns regarding ENDS, including: health risks to users and non-users, efficacy in smoking cessation, and interference with tobacco control efforts. In terms of health risks, ENDS contain less toxic substances (such as tar and carbon monoxide) than conventional cigarettes (Etter 2011), but data are limited (Goniewicz 2014; Orr 2014), and ENDS do contain other by-products from metals, plastics, rubbers, ceramics, fibres, and foams (Brown 2014b). The WHO state there is sufficient evidence to caution pregnant women about the use of ENDS due to concerns about the risks of exposure on fetal and child brain development (Dwyer 2009; WHO 2013), including from flavourings (Bahl 2012), and concludes ENDS pose potential threats to adolescents and fetuses, but this is less than conventional cigarettes. In terms of smoking cessation efficacy, there has been one placebo-RCT investigating ENDS, conducted in non-pregnant smokers; this found no significant difference in smoking cessation rates between ENDS and placebo-ENDS groups (Bullen 2013). A non-placebo controlled trial showed some effect on smoking cessation (Caponnetto 2013), and there are mixed results from uncontrolled studies (again, all in non-pregnant smokers) (Adkison 2013; Brown 2014a; Grana 2014a; Vickerman 2013), with systematic reviews concluding there are limited data and evidence of effectiveness for smoking cessation (Drummond 2014; Farsalinos 2014; Franck 2014; Grana 2014; Harrell 2014). We are not aware of any studies investigating ENDS use in pregnant smokers.

\section{Why it is important to do this review}

Guidelines from many countries recommend that NRT can be offered for smoking cessation in pregnancy to heavy smokers who have been unable to quit smoking using behavioural or psychosocial methods (Murin 2011; National Institute for Clinical Excellence 2002); Oncken 2009b; Osadchy 2009; Rore 2008). We 
have been unable to find any clinical guidelines which recommend using bupropion and varenicline in pregnancy. These treatments are not recommended in pregnancy as there is very limited evidence for their safety (Rore 2008); also, using them would involve fetal exposure to potential additional toxins (i.e. possibly within these drugs) that could be entirely avoided. In most high-income countries (e.g. Canada, US, Australia, New Zealand), guidelines recommend that pregnant women are offered intermittent NRTdelivery formulations (e.g. gum, lozenges, spray - classified as category $\mathrm{C}$ drugs in pregnancy), rather than continuous ones (e.g. patches - classified as category D) (Bruin 2010). The theoretical rationale for this is that the overall dose of nicotine delivered by intermittent formulations may be lower than that delivered by continuous ones (Oncken 2009a), and that the peaks in blood nicotine concentrations are more extreme, mimicking the action of smoking. However, some experts recommend patches as the lower peak nicotine levels associated with these may induce fewer side effects, such as gum and throat irritation (Oncken 2009b; Rore 2008).

Consensus-based recommendations about using NRT for smoking cessation in pregnancy are underpinned by a belief that medicinal NRT is safer than smoking. (Benowitz 2000) However, to date, individual trials have had inconsistent findings (Pollak 2007; Wisborg 2000), and there is no conclusive evidence that NRT is either effective or safe in pregnancy (Coleman 2011; Coleman 2012). There are also reports of low adherence to NRT regimens; low adherence could reduce efficacy and suggests the acceptability of NRT use in pregnancy may be limited. (Coleman 2011; Coleman 2012)

Given that NRT appears to be widely accepted for cautious use in pregnancy, a Cochrane review investigating the efficacy and safety of this clinical practice and also the potential for other drugs to be safely used is warranted. Additionally, although ENDS (ecigarettes) are not recognised or regulated as a smoking cessation treatment, trials investigating their efficacy are underway in nonpregnant populations, hence we have included a search for relevant trials in pregnant smokers as part of this review. A robust synthesis of research evidence on the use of pharmacological treatments for cessation in pregnancy will help advance clinical practice in an area of substantial clinical need.

\section{O B JECT IVES}

1. To determine whether or not nicotine replacement therapy, bupropion, varenicline, other drug treatments or electronic nicotine delivery systems (ENDS) (e-cigarettes) used in pregnancy, are effective for smoking cessation in later pregnancy and after childbirth.

2. To determine whether or not nicotine replacement therapy, bupropion, varenicline, other drug treatments or ENDS used in pregnancy, affect infants' mean birthweight or preterm birth.

3. To determine whether or not nicotine replacement therapy, bupropion, varenicline, other drug treatments or ENDS used in pregnancy, affect rates of caesarean section or adverse perinatal outcomes.

4. To determine whether or not nicotine replacement therapy, bupropion, varenicline, other drug treatments or ENDS used in pregnancy, affect post-perinatal infant outcomes.

5. To document levels of i) adherence to treatment regimens and ii) minor adverse events in trials investigating the efficacy pharmacotherapies or ENDS for smoking cessation in pregnancy.

6. To document any reported long-term effects of smoking cessation pharmacotherapies or ENDS.

\section{METHOD S}

\section{Criteria for considering studies for this review}

\section{Types of studies}

Trials that investigate the efficacy of pharmacotherapies for smoking cessation in pregnancy are included.

Trials in pregnant women investigating the efficacy of either pharmacotherapies or of electronic nicotine delivery systems (ENDS) for smoking cessation are included.

Randomised controlled trials (RCTs) with designs that permit the independent effects of any type of pharmacotherapy or ENDS on smoking cessation will be included. Trials must provide very similar (ideally identical) levels of behavioural support or cognitive behaviour therapy (CBT) to participants in active drug and comparator trial arms; behavioural support is effective for smoking cessation in pregnancy (Chamberlain 2013), and differences in its provision would be expected to affect cessation and birth outcomes, potentially rendering findings difficult to interpret.

The following RCT designs are acceptable.

1. Placebo-RCTs: any form of NRT or other pharmacotherapy or ENDS, with or without behavioural support/CBT, or brief advice, compared with an identical placebo plus behavioural support of similar intensity.

2. RCTs providing a comparison between i) any form of NRT or other pharmacotherapy or ENDS plus behavioural support/ CBT or brief advice and, ii) behavioural support of similar (ideally identical) intensity.

Parallel- or cluster-randomised design trials are eligible for inclusion. However, quasi-randomised, cross-over and within-participant designs are not eligible for inclusion due to the potential biases associated with these designs.

Pharmacological interventions for promoting smoking cessation during pregnancy (Review) 


\section{Types of participants}

Women who are pregnant and who also smoke.

\section{Types of interventions}

Pharmacological treatments aimed at promoting smoking cessation including, but not exclusive to, treatments that have been proven effective in non-pregnant adults (e.g. NRT (Stead 2012), bupropion (Hughes 2014), varenicline (Cahill 2012); and ENDS used to promote smoking cessation.

\section{Types of outcome measures}

Outcomes include measures of efficacy, safety and adherence with treatments. Measures include maternal and infant outcomes assessed in pregnancy, around childbirth and up to two years afterwards.

\section{Primary outcomes}

Self-reported abstinence from smoking in later pregnancy taken at the latest point prior to birth at which this is measured and, where available, validated using biochemical means with cut points derived by expert consensus: 8 ppm (parts per million) for exhaled carbon monoxide (SRNT2002) and $10 \mathrm{ng} / \mathrm{mL}$ for saliva cotinine (SRNT2002). When validated abstinence data were available, these were used in preference to self-report. Where available, we also used prolonged, continuous abstinence measures timed from a quit date set in early pregnancy and which allowed temporary lapses to smoking as per the Russell Criteria for outcome measurement in cessation studies (West 2005). However, point prevalence abstinence measures were substituted for these as required.

\section{Secondary outcomes}

1. Abstinence from smoking after childbirth

2. Safety
i) Miscarriage/spontaneous abortion
ii) Stillbirth
iii) Mean unadjusted birthweight
iv) Low birthweight (less than $2500 \mathrm{~g}$ )
v) Preterm birth (less than 37 weeks' gestation)
vi) Neonatal intensive care unit admissions.
vii) Neonatal death
viii) Caesarean section
ix) Maternal hypertension
x) Infant respiratory symptoms
xi) Infant development

3. Adherence data

4. Non-serious side effects (serious adverse event data contributed to 'safety' outcomes, above)
5. Any reported long-terms effects of smoking cessation pharmacotherapies

NB: A specific search was not made for 3 and 4 above but, if present, these data were extracted from included studies and described qualitatively.

\section{Search methods for identification of studies}

The following methods section of this review is based on a standard template used by the Cochrane Pregnancy and Childbirth Group.

\section{Electronic searches}

We searched the Cochrane Pregnancy and Childbirth Group's Trials Register by contacting the Trials Search Co-ordinator (11 July 2015).

The Cochrane Pregnancy and Childbirth Group's Trials Register is maintained by the Trials Search Co-ordinator and contains trials identified from:

1. monthly searches of the Cochrane Central Register of Controlled Trials (CENTRAL);

2. weekly searches of MEDLINE (Ovid);

3. weekly searches of Embase (Ovid);

4. monthly searches of CINAHL (EBSCO);

5. handsearches of 30 journals and the proceedings of major conferences;

6. weekly current awareness alerts for a further 44 journals plus monthly BioMed Central email alerts.

Details of the search strategies for CENTRAL, MEDLINE, Embase and CINAHL, the list of handsearched journals and conference proceedings, and the list of journals reviewed via the current awareness service can be found in the 'Specialized Register' section within the editorial information about the Cochrane Pregnancy and Childbirth Group.

\section{Searching other resources}

We checked relevant, cited studies while reviewing the trial reports and also from any reviews identified. We contacted trial authors, as necessary, to locate additional unpublished data.

We did not apply any language or date restrictions.

\section{Data collection and analysis}

For methods used in the previous version of this review, see Coleman 2012.

For this update, the following methods were used to assess the nine reports that were identified as a result of the updated search. The following methods section of this review is based on a standard template used by the Cochrane Pregnancy and Childbirth Group. 


\section{Selection of studies}

This describes identification of papers published since the first version of this review and added to those included in this earlier review (see Other published versions of this review). Two review authors, Tim Coleman (TC) and Catherine Chamberlain (CC), working independently, inspected the search results. Separate lists of titles and abstracts that were potentially suitable for inclusion were made and any disagreements were resolved by discussion with Sue Cooper (SC)

\section{Data extraction and management}

We designed a data extraction form based on that used by Lumley 2009 and, for eligible studies, three review authors (TC, Jo Leonardi-Bee, JLB and Mary-Ann Davey, MAD) used this to extract data from all included trials; the third included paper was authored by TC and SC, so Catherine Chamberlain (CC) and JLB conducted data extraction for this. Extracted data were compared, with any discrepancies being resolved through discussion or, if required, by consulting another author (SC). TC entered data into Review Manager software (RevMan 2014), double checking this for accuracy. Studies that could only be excluded after reading the full text are listed in the Characteristics of excluded studies table. When information regarding any of the above was unclear, we contacted authors of the reports to provide further details.

\section{Assessment of risk of bias in included studies}

TC and SC independently assessed risk of bias for all studies which they had not authored, using criteria adapted from those in the Cochrane Handbook for Systematic Reviews of Interventions (Higgins 2011). Criteria were adapted such that the sixth criterion for' other sources of bias' addressed biochemical validation of smoking status at the primary outcome point of included trials (further details below). Any disagreements were resolved by discussion without the need to involve a third review author. An identical process was followed by two other authors, CC and JL-B, for the two studies that SC and TC had authored (Coleman 2012; Cooper 2014).

For all studies we assessed the following quality domains.

\section{(I) Random sequence generation (checking for possible selection bias)}

We determined whether the method used to generate the allocation sequence was sufficiently described to allow an assessment of whether it should produce comparable groups.

We assessed the method as:

- low risk of bias (any truly random process, e.g. random number table; computer random number generator);

- high risk of bias (any non-random process, e.g. odd or even date of birth; hospital or clinic record number);

- unclear risk of bias.
(2) Allocation concealment (checking for possible selection bias)

We determined the method used to conceal the allocation sequence and whether intervention allocation could have been foreseen in advance of, or during recruitment, or changed after assignment. We assessed the methods as:

- low risk of bias (e.g. telephone or central randomisation; consecutively numbered sealed opaque envelopes);

- high risk of bias (open random allocation; unsealed or nonopaque envelopes, alternation; date of birth);

- unclear risk of bias.

\section{(3) Blinding (checking for possible performance bias)}

We determined the methods used, if any, to blind study participants and personnel from knowledge of which intervention a participant received. In the previous version of this review, we categorised studies that used placebo to be at low risk of bias and those which used a behavioural control only as at high risk of bias. Using this categorisation of bias, findings with respect to efficacy of nicotine replacement therapy were different for placebo (low bias) and non-placebo (at risk of bias) randomised controlled trials, so we have maintained the same classification for this update. In the 'Risk of bias' table we note whether or not participants, personnel or outcome assessors were blinded to outcome assessment.

(4) Incomplete outcome data (checking for possible attrition bias through withdrawals, dropouts, protocol deviations)

We determined for the primary outcome (i.e. smoking cessation), the completeness of data including attrition and exclusions from the analysis and whether an intention-to-treat analysis (i.e. reporting trial arm cessation rates amongst all those who were originally randomised to that arm) was reported. We assessed whether attrition and exclusions were reported, the numbers included in the analysis at each stage (compared with the total randomised participants), reasons for attrition or exclusion where reported, and whether missing data were balanced across groups or were related to outcomes.

\section{(5) Selective reporting bias}

We determined the possibility of selective outcome reporting bias and assessed methods as:

- low risk of bias (where it was clear that all of the study's prespecified outcomes and all expected outcomes of interest to the review have been reported);

- high risk of bias (where not all the study's pre-specified outcomes have been reported; one or more reported primary outcomes were not pre-specified; outcomes of interest are reported incompletely and so cannot be used; study fails to include results of a key outcome that would have been expected to have been reported); 
- unclear risk of bias.

(6) Biochemical validation of smoking status at primary outcome point (checking for detection bias)

We determined, the timing of, and methods used to ascertain smoking status at the primary outcome point. In pregnancy, biochemical validation is considered important to ensure that study participants are not biased towards reporting smoking cessation and we used cut points derived by expert consensus: 8 ppm where exhaled carbon monoxide is used for validation and $10 \mathrm{ng} / \mathrm{mL}$ for saliva cotinine.

\section{(7) Other risk of bias}

We made explicit judgements about whether studies were at high risk of bias, according to the criteria given in the Handbook (Higgins 2011). As drug efficacy was being assessed, allocation concealment and blinding were considered particularly important for differentiating between placebo and active drug effects. Also, given that smoking in pregnancy attracts stigma in many societies, biochemical validation of smoking status was considered important as a means of minimising any 'desirable' response bias from trial participants. We assessed the likely magnitude and direction of the bias and whether this was likely to impact on the findings.

\section{Measures of treatment effect}

\section{Dichotomous data}

For dichotomous data (all outcomes except mean birthweight), results are presented as summary risk ratios with $95 \%$ confidence intervals.

\section{Continuous data}

For mean birthweight (continuous data), we present the mean difference in mean birthweight between trials' control and intervention group infants with $95 \%$ confidence intervals.

\section{Unit of analysis issues}

\section{Multiple pregnancies}

The unit of analysis for smoking cessation was the trial participant, as clustering of babies within mothers is not relevant to this outcome. For all other outcomes, analyses were conducted amongst singleton births only; this approach was taken because adverse pregnancy events/outcomes, adverse infant birth outcomes and poorer infant development are strongly associated with multiple pregnancy. Hence, analysing multiple and singleton pregnancies together for these outcomes could render review findings difficult to interpret. There were not sufficient outcome data from multiple births for these to be analysed separately.

\section{Cluster-randomised trials}

This study design is eligible for inclusion, however no cluster-randomised trials were identified in this update. In future updates, we will include cluster-randomised trials in the analyses along with individually-randomised trials. We will adjust their sample sizes or standard errors using the methods described in the Handbook [Section 16.3.4 or 16.3.6] using an estimate of the intracluster correlation co-efficient (ICC) derived from the trial (if possible), from a similar trial or from a study of a similar population. If we use ICCs from other sources, we will report this and conduct sensitivity analyses to investigate the effect of variation in the ICC. If we identify both cluster-randomised trials and individually-randomised trials, we plan to synthesise the relevant information. We will consider it reasonable to combine the results from both if there is little heterogeneity between the study designs and the interaction between the effect of intervention and the choice of randomisation unit is considered to be unlikely.

We will also acknowledge heterogeneity in the randomisation unit and perform a sensitivity analysis to investigate the effects of the randomisation unit.

\section{Cross-over trials}

This is not an eligible study design for this review.

\section{Dealing with missing data}

For smoking outcomes we noted levels of attrition and the denominator was the number of women randomised; at all outcome points, participants whose smoking status was unknown were assumed to be smoking (intention-to-treat analysis).

For other outcomes, the following denominators were used.

a) For pre-birth outcomes, spontaneous abortion/miscarriage and stillbirth, the denominator used was the number of women randomised with viable singleton pregnancies at the time of randomisation. Where terminations occurred after randomisation, terminated fetuses were excluded from the denominator if terminations were performed on a presumed viable fetus for non-medical reasons. Similarly, pregnancies that were documented as non-viable at the point of randomisation were also excluded from this denominator (e.g. missed abortion). Where terminations were undertaken for medical reasons and which were judged incompatible with life, these cases were included in denominators and also within numerators; they were counted as miscarriages, if performed before 24 weeks and as stillbirths if conducted after this time point.

b) For mean unadjusted birthweight (i.e. the only birth outcomes measured on a continuous scale), the denominator used was the number of singleton births for which this outcome was recorded. 
c) For dichotomous birth outcomes: e.g. low birthweight; preterm birth; neonatal intensive care admissions and neonatal death, the denominator used was the number of live births from singleton pregnancies.

d) For infant outcomes: the number of live births was used.

For selected secondary outcomes and where this was appropriate and feasible, we conducted sensitivity analyses to investigate the impact of missing data on pooled treatment effect estimates.

For all outcomes, we carried out analyses, as far as possible, on an intention-to-treat basis (caveats outlined above); we attempted to include all participants randomised to each group in analyses, and all participants were analysed in the group to which they were allocated regardless of whether or not they received the allocated intervention.

\section{Assessment of heterogeneity}

We assessed statistical heterogeneity in each meta-analysis using the $\mathrm{I}^{2}$ test and regarded heterogeneity as substantial and, hence worthy of further investigation (see below), if the $\mathrm{I}^{2}$ was greater than $50 \%$, and regarded it as considerable and incompatible with presenting as pooled analyses if the $\mathrm{I}^{2}$ was more than $75 \%$. Where it was not possible to perform a meta-analysis due to considerable levels of heterogeneity ( $\mathrm{I}^{2}$ greater than $75 \%$ ), we summarised the data for each trial and conducted subgroup analyses (see below) to explore reasons for heterogeneity.

\section{Assessment of reporting biases}

As there were less than 10 studies in all meta-analyses, we did not draw funnel plots to assess the potential for reporting bias. In future updates of this review, if there are 10 or more studies, we will investigate reporting biases (such as publication bias) using funnel plots. We will assess funnel plot asymmetry visually if asymmetry is suggested by a visual assessment, and we will perform exploratory analyses to investigate it.

\section{Data synthesis}

We carried out statistical analysis using the Review Manager software (RevMan 2014). We suspected that the level of heterogeneity between the trials due to clinical and methodological diversity would be sufficient to suggest that the treatment effects may differ across the trials, therefore, we elected to use a random-effects model for combining trials together in the meta-analysis; the overall treatment effect from this kind of meta-analysis represents an average. Thus, for studies with a similar type of active intervention, we performed meta-analysis to calculate a weighted treatment effect across studies, using a random-effects meta-analysis. Where it was not possible to perform a meta-analysis due to considerable levels of heterogeneity ( $\mathrm{I}^{2}$ greater than $75 \%$ ), the data were summarised for each trial. In future updates of the review, where sufficient numbers of studies are included in the meta-analyses, we may consider performing random-effects meta-regressions analyses to further explore reasons for heterogeneity or to analyse adherence data. A caveat to using this method for adherence data is that there is currently no standard method for reporting adherence; however, for meta-regression to be undertaken, studies must report adherence data similarly.

\section{Subgroup analysis and investigation of heterogeneity}

We assessed statistical heterogeneity in each meta-analysis using $\mathrm{I}^{2}$ and additionally reported $\mathrm{Tau}^{2}$. An exploration of heterogeneity was performed for primary and secondary outcomes where the $\mathrm{I}^{2}$ was greater than $50 \%$. Where substantial heterogeneity was detected between studies, an overall pooled result was presented; however, readers are advised to use caution in interpreting results due to the presence of heterogeneity.

For smoking cessation outcomes, we planned one subgroup analysis comparing placebo-RCTs with RCTs that did not use a placebo (i.e. non-placebo controlled RCTs). For secondary outcomes, where the $\mathrm{I}^{2}$ was greater than $50 \%$, indicating substantial heterogeneity, we also performed this subgroup analysis as an exploration of heterogeneity. It was not, however, conducted routinely for all secondary outcomes.

We assessed differences between subgroups statistically using random-effects subgroup interaction tests, and present the $\mathrm{P}$ values from the tests.

\section{Sensitivity analysis}

Depending on the availability of data, we planned two sensitivity analyses using smoking cessation outcomes.

1. Including only trials with biochemical validation of smoking status.

2. Excluding any trials which reported substantially lower adherence with treatment than others (NB: we anticipated defining 'low adherence' after included studies had been identified, because there was no normative data on adherence with NRT in trials in pregnancy).

Neither of these analyses were undertaken in the current review (explanations follow in results section); data permitting, they will be undertaken in future review updates.

\section{R E S U L T S}

\section{Description of studies}




\section{Results of the search}

Searches conducted since the last version of this review identified 10 trial reports for potential inclusion. Three were conference reports describing an already-included study (Coleman 2012), three are ongoing studies (see below). No studies were excluded.

The four remaining papers were obtained and these were judged to meet the inclusion criteria and are included in this update (Berlin 2014; El-Mohandes 2013; Stotts 2015). A further paper, which had not been published, and so was not identified by searches, was also deemed relevant (Cooper 2014). This manuscript was authored by members of the review team and reported two-year follow-up for a study included in the previous version of this review (Coleman 2012). Six trials included in previous versions of this review are also included in this update (Coleman 2012; Hotham 2006; Kapur 2001; Oncken 2008; Pollak 2007; Wisborg 2000). This updated review, therefore, includes nine trials (27 reports). It contains data from three additional trials published since the previous version (Berlin 2014; El-Mohandes 2013; Stotts 2015), and involves 2210 pregnant smokers. We added three newly identified reports of Coleman 2012, and also one paper reporting two-year outcomes (Cooper 2014) for this already included study.

\section{Ongoing studies}

There are five ongoing studies. A previously-identified ongoing study has now stopped due to recruitment problems (Koren 2008), and progress with another was uncertain as the relevant trial registry entry had not been updated for over two years; however, this is not an RCT and would not be included in this review (Oncken 2009c). Other ongoing studies include a nicotine replacement therapy (NRT) trial (Oncken 2012), and two trials of bupropion (Hankins 2011; Kranzler 2014). For further details,see Characteristics of ongoing studies.

\section{Included studies}

\section{Interventions}

Eight studies investigated the efficacy of different forms of NRT; one study investigated bupropion (Stotts 2015), and no trials investigated other smoking cessation pharmacotherapies or electronic nicotine delivery systems (ENDS).

\section{Nicotine replacement therapy (NRT) studies}

All studies investigated the efficacy of NRT provided with behavioural support and either compared this with behavioural support alone or support plus a placebo; therefore, studies measured the effect of NRT provided as an adjunct to behavioural support. Six papers (Berlin 2014; Coleman 2012; Cooper 2014; Kapur 2001; Oncken 2008; Wisborg 2000) described five placebo-
RCTs (Berlin 2014; Coleman 2012; Kapur 2001; Oncken 2008; Wisborg 2000). Three trials compared NRT plus behavioural support with behavioural support alone (El-Mohandes 2013; Hotham 2006; Pollak 2007), and in these, participants could not be blinded to treatment. One study used $2 \mathrm{mg}$ nicotine gum (Oncken 2008), six trials used nicotine patches; the eighth offered a choice of NRT formulations; approximately two thirds of participants chose patches and the remainder elected to use gum and lozenges (Pollak 2007).

Four studies used $15 \mathrm{mg} / 16$-hour nicotine patches (Coleman 2012; Hotham 2006; Pollak 2007; Wisborg 2000) and one of these used a higher nicotine dose ( $21 \mathrm{mg} / 16$-hour) for participants who reported smoking more than 15 daily cigarettes (Pollak 2007). Two studies attempted to match nicotine doses prescribed with either saliva (Berlin 2014), or urinary cotinine levels (El-Mohandes 2013) obtained at earlier appointments. Depending on cotinine levels, women in one study were treated with combinations of 10 $\mathrm{mg}$ and $20 \mathrm{mg}$ 16-hour patches (Berlin 2014), and in the other with $21 \mathrm{mg}, 14 \mathrm{mg}$ or $7 \mathrm{mg}$ 24-hour patches with instructions to remove these at night (El-Mohandes 2013). One trial advised women to use trial treatments from randomisation until childbirth, irrespective of whether or not they relapsed to smoking (Berlin 2014); others advised women to stop using NRT if they re-started smoking and had a defined period for use of NRT/trial patches.

\section{Bupropion study}

One study was a placebo-controlled RCT investigating bupropion which experienced recruitment challenges and randomised only 11 women (Stotts 2015).

\section{Setting}

Studies were conducted in the USA $(\mathrm{n}=4)$ (El-Mohandes 2013; Oncken 2008; Pollak 2007; Stotts 2015) Australia ( $=1)$ (Hotham 2006), Canada ( $\mathrm{n}=1)$ (Kapur 2001), Denmark $(\mathrm{n}=1)$ (Wisborg 2000), France ( $\mathrm{n}=1)$ (Berlin 2014) and England ( $\mathrm{n}=$ 1) (Coleman 2012).

\section{Outcomes}

The small bupropion trial (Stotts 2015) ( $\mathrm{n}=11)$ ascertained smoking cessation at nine weeks after enrolment (mean gestation at enrolment $=16$ weeks $)$ and in a small NRT trial $(n=40)$, smoking cessation was ascertained between 20 and 28 weeks' gestation (Kapur 2001), but in all others this was ascertained at 32 weeks or later. In all studies, biological samples were obtained from participants and, after any necessary clarification with authors, we determined that all used such samples to validate reported cessation at the primary endpoint; four studies used exhaled carbon monoxide (CO) (El-Mohandes 2013; Hotham 2006; Kapur 2001; Oncken 2008), four saliva cotinine (Berlin 2014; Pollak 2007; Stotts 2015; 
Wisborg 2000), and two used both (Coleman 2012; Kapur 2001); only one reported thiocyanate levels (Kapur 2001) (cut points are listed in Characteristics of included studies section). For two studies, cut points were obtained from the trial authors (Pollak 2007; Wisborg 2000), and we obtained further data on biochemical validation from authors of a trial which used a higher than standard cut point for saliva cotinine $(26 \mathrm{ng} / \mathrm{mL}$ ) (Wisborg 2000). This revealed that the cotinine assay used had a lower limit of $20 \mathrm{ng} /$ $\mathrm{mL}$, which was also above the currently accepted cut point of 10 $\mathrm{ng} / \mathrm{mL}$, so some smokers may have been wrongly been categorised as abstinent in this study.

The periods of abstinence from smoking which participants were required to demonstrate varied across studies. For smoking outcomes measured at delivery, three studies reported both seven-day point prevalence abstinence from smoking and a measure of continuous abstinence simultaneously (Berlin 2014; Coleman 2012; Pollak 2007); however definitions varied. One study (Coleman 2012), permitted a small number of temporary lapses to smoking as recommended by the 'Russell Criteria' for outcome measurement in smoking cessation studies (West 2005). The remaining two studies did not permit temporary lapses and defined continuous abstinence as seven-day point prevalence abstinence recorded on three (Pollak 2007), or up to seven occasions (Berlin 2014). Four studies reported only seven-day point prevalence abstinence (Oncken 2008; Pollak 2007; Stotts 2015; Wisborg 2000), and three reported point prevalence abstinence for an unstated period (El-Mohandes 2013; Hotham 2006; Kapur 2001). Four studies reported seven-day point prevalence abstinence data at time points after childbirth: Wisborg 2000 provided data at three and 12 months postnatally; Coleman 2012 at six, 12 and 24 months; Oncken 2008 at six to 12 weeks (biochemically-validated data), and Pollak 2007 at three months. Additionally, Coleman 2012 reported continuous abstinence between a quit date and each time point, allowing for temporary lapses too.

Infant and fetal safety outcomes were reported in six studies (Berlin 2014; Coleman 2012; El-Mohandes 2013; Oncken 2008; Pollak 2007; Wisborg 2000); all six reported mean birthweight, mean gestation at delivery and the incidences of low birthweight births (defined as below $2500 \mathrm{~g}$ ). Five of these studies (Berlin 2014; Coleman 2012; Oncken 2008; Pollak 2007; Wisborg 2000), reported rates of preterm birth (born before 37 weeks' gestation), miscarriage/spontaneous abortion and stillbirth and four trials also reported infants' rates of special care admission and neonatal death (Berlin 2014; Coleman 2012; Oncken 2008; Pollak 2007). Two trials (Berlin 2014; Coleman 2012) reported data on maternal hypertension in pregnancy and rates of congenital malformation and caesarean section. Table 1 gives details of twin birth pregnancies in studies where these occurred; also, for those trials that reported birth outcomes, this gives details, within singleton pregnancies, of fetal loss in pregnancy and of subsequent live births. Two trials (Berlin 2014; Pollak 2007) reported with single and multiple pregnancy data together but, authors supplied data for singleton pregnancies separately.

With regard to the pre-birth fetal outcomes of miscarriage/spontaneous abortion and stillbirth, Oncken 2008 reported that, within singleton pregnancies, three control group participants had terminations which were performed for social reasons (presumed healthy fetus), so these fetuses were removed from the denominator for control group analyses (control group $\mathrm{n}=91$ ). Also, Pollak 2007 reported one fetal death prior to randomisation that was documented by ultrasound scanning (i.e. a 'missed abortion') in the NRT group, so this fetus was removed from the denominator for NRT group (NRT group $n=121$ ). Coleman 2012 reported one termination and one fetal death prior to randomisation in women allocated to NRT, so these two cases were removed from the NRT group denominator (NRT group $\mathrm{n}=515$ ). Berlin 2014, reported one termination in each trial group, with both being conducted for fetal abnormalities which were not assessed as being compatible with survival at birth. Consequently, as these terminations were undertaken at 25 (placebo group) and 32 weeks, they have been counted as stillbirths the analysis and remained in the denominator too.

Only one study reported longer-term smoking and infant outcomes after birth (Coleman 2012); this trial reported infants' 'survival without developmental impairment', and respiratory symptoms at two years of age and self-reported maternal smoking at six, 12, and 24 months after childbirth.

\section{Excluded studies}

One trial was excluded as it had a quasi-randomised design (Hegaard 2003); its intervention group was formed by inviting women with non-even birth dates for antenatal care on days when the intervention was delivered. Also, NRT was offered to intervention group participants as part of a multi-modal intervention strategy, which was delivered by specially-trained staff who were only present in antenatal clinics on study days. The control arm, however, was 'usual care' delivered by the usual clinic staff; consequently, it was not judged possible to identify the independent effect of NRT on smoking cessation from this study. One study (Eades 2012) did not specifically deal with a pharmacological intervention, but tested another multi-modal one. In this trial, women were offered NRT following failed quit attempts made after randomisation at an earlier time point and there was no requirement for participants to agree to use the NRT offered. One non-randomised study was also excluded (Oncken 2009a).

\section{Risk of bias in included studies}

The risk of bias was generally low across trials with virtually all domains of the 'Risk of bias' assessment tool being satisfied for the majority of studies (Figure 1), and an absence of blinding was the principal difference between trials. Figure 2 shows the degree to which individual trials met 'Risk of bias' criteria. 
Figure I. Methodological quality graph: review authors' judgements about each methodological quality item presented as percentages across all included studies.

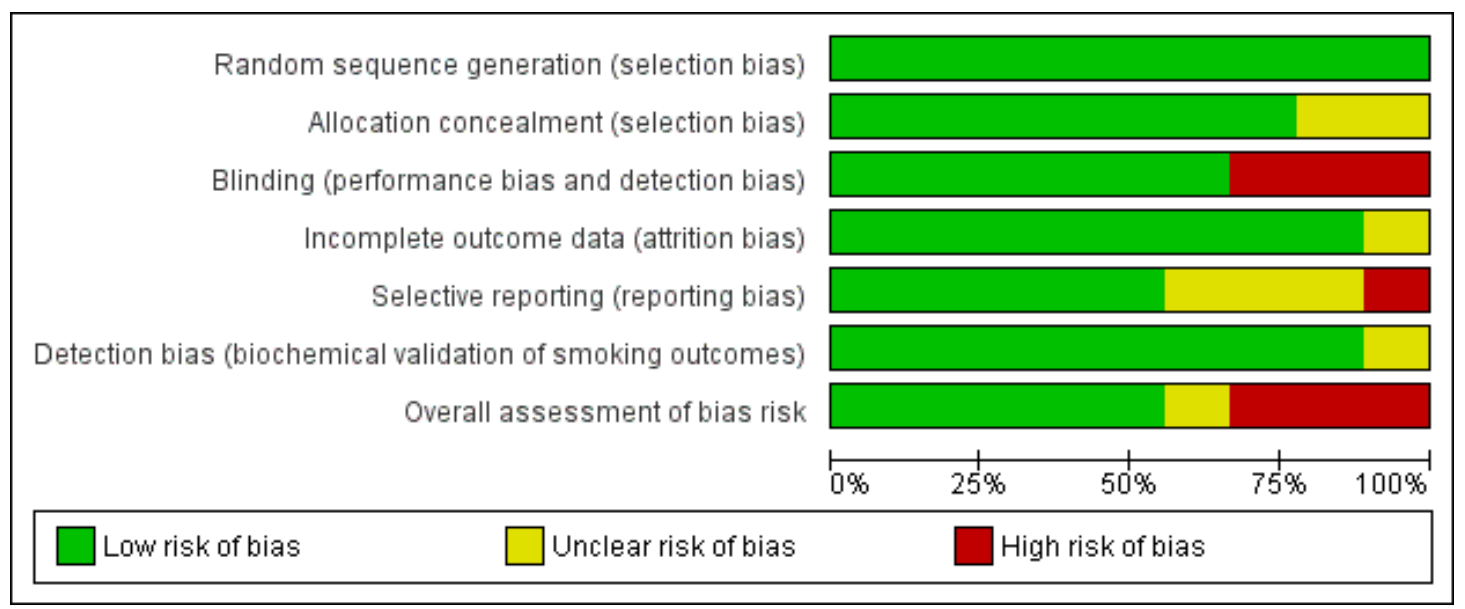


Figure 2. Methodological quality summary: review authors' judgements about each methodological quality item for each included study.

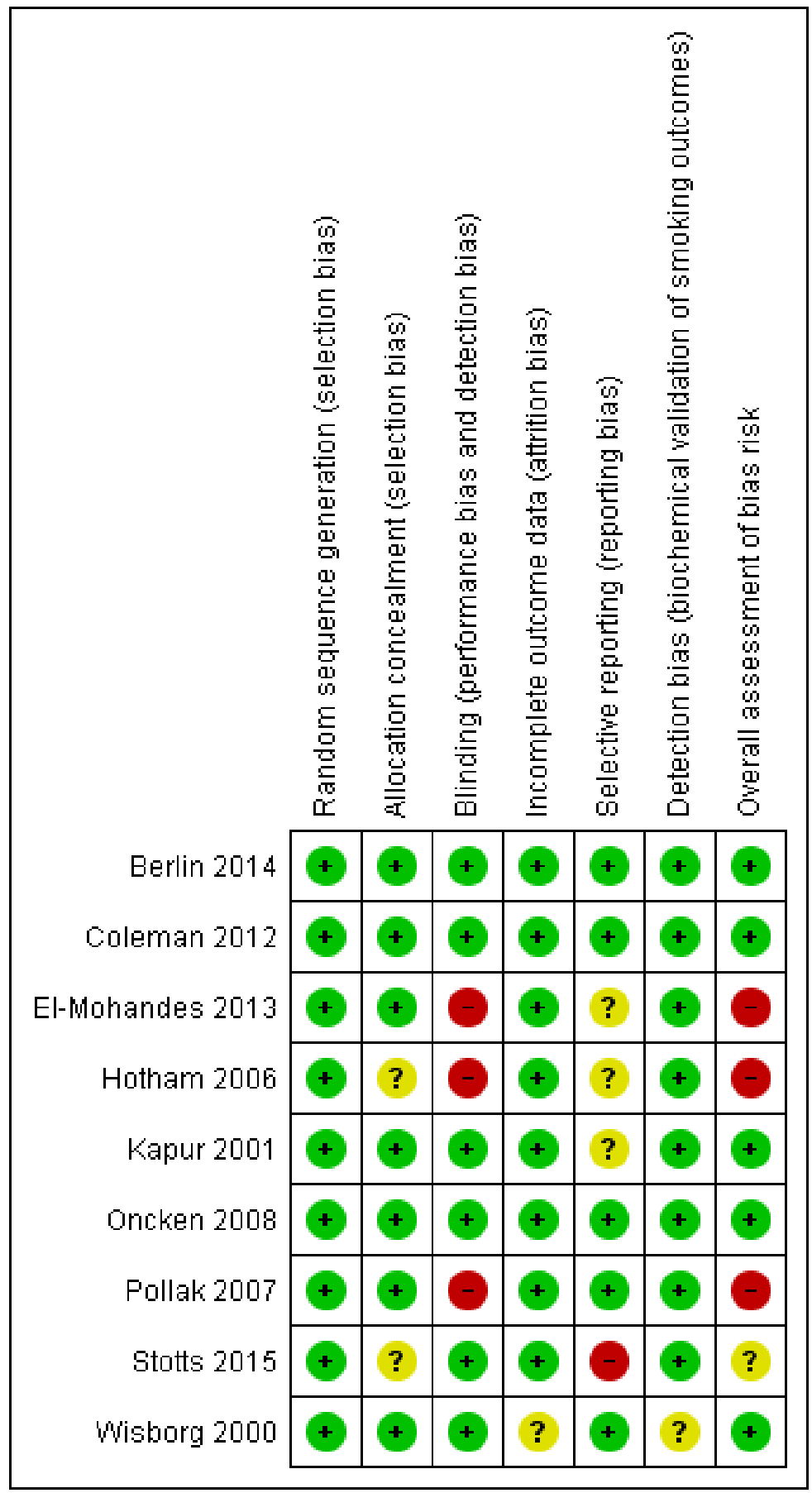

Pharmacological interventions for promoting smoking cessation during pregnancy (Review)

Copyright $\odot 2015$ The Cochrane Collaboration. Published by John Wiley \& Sons, Ltd. 


\section{Allocation}

Computer-generated random number sequences were used to generate randomisation in all studies. One study (Hotham 2006), used sealed envelopes after random numbers had been generated but it was not clear if these were opaque and sequentially numbered, and another study gave no details of how randomisation was operationalised (Stotts 2015), so allocation for both studies was judged to be unclear whilst others were rated as satisfactory (low risk of bias).

\section{Blinding}

This was judged unsatisfactory in studies that had no placebo control - it was the principal difference between studies judged likely to cause bias. Six trials were placebo-RCTs (Berlin 2014; Coleman 2012; Kapur 2001; Oncken 2008; Stotts 2015; Wisborg 2000), and three compared behavioural support alone with NRT and behavioural support (El-Mohandes 2013; Hotham 2006; Pollak 2007).

\section{Detection bias (biochemical validation of smoking outcomes)}

In smoking cessation studies, bias can occur at outcome ascertainment if trial participants report that they have stopped smoking when actually they have not. Generally, it is perceived that the broadly negative social view of smoking can result in self-perceived pressure on participants in smoking cessation studies to be seen as having successfully stopped smoking and this may result in false reporting of abstinence from smoking at follow-up. Trialists attempt to minimise this bias (detection bias) through use of biochemical validation of self-reported smoking status data which is collected for trial outcomes. As all included trials validated self-reported smoking outcomes, this is not a major issue for this review. However, one included study (Wisborg 2000) used a cut point for saliva cotinine $(26 \mathrm{ng} / \mathrm{mL})$, which was substantially higher than the currently accepted level $(10 \mathrm{ng} / \mathrm{mL})$ and, additionally, used an assay with a lower limit of measurement of $20 \mathrm{ng} / \mathrm{mL}$ (i.e. samples in the 0 to $20 \mathrm{ng} / \mathrm{mL}$ range were reported as $20 \mathrm{ng} / \mathrm{mL}$ (Wisborg 2000). This means that, in this study, some of those few participants who falsely reported themselves as not smoking might have had their false reports of abstinence validated as true (i.e. some participants who were actually smoking might not have had this detected by the validation process). Of course, no validation process is perfect and, using any cut point, some false reports of cessation would be accepted as true, but with a known high cut point as in (Wisborg 2000), one would expect this to occur more frequently. However, the use of biochemical validation in this study would be still be expected to detect heavier smokers who made false reports of abstinence, so validated data from this study were still used in preference to self-report data. The one bupropion study (Stotts $2015)$ also used a relatively high cut point $(20 \mathrm{ng} / \mathrm{mL})$, so similar issues are also relevant to this trial.

\section{Incomplete outcome data}

This was judged to be satisfactory across all studies; for smoking data an intention-to-treat analysis was followed in all studies, so that those participants who could not be contacted at follow-up were assumed to have returned to smoking. This approach assumes that where data on smoking status are missing, participants are smoking; it should be noted that this assumption is conservative and is the standard approach taken when assessing the efficacy of smoking cessation interventions. Follow-up for birth outcomes was generally high with one exception. The treatment group allocation for seven women who experienced miscarriage after being randomised within one study (Wisborg 2000), could not be ascertained, so this trial was rated as being unclear with respect to this criterion.

\section{Selective reporting}

Four studies were judged unsatisfactory with respect to selective reporting bias. Hotham 2006 and Stotts 2015 both collected data on a number of outcomes that were not reported in the trial manuscript; for Hotham 2006, we unsuccessfully requested birthweight data for this review's meta analysis. El-Mohandes 2013 et al informed the review team that within their trial, some data on secondary smoking cessation outcomes were collected, but this had not been reported within the trial manuscript; in both studies, primary outcomes were reported, however. No birth outcomes were reported in Kapur 2001.

\section{Other potential sources of bias}

In one study (El-Mohandes 2013), an unanticipated potential source of bias was identified; two participants were screened and randomised on two separate occasions, each pregnancy was counted as a discrete study participation and both women were included twice in the trial analysis. This was considered as having the potential to introduce bias into what was a relatively small study and this was, therefore allocated a 'high' 'Risk of bias' assessment. Both Hotham 2006 and Pollak 2007 were also judged to be at high risk of other bias, due to concerns regarding lack of blinding using a placebo.

Pharmacological interventions for promoting smoking cessation during pregnancy (Review) 


\section{Effects of interventions}

\section{Primary outcomes (efficacy)}

In a pooled analysis of eight included studies and 2199 participants, there was an indication that NRT as an adjunct to behavioural support is effective for smoking cessation in pregnancy (risk ratio (RR) $(1.43,95 \%$ confidence interval (CI) 1.03 to 1.93 , $\mathrm{Tau}^{2}=0.03, \mathrm{I}^{2}=18 \%$, Analysis 1.1).

In the subgroup analysis that compared active NRT with placebo, heterogeneity between studies was substantially reduced and although the risk ratio for smoking cessation with NRT was lower but in the same direction, it was not significant (RR 1.28, 95\% CI 0.99 to $1.66, \mathrm{Tau}^{2}=0.00, \mathrm{I}^{2}=0 \%$, five studies, 1926 women, Analysis 1.1), whereas, the estimate derived from non-placebo controlled trials indicated efficacy (RR 8.51, 95\% CI 2.05 to 35.28 , $\mathrm{Tau}^{2}=0.00, \mathrm{I}^{2}=0 \%$, three studies, 273 women $)(\mathrm{P}$ value for random-effects subgroup interaction test $=0.01$; see Analysis 1.1). The planned sensitivity analysis relating to adherence with treatment could not be conducted as trials reported adherence so differently that it was not possible to categorise one or more trials as having substantially worse or better treatment adherence than others.

The impact of NRT as an adjunct to behavioural support on cessation at time points after childbirth was investigated by pooling data from studies that provided postnatal follow-up data on smoking behaviour. In a pooled analysis of studies which reported non-validated seven-day point prevalence of abstinence from smoking at or before six months after childbirth (predominantly at or around three months), there was no evidence that NRT compared to placebo or non-placebo controlled trials was effective for smoking cessation; (RR for cessation with NRT versus placebo $1.15,95 \%$ CI 0.75 to 1.77 , $\mathrm{Tau}^{2}=0.00, \mathrm{I}^{2}=0 \%$, two studies, 444 women Analysis 1.2). Although this analysis included a large trial with follow-up at six months (as opposed to three months), removing this study from the analysis did not substantially alter findings, indicating no effect for NRT when using data from studies in which all collected data close to the three-month time point. Similarly, the pooled estimate for non-validated seven-day point prevalence of smoking abstinence RR of NRT compared to placebo at one year after childbirth did not indicate that NRT had an effect at this time point; RR $1.04,95 \%$ CI 0.57 to $1.88, \mathrm{Tau}^{2}=0.00, \mathrm{I}^{2}$ $=0 \%$, one study, 246 women Analysis 1.3. The one study which monitored continuous cessation from a quit date set in pregnancy to postnatal time points alongside seven-day point prevalence abstinence data collected at the same time points (Coleman 2012) reported higher point prevalence than continuous cessation rates at each time point and rates of continuous cessation until two years after childbirth were low (2.9\% in NRT group versus 1.7\% in placebo, adjusted $\mathrm{P}$ value $=0.12$ ).

In the one trial of bupropion (Stotts 2015), two (out of five) placebo group participants had validated smoking cessation, but no bupropion group participants reported abstinence.

\section{Secondary outcomes (safety)}

Two study papers reported birth outcomes from single and multiple birth infants together (Berlin 2014; Pollak 2007) and authors kindly provided data on birth outcomes within singleton pregnancies only. Table 1 gives details of twin births and fetal loss in pregnancy.

There was no significant difference in risk of miscarriage/spontaneous abortion between trials NRT and control groups (RR 1.47, 95\% CI 0.45 to $4.77, \mathrm{Tau}^{2}=0.00, \mathrm{I}^{2}=0 \%$, four studies, 1782 women, Analysis 2.1). However, despite contacting study authors, we could not determine the treatment allocation for seven miscarriages from one study, which is not included in this comparison (Wisborg 2000). If we assume that all miscarriages from this study occurred in either the NRT or control groups (i.e. the extremes of how these could actually be distributed), this results in the following effect estimates: (all assumed in NRT group, RR 1.82, 95\% CI 0.59 to 5.64; all assumed in control group, RR $0.74,95 \%$ CI 0.19 to 2.81 ). NB: these are hypothetical scenarios including partially-hypothesised data and so, are not included with presented findings. There was no significant difference between the numbers of stillbirths in the NRT and control arms of trials (RR 1.24, 95\% CI 0.54 to $2.84, \mathrm{Tau}^{2}=0.00 ; \mathrm{I}^{2}=0 \%$, four studies, 1777 women, Analysis 2.2).

The pooled estimate for control group birthweight was higher than for the NRT group, but this difference was not significant (mean difference (MD) $100.54 \mathrm{~g}, 95 \% \mathrm{CI}-20.84$ to $221.91, \mathrm{Tau}^{2}=$ $15624.49, I^{2}=75 \%$, six studies, 2068 women), and heterogeneity was high and on the borderline for presenting pooled estimates (Analysis 2.3); consequently, the result for this comparison must be interpreted with caution. Reasons for this heterogeneity are unclear; it is not easily explained by study design as one large placebo-RCT (Coleman 2012) and a smaller non-placebo one (Pollak 2007), in contrast to other studies, both reported nonsignificantly lower birthweight in NRT group infants. There was a lower incidence of low birthweight births in NRT group women but again, this was not significant and was found in the context of much heterogeneity so caution is again warranted (RR 0.74, 95\% CI 0.41 to $1.34, \mathrm{Tau}^{2}=0.33, \mathrm{I}^{2}=71 \%$ six trials, 2037 women, Analysis 2.4). Again, the pattern of heterogeneity was difficult to understand; the same two studies (Coleman 2012; Pollak 2007) reported non-significantly higher rates of low birthweight infants in the NRT arm.

Preterm births (RR 0.87, 95\% CI 0.67 to $1.14, \mathrm{Tau}^{2}=0.00, \mathrm{I}^{2}$ $=0 \%$, six studies, 2048 women, Analysis 2.5 ), neonatal intensive care unit admissions (RR 0.90, 95\% CI,0.64 to $1.27, \mathrm{Tau}^{2}=0.00$, $\mathrm{I}^{2}=0 \%$, four studies, 1756 women, Analysis 2.6), and neonatal deaths (RR 0.66, 95\% CI 0.17, 2.62, $\mathrm{Tau}^{2}=0.00, \mathrm{I}^{2}=0 \%$, four studies, 1746 women, Analysis 2.7), were all less frequent in NRT groups, but differences between NRT and control groups were 
not significant. It was possible to meta-analyse rates of congenital anomalies and of caesarean birth in NRT and control groups (two studies, Berlin 2014; Coleman 2012, 1401 women) (Analysis 2.8 and Analysis 2.9 respectively). There was no significant difference in rates of congenital anomaly (RR $0.73,95 \%$ CI 0.36 to 1.48 , $\left.\mathrm{Tau}^{2}=0, \mathrm{I}^{2}=0 \%\right)$, or in caesarean section rates (RR $1.18,95 \% \mathrm{CI}$ $\left.0.83,1.69, \mathrm{Tau}^{2}=0.03, \mathrm{I}^{2}=46 \%\right)$ between trial groups. The two studies that provided data on hypertension gave these in different formats; Coleman 2012 reported that 24 (4.6\%) in the NRT group compared to $25(4.7 \%)$ in placebo were noted to have hypertension in pregnancy (i.e. blood pressure of greater than 140/ $90 \mathrm{mmHg}$ ) on at least two occasions (no statistical comparison presented). Berlin 2014 reported significantly higher median diastolic blood pressure in the NRT group [median BP $=70$, interquartile range $(\mathrm{IQR})=60$ to $80 \mathrm{mmHg}$ ] compared to placebo [median $\mathrm{BP}=62, \mathrm{IQR}=60$ to $80 \mathrm{mmHg}$ ], $(\mathrm{P}=0.02)$. Berlin 2014 also reported an interaction between treatment group and time (i.e. during pregnancy) for increases in diastolic blood pressure (BP), though absolute increases in BP were small.

Coleman 2012 and Berlin 2014 also reported the distribution of other birth outcomes between NRT and placebo groups such as Apgar score at five minutes after birth, cord arterial blood $\mathrm{pH}$, intraventricular haemorrhage, neonatal convulsions, necrotising enterocolitis, mechanical ventilation of infant, assisted vaginal delivery and maternal death; no statistically significant differences were noted.

In the bupropion trial (Stotts 2015), there was no significant difference in mean birthweight or mean length of infants in trial groups.

Coleman 2012 was the only study identified which reported infant outcomes after the neonatal period. Using a composite, self-report outcome based on the 'Ages and Stages Questionnaire 3rd Edition (ASQ-3)' instrument (Squires 2009), significantly better infant developmental outcomes were observed in infants born to women who had been randomised to NRT; compared to placebo group infants for those born in the NRT group, the odds ratio (OR) for infant survival to two years of age 'without impairment' (i.e. normal development) was $1.40,95 \%$ CI 1.05 to 1.86 . However, there was no difference in parental reports of infants' respiratory symptoms; OR for reporting of any respiratory problem in NRT group was $1.32,95 \% \mathrm{CI} 0.97$ to 1.74 .

\section{Adherence/compliance and side effects}

Where adherence was reported, this was generally low as the majority of participants in all studies did not use complete courses of NRT offered; Table 2 summarises adherence data reported in trials. Berlin 2014 differs from other studies in that transdermal patches were offered to women between their quit dates and delivery. Much higher self-reported adherence rates are noted from this study; however it is difficult to reconcile these with reported rates of intervention discontinuation and direct comparison with other studies is not possible.

Only a narrative reporting of non-serious side-effect data is possible. Five trials reported non-serious side effects (Berlin 2014, Coleman 2012; Hotham 2006; Oncken 2008; Wisborg 2000): one reported their frequency within women using NRT, noting that five $(25 \%)$ participants in the NRT group experienced minor symptoms and two women stopped using patches after unpleasant effects (Hotham 2006). However, this trial did not monitor non-serious symptoms in the control group, so this figure is difficult to interpret. Oncken 2008 reported that at least $10 \%$ of participants experienced headache, dizziness, fatigue, heartburn, nausea or vomiting, with $14(15 \%)$ in the NRT and $12(12 \%)$ in the control groups discontinuing treatment due to adverse effects. Wisborg 2000 noted that 11 participants stated that adverse effects (e.g. skin irritations and headache) made them discontinue patches, but did not report treatment allocations; also five participants in this trial reported palpitations and two nausea. Coleman 2012 noted 535 non-serious adverse events reported by 521 NRT group participants and 450 reported by the 529 placebo group ones. Berlin 2014 reported a range of non-serious adverse events noting that more non-gynaecological ones occurred in the NRT group, but this was principally due to skin reactions. In this study, $11 \%$ of participants in the NRT suffered a skin reaction at the patch site compared with $4 \%$ in the placebo one.

\section{Sensitivity analyses}

The two potential sensitivity analyses were not undertaken. All studies provided biochemically-validated outcome data at delivery so no validated/non-validated comparison was possible. Adherence data (above) were so variably recorded that no synthesis or comparison was possible.

\section{DISCUSSION}

\section{Summary of main results}

There is evidence of borderline significance suggesting that nicotine replacement therapy (NRT) used with behavioural support by pregnant women for smoking cessation may increase smoking abstinence in late pregnancy by approximately $40 \%$. There was no consistent evidence of NRT having either a positive or negative impact on birth outcomes but findings from the only trial which followed infants after the neonatal period found that those born to NRT group women were less likely to experience developmental impairment which suggests that NRT used in pregnancy may improve infant developmental outcomes.

There was only one small bupropion trial and none of varenicline or electronic nicotine delivery systems (ENDS).

Caution is required when interpreting the pooled estimate for the effect of NRT, used in pregnancy, for smoking cessation in later pregnancy as subgroup analyses revealed very different treatment 
effects from placebo and non-placebo controlled studies suggesting clinical heterogeneity; it is possible that these findings occurred because of unexplained biases, presumably within the less robust, non-placebo controlled trials. The actual efficacy of NRT used for smoking cessation in pregnancy may, therefore, be closer to the risk ratio estimate derived from placebo-controlled trials, which reached only borderline significance (Analysis 1.1).

\section{Overall completeness and applicability of evidence}

As the only difference between the arms of included trials was the provision of pharmacotherapy versus placebo or no placebo to all participants, we have isolated the independent effects of NRT which are of most importance to clinicians and policy-makers. It has been mandatory, since July 2005, for clinical trials to be recorded on a trials register so, we are confident that our method of searching for those that reported after the previous Cochrane searches were conducted will have identified all relevant research reports. Findings reported in this review are based on currentlyaccepted, evidence-based cut points for determining abstinence from smoking (SRNT2002), rather than ones which might have been acceptable in the past, enhancing the validity of findings.

\section{Quality of the evidence}

Included trials were generally of a high standard; the principal difference in studies' propensity to bias was judged to come from the use/non use of placebo controls. Trials which used a placebocontrolled design were considered to be at a lower risk of bias than those which did not; the reduction in heterogeneity observed after dividing trials according to this criterion seems to vindicate this judgement.

\section{Potential biases in the review process}

The search for studies in this area was performed using the Cochrane Pregnancy and Childbirth Group's Trials Register (which is updated weekly to monthly with information from the Cochrane Central Register of Controlled Trials (CENTRAL), MEDLINE, Embase, handsearches from 30 journals and conference proceedings of major conferences and alerts for a further 44 journals). It is unlikely that studies that have been conducted have been missed, however unpublished studies, or ongoing studies not registered in clinical trial registries could be missing. Should such studies be identified, we will include them in future updates of the review.

We aimed to reduce bias wherever possible by having at least two review authors independently working on study selection, data extraction and 'Risk of bias' assessment.

\section{Agreements and disagreements with other studies or reviews}

This review explicitly assesses the efficacy and safety of pharmacological therapies used for smoking cessation in pregnancy. Some trials of smoking cessation in pregnancy test NRT as part of multimodal intervention strategies and these are included in an associated review (Chamberlain 2013). However, this review is concerned with the efficacy and safety of pharmacological therapies when used for smoking cessation in pregnancy, and examines the independent safety and efficacy of pharmacological interventions. Since the previous version of this review was published (Coleman 2012) another systematic review which investigates the efficacy of smoking cessation medications in pregnancy (Myung 2012) and a critique (Coleman 2013) have been published. Searches for the (Myung 2012) review were completed before three studies included in the current review were published (Berlin 2014; Coleman 2012: El-Mohandes 2013); additionally this included the large non-randomised trial described above which was excluded from the current review (Hegaard 2003) and a non-RCT investigating bupropion (Chan 2005). Myung 2012 et al concluded that 'pharmacotherapy had a significant effect on smoking cessation' (risk ratio 1.80 ; $95 \%$ confidence interval 1.32 to 2.44 ). However, as this analysis pooled bupropion and NRT studies together, clinical implications are uncertain. Additionally, the efficacy estimate is likely to be inflated by inclusion of a large quasiRCT which tested the offer of NRT as part of a multi-modal cessation intervention (Hegaard 2003) and the deployment of a 'fixed-effect' approach to meta-analysis. We believe that accruing evidence suggests that placebo and non-placebo RCTs produce different findings and, so a 'random-effects' approach is better justified.

A systematic review of trials conducted in non-pregnant women has shown that NRT is effective outside of pregnancy (Stead 2012); however, the reasons why this does not appear to be the case in pregnancy are not known. Participants in trials included within the current review made relatively little use of offered NRT and, as NRT can only be effective if it is actually used, low adherence with therapy may explain review findings. If low adherence explains the difference in findings between this and the 'non-pregnancy' NRT review (Stead 2012), then understanding the phenomenon of low adherence could be important. Another possible explanation for lack of efficacy noted in pregnancy could be that increased metabolism of nicotine in pregnancy (Dempsey 2001) results in NRT generating lower blood nicotine levels in pregnancy and this reduced nicotine substitution could, in turn, increase women's experience of withdrawal symptoms causing them to stop NRT early. Logically, if in trials to date, increased metabolism underpinned women's low adherence with NRT, higher doses of NRT could be needed for this to be effective in pregnancy.

Pharmacological interventions for promoting smoking cessation during pregnancy (Review) 


\section{A U THORS'CONCLUSIONS}

\section{Implications for practice}

There is weak evidence to suggest that using NRT with behavioural support for smoking cessation in pregnancy is effective; there is no evidence that NRT has either a positive or negative impact on pregnancy and infant outcomes. Efficacy findings should be treated cautiously as their derivation includes data from nonplacebo RCTs which appear to have higher risks of bias. It is possible that the actual efficacy of NRT in pregnancy is better represented by the borderline significant findings from meta-analysis of placebo-RCTs. NRT is already used quite widely in some jurisdictions and accruing evidence is that this clinical practice does no harm, with evidence from one trial suggesting that NRT used in pregnancy for smoking cessation results in improved child development (Coleman 2012). There was only one trial of bupropion and none investigating varenicline or ENDS; and so we cannot comment on their use in pregnancy.

\section{Implications for research}

As most included trials involved standard doses of NRT (principally $15 \mathrm{mg}$, delivered via a 16-hour patch), further RCTs should focus on the dose of NRT employed. There are strong reasons to suspect that NRT used at higher doses than in most trials within this review, could be effective in pregnancy and large, well-conducted placebo-RCTs investigating the efficacy and safety of higher doses of NRT in pregnancy should be conducted. RCTs of higherdose NRT should attempt to increase adherence with treatment and they should also monitor infant outcomes to seek replication of SNAP (Smoking, Nicotine, and Pregnancy) trial findings (Coleman 2012); there is no evidence that NRT is harmful in pregnancy, indeed what evidence there is indicates that it may be beneficial for infants. Qualitative research designed to gain understanding of why pregnant women have low adherence with NRT is needed. Future studies could increase adherence by permitting women who smoke temporarily to continue using transdermal patches or other trial treatments and also by providing NRT or placebo throughout pregnancy; both approaches were employed by Berlin 2014. Studies investigating bupropion and varenicline, if judged ethical, are also needed.

\section{ACKNOW LEDGEMENTS}

The authors Sue Cooper (SC), Jo Leonardi-Bee (JLB) and Tim Coleman (TC) are members of the UK Centre for Tobacco and Alcohol Studies (UKCTAS). Funding from the British Heart Foundation, Cancer Research UK, the Economic and Social Research Council, the Medical Research Council and the National Institute of Health Research, under the auspices of the UK Clinical Research Collaboration, is gratefully acknowledged.

SC and TC are members of the NIHR School for Primary Care Research.

TC, SC and JLB were funded by the National Institute for Health Research (NIHR) under its Programme Grants for Applied Research programme (grant number RP-PG 0109-10020). The views expressed in this article are those of the authors and not necessarily those of the NHS, the NIHR or the Department of Health.

The research was also supported by the National Institute for Health Research (NIHR) Collaboration for Leadership in Applied Health Research and Care East Midlands at NHS Nottingham City CCG.

Catherine Chamberlain (CC) acknowledges support from the Indigenous Health Equity Unit.

The authors would like to thank Ivan Berlin, Michelle Kiely, Sylvia Tan, Kathryn Pollak and Pauline Lyna for responding to data requests so conscientiously.

This project was supported by the National Institute for Health Research, via Cochrane Infrastructure funding to Cochrane Pregnancy and Childbirth. The views and opinions expressed therein are those of the authors and do not necessarily reflect those of the Systematic Reviews Programme, NIHR, NHS or the Department of Health.

\section{R E F E R E N C E S}

\section{References to studies included in this review}

Berlin 2014 \{published data only\}

Berlin I. Study of Nicotine Patch in Pregnancy (SNIPP). ClinicalTrials.gov (http://clinicaltrials.gov/ct2/show/ NCT00507975) (accessed 2008).

* Berlin I, Grange G, Jacob N, Tanguy ML. Nicotine patches in pregnant smokers: randomised, placebo controlled, multicentre trial of efficacy. BMJ 2014;348:1622.
Coleman 2012 \{published data only\}

Bowker KA, Lewis S, Coleman T, Vaz LR, Cooper S. Comparison of cotinine levels in pregnant women whilst smoking and when using nicotine replacement therapy. Nicotine \& Tobacco Research 2014;16(6):895-8.

* Coleman T, Cooper S, Thornton JG, Grainge MJ, Watts $\mathrm{K}$, Britton J, et al. Smoking, Nicotine, and Pregnancy (SNAP) Trial Team. A randomized trial of nicotinereplacement therapy patches in pregnancy. New England 
Journal of Medicine 2012;366:808-18.

Coleman T, Thornton J, Britton J, Lewis S, Watts K, Coughtrie MW, et al. Protocol for the smoking, nicotine and pregnancy (SNAP) trial: double-blind, placeborandomised, controlled trial of nicotine replacement therapy in pregnancy. BMC Health Services Research 2007;3(7):2. Cooper S, Lewis S, Thornton JG, Marlow N, Watts K, Britton J, et al. Smoking, Nicotine and Pregnancy Trial Team. The SNAP trial: a randomised placebo-controlled trial of nicotine replacement therapy in pregnancy - clinical effectiveness and safety until 2 years after delivery, with economic evaluation. Health Technology Assessment 2014;18 (54):1-128.

Cooper S, Taggar J, Lewis S, Marlow N, Dickinson A, Whitemore R, et al. Smoking, Nicotine and Pregnancy (SNAP) Trial Team. Effect of nicotine patches in pregnancy on infant and maternal outcomes at 2 years: follow-up from the randomised, double-blind, placebo-controlled SNAP trial. Lancet. Respiratory Medicine 2014;2(9):728-37. Essex HN, Parrott S, Wu Q, Li J, Cooper S, Coleman T. Cost-effectiveness of nicotine patches for smoking cessation in pregnancy: A placebo randomised controlled trial (SNAP). Nicotine \& Tobacco Research 2014;17(6):636-42. Grainge M, Coleman T, Cooper S, Thornton J, Watts $\mathrm{K}$, Britton J, et al. Double-blind, placebo-controlled randomised trial of nicotine replacement therapy patches in pregnancy. Journal of Perinatal Medicine 2012;39 Suppl: 172.

Thornton JG, Coleman T, Britton J, Cooper S, Watts K, Lewis $S$, et al. The smoking, nicotine and pregnancy (SNAP) trial: Main results. Archives of Disease in Childhood: Fetal and Neonatal Edition 2011;96(Suppl 1):Fa109.

El-Mohandes 2013 \{published data only\}

* El-Mohandes AAE, Windsor R, Tan S, Perry D, Gantz M, Kiely M. A randomized clinical trial of trans-dermal nicotine replacement in pregnant African-American smokers. Maternal \& Child Health Journal 2013;17(5): 897-906.

Eunice Kennedy Shriver National Institute of Child Health and Human Development. Effectiveness of nicotine replacement therapy in reducing the risk of nicotine exposure in pregnant minority smokers. Clinicaltrials.gov (http://clinicaltrials.gov/ct2/show/NCT00341432?term= NCT00341432\&rank=1) (accessed 2006).

Hotham 2006 \{published data only (unpublished sought but not used)\} Atkinson E, Hotham L, Baghurst P. Nicotine replacement therapy as an adjunct to smoking cessation counselling in pregnancy: a randomised study to evaluate efficacy in an antenatal clinic setting. Australian and New Zealand Journal of Obstetrics and Gynaecology 2003;43(2):17787. Refereed abstracts of original presentations at the 2nd International Meeting of the International Society of Perinatal Obstetricians; 10-13 November 2002; Adelaide. * Hotham ED, Gilbert AL, Atkinson ER. A randomisedcontrolled pilot study using nicotine patches with pregnant women. Addictive Behaviors 2006;31(4):641-8.

Hotham ED, Gilbert AL, Atkinson ER. Case studies of three pregnant smokers and their use of nicotine replacement therapy. Midwifery 2005;21(3):224-32.

Kapur 2001 \{published data only\}

Kapur B, Hackman R, Selby P, Klein J, Koren G. Randomized, double-blind, placebo-controlled trial of nicotine replacement therapy in pregnancy. Current Therapeutic Research - Clinical and Experimental 2001;62 (4):274-8.

\section{Oncken 2008 \{published data only\}}

* Oncken C, Dornelas E, Greene J, Sankey H, Glasmann A, Feinn R, et al. Nicotine gum for pregnant smokers: a randomized controlled trial. Obstetrics \& Gynecology 2008; 112(4):859-67.

Oncken C, Dornelas E, Greene J, Sankey H, Glasmann A, Kranzler HR. Nicotine gum for pregnant smokers: a randomized controlled trial. Proceedings of the 70th Annual Scientific Meeting of the College on Problems on Drug Dependence; 2008 June 14-19; San Juan, Puerto Rico. 2008:143.

\section{Pollak 2007 \{published data only\}}

Fish LJ, Peterson BL, Namenek-Brouwer RJ, Lyna P, Oncken CA, Swamy GK, et al. Adherence to nicotine replacement therapy among pregnant smokers. Nicotine and Tobacco Research 2009;11(5):514-8.

* Pollak KI, Oncken CA, Lipkus IM, Lyna P, Swamy GK, Pletsch PK, et al. Nicotine replacement and behavioral therapy for smoking cessation in pregnancy. American Journal of Preventive Medicine 2007;33(4):297-305. Pollak KI, Oncken CA, Lipkus IM, Peterson BL, Swamy GK, Pletsch PK, et al. Challenges and solutions for recruiting pregnant smokers into a nicotine replacement therapy trial. Nicotine and Tobacco Research 2006;8(4): 547-54.

Pollak KI, Oncken CA, Lipkus IM, Peterson BL, Swamy GK, Pletsch PK, et al. Effectiveness of adding nicotine replacement therapy to cognitive behavioural therapy for smoking cessation in pregnant smokers: the Baby Steps Trial. Society for Research on Nicotine and Tobacco 13th Annual Meeting; 2007 Feb 21-24; Austin, Texas. 2007:25, Abstract no: PA6-3.

Swamy GK, Roelands JJ, Peterson BL, Fish LJ, Oncken CA, Pletsch PK, et al. Predictors of adverse events among pregnant smokers exposed in a nicotine replacement therapy trial. American Journal of Obstetrics and Gynecology 2009; 201:354.e1-354.e7.

\section{Stotts 2015 \{published data only\}}

Stotts A. Double blind, placebo-controlled pilot study of Bupropion to promote smoking cessation during pregnancy. ClinicalTrials.gov (accessed 21 May 2013) 2011.

* Stotts AL, Northrup TF, Cinciripini PM, Minnix JA, Blalock JA, Mullen PD, et al. Randomized, controlled pilot trial of bupropion for pregnant smokers: challenges and future directions. American Journal of Perinatology 2015;32 (4):351-6.

\section{Wisborg 2000 \{published data only\}}

Wisborg K. Nicotine patches to pregnant smokers - a randomised study. 1st International Conference of the 
Society for Research on Nicotine and Tobacco; 1998 August 22-23; Copenhagen, Denmark. 1998.

* Wisborg K, Henriksen TB, Jespersen LB, Secher NJ. Nicotine patches for pregnant smokers: a randomized controlled study. Obstetrics \& Gynecology 2000;96(6): $967-71$.

\section{References to studies excluded from this review}

Eades 2012 \{published data only\}

* Eades SJ, Sanson-Fisher RW, Wenitong M, Panaretto K, D'Este C, Gilligan C, et al. An intensive smoking intervention for pregnant Aboriginal and Torres Strait Islander women: a randomised controlled trial. Medical Journal of Australia 2012;197(1):42-6.

Gilligan C. A pilot randomised controlled trial to test the effectiveness of an intervention to help Aboriginal and Torres Strait Islander women to quit smoking during pregnancy: study design and preliminary results [thesis]. Newcastle, Australia: University of Newcastle 2008.

Hegaard 2003 \{published data only\}

Hegaard HK, Kjaergaard H, Moller LF, Wachmann $\mathrm{H}$, Ottesen B. Multimodal intervention raises smoking cessation rate during pregnancy. Acta Obstetricia et Gynecologica Scandinavica 2003;82(9):813-9.

Oncken 2009a \{published data only\} Oncken C, Campbell W, Chan G, Hatsukami D, Kranzler HR. Effects of nicotine patch or nasal spray on nicotine and cotinine concentrations in pregnant smokers. Journal of Maternal-Fetal and Neonatal Medicine 2009;22(9):751-8.

\section{References to ongoing studies}

\section{Hankins 2011 \{published data only\}}

Hankins GDV. Bupropion for smoking cessation during pregnancy. ClinicalTrial.gov (http://clinicaltrials.gov) (accessed March 2014) 2011.

Koren 2008 \{published data only (unpublished sought but not used)\} Koren G. Study of nicotine replacement therapy in pregnancy. ClinicalTrials.gov (http://clinicaltrials.gov) (accessed 4 January 2009).

\section{Kranzler 2014 \{published data only\}} Kranzler HR. Placebo-controlled trial of bupropion for smoking cessation in pregnant women. ClinicalTrials.gov (http://clinicaltrials.gov/) (accessed 2 September 2014) 2014.

Oncken 2009c \{published data only\}

Oncken C. Pilot study of nicotine replacement for smoking cessation during pregnancy. http://clinicaltrials.gov/ct2/ show/NCT00888979 (accessed 3 February 2012) 2009.

Oncken 2012 \{published data only\}

Oncken C. Nicotine replacement for smoking cessation during pregnancy. ClinicalTrials.gov (accessed May 2014) 2012.

\section{Additional references}

Action on Smoking and Health 2014

ASH Briefing on electronic cigarettes. Action on Smoking and Health (http://ash.org.uk/information/facts-and-stats/ ash-briefings) [accessed on 18 December 2014] 2014.

Adkison 2013

Adkison SE, O'Connor RJ, Bansal-Travers M, Hyland A, Borland R, Yong HH, et al. Electronic nicotine delivery systems: international tobacco control four-country survey. American Journal of Preventive Medicine 2013;44(3): 207-15.

Al-Sahab 2010

Al-Sahab B, Saqib M, Hauser G, Tamim H. Prevalence of smoking during pregnancy and associated risk factors among Canadian women: a national survey. BMC Pregnancy and Childbirth 2010;10:24; doi:10.1186/1471-2393-10-24.

\section{Andreski 1995}

Andreski P, Breslau N. Maternal smoking among blacks and whites. Social Science and Medicine 1995;41(2):227-33.

Ascher 1995

Ascher JA, Cole JO, Colin JN, Feighner JP, Ferris RM, Fibiger HC, et al. Bupropion: a review of its mechanism of antidepressant activity. Journal of Clinical Psychiatry 1995; 56(9):395-401.

Auf 2014

Auf R. Electronic cigarettes and smoking cessation: a quandary?. Lancet 2014;383(9915):408.

\section{Aveyard 2007}

Aveyard R, West R. Managing smoking cessation. BMJ 2007;335:37-41.

Bahl 2012

Bahl V, Lin S, Xu N, Davis B, Wang YH, Talbot P. Comparison of electronic cigarette refill fluid cytotoxicity using embryonic and adult models. Reproductive Toxicology 2012;34(4):529-37.

Baric 1977

Baric L, MacArthur C. Health norms in pregnancy. British Journal of Preventive and Social Medicine 1977;31(1):30-8.

Benowitz 2000

Benowitz NL, Dempsey DA, Goldenberg RL, Hughes JR, Dolan-Mullen P, Ogburn PL, et al. The use of pharmacotherapies for smoking cessation during pregnancy. Tobacco Control 2000;9 Suppl 3(0964-4563):III91-4.

\section{Benowitz 2014}

Benowitz NL. Emerging nicotine delivery products. Implications for public health. Annals of the American Thoracic Society 2014;11(2):231-5.

\section{Bialous 2014}

Bialous SA, Sarma L. Electronic cigarettes and smoking cessation: a quandary?. Lancet 2014;383(9915):407-8.

Blalock 2005

Blalock JA, Fouladi RT, Wetter DW, Cinciripini PM. Depression in pregnant women seeking smoking cessation treatment. Addictive Behaviors 2005;30(6):1195-208. 


\section{Brown 2014a}

Brown J, Beard E, Kotz D, Michie S, West R. Real-world effectiveness of e-cigarettes when used to aid smoking cessation: a cross-sectional population study. Addiction 2014;109(9):1531-40.

\section{Brown 2014b}

Brown CJ, Cheng JM. Electronic cigarettes: product characterisation and design considerations. Tobacco Control 2014;23(Suppl 2):ii4-ii10.

Bruin 2010

Bruin JE, Gerstein HC, Holloway AC. Long-term consequences of fetal and neonatal nicotine exposure: a critical review. Toxicological Sciences 2010;116(2):364-74.

Bullen 2013

Bullen C, Howe C, Laugesen M, McRobbie H, Parag V, Williman J, et al. Electronic cigarettes for smoking cessation: a randomised controlled trial. Lancet 2013;382 (9905):1629-37.

Bush 2003

Bush J, White M, Kai J, Rankin J, Bhopal R. Understanding influences on smoking in Bangladeshi and Pakistani adults: community based, qualitative study. BMJ 2003;326:962.

\section{Cahill 2012}

Cahill K, Stead LF, Lancaster T. Nicotine receptor partial agonists for smoking cessation. Cochrane Database of Systematic Reviews 2012, Issue 4. [DOI: 10.1002/ 14651858.CD006103.pub6]

Caponnetto 2013

Caponnetto P, Campagna D, Cibella F, Morjaria JB, Caruso M, Russo C, et al. EffiCiency and Safety of an eLectronic cigAreTte (ECLAT) as tobacco cigarettes substitute: a prospective 12-month randomized control design study. PLoS ONE 2013;8(6):e66317.

\section{CDCP 2002}

Centers for Disease Control and Prevention. Women and smoking: a report of the Surgeon General (executive summary). Morbidity and Mortality Weekly Report 51 (No. RR-12) 2002, issue Available at: http://www.cdc.gov/ mmwr/preview/mmwrhtml/rr5112a4.htm:Accessed 9/8/ 2015.

Chamberlain 2013

Chamberlain C, O'Mara-Eves A, Oliver S, Caird JR, Perlen SM, Eades SJ, et al. Psychosocial interventions for supporting women to stop smoking in pregnancy. Cochrane Database of Systematic Reviews 2013, Issue 10. [DOI: 10.1002/14651858.CD001055.pub4]

Chan 2001

Chan A, Keane RJ, Robinson JS. The contribution of maternal smoking to preterm birth, small for gestational age and low birth weight among aboriginal and non-aboriginal births in South Australia. Medical Journal of Australia 2001; 174(8):389-93.

\section{Chan 2005}

Chan B, Einarson A, Koren G. Effectiveness of bupropion for smoking cessation during pregnancy. Journal of Addictive Diseases 2005;24(2):19-23.

\section{Cnattingius 2004}

Cnattingius S. The epidemiology of smoking during pregnancy: smoking prevalence, maternal characteristics, and pregnancy outcomes. Nicotine and Tobacco Research 2004;6(S2):S125-S140.

Cobb 2010

Cobb NK, Byron MJ, Abrams DB, Shields PG. Novel nicotine delivery systems and public health: the rise of the "e-cigarette". American Journal of Public Health 2010;100 (12):2340-2.

\section{Coe 2005}

Coe JW, Brooks PR, Vetelino MG, Wirtz MC, Arnold EP, Huang J, et al. Varenicline: an alpha4beta2 nicotinic receptor partial agonist for smoking cessation. Journal of Medicinal Chemistry 2005;48(10):3474-7.

\section{Coleman 2011}

Coleman T, Chamberlain C, Cooper S, Leonardi-Bee J. Efficacy and safety of nicotine replacement therapy for smoking cessation in pregnancy: systematic review and meta-analysis. Addiction 2011;106 (1):52-61.

\section{Coleman 2013}

Coleman T, Chamberlain C, Davey MA, Cooper SE, Leonardi-Bee J. Efficacy of nicotine replacement therapy in pregnancy. BJOG: an international journal of obstetrics and gynaecology 2013;120(3):373-4.

\section{Cooper 1994}

Cooper BR, Wang CM, Cox RF, Norton R, Shea V, Ferris RM, et al. Evidence that the acute behavioral and electrophysiological effects of bupropion (Wellbutrin) are mediated by a noradrenergic mechanism. Neuropsychopharmacology 1994;11(2):133-41.

\section{Cooper 2014}

Cooper S, Taggar J, Lewis S, Marlow N, Dickinson A, Whitemore R, et al. Effect of nicotine patches in pregnancy on infant and maternal outcomes at 2 years: follow-up from the randomised, double-blind, placebo-controlled SNAP trial. Lancet Respiratory Medicine 2014;2(9):728-37.

\section{Crawford 2008}

Crawford JT, Tolosa JE, Goldenberg RL. Smoking cessation in pregnancy: why, how, and what next. Clinical Obstetrics and Gynecology 2008;51(2):419-35.

\section{Crittenden, 2007}

Crittenden, KS, Manfredi C, Cho YI, Dolecek TA. Smoking cessation processes in low-SES women: the impact of timevarying pregnancy status, healthcare messages, stress and health concerns. Addictive Behaviours 2007;32(7):1347-66.

\section{Dempsey 2001}

Dempsey DA, Benowitz NL. Risks and benefits of nicotine to aid smoking cessation in pregnancy. Drug Safety 2001;24 (4):277-322.

\section{Dixon 2009}

Dixon L, Aimer P, Fletcher L, Guilliland K, Hendry C. Smoke free outcomes with midwife lead maternity carers: an analysis of smoking during pregnancy from the New Zealand College of Midwives Midwifery database 2004- 
2007. New Zealand College of Midwives Journal 2009;40: 13-9.

\section{Doyle 2014}

Doyle C, Patterson S, Scott J. Electronic cigarettes and smoking cessation: a quandary?. Lancet 2014;383(9915): 408.

Drummond 2014

Drummond MB, Upson D. Electronic cigarettes. Potential harms and benefits. Annals of the American Thoracic Society 2014;11(2):236-42.

Dwyer 2009

Dwyer JB, McQuown SC, Leslie FM. The dynamic effects of nicotine on the developing brain. Pharmacology \& Therapeutics 2009;122(2):125-39.

Ebert 2007

Ebert LM, Fahy K. Why do women continue to smoke in pregnancy?. Women and Birth 2007;20(4):161-8.

\section{Etter 2011}

Etter JF, Bullen C. Electronic cigarette: users profile, utilization, satisfaction and perceived efficacy. Addiction 2011;106(11):2017-28.

Farsalinos 2014

Farsalinos KE, Polosa R. Safety evaluation and risk assessment of electronic cigarettes as tobacco cigarette substitutes: a systematic review. Therapeutic Advances in Drug Safety 2014;5(2):67-86.

Fish 2009

Fish LJ, Peterson BL, Namenek Brouwer RJ, Lyna P, Oncken CA, Swamy GK, et al. Adherence to nicotine replacement therapy among pregnant smokers. Nicotine \& Tobacco Research 2009:11(5):514-8.

Franck 2014

Franck C, Budlovsky T, Windle SB, Filion KB, Eisenberg MJ. Electronic cigarettes in North America: history, use, and implications for smoking cessation. Circulation 2014; 129(19): 1945-52.

Frost 1994

Frost FJ, Cawthorn ML, Tollestrup K, Kenny FW, Schrager LS, Nordlund DJ. Smoking prevalence during pregnancy for women who are and women who are not Medicaidfunded. American Journal of Preventive Medicine 1994;10 (2):91-6.

\section{Gaither 2009}

Gaither KH, Brunner-Huber LR, Thompson ME, HuetHudson YM. Does the use of nicotine replacement therapy during pregnancy affect pregnancy outcomes. Maternal and Child Health Journal 2009;13(4):497-504.

\section{Gilligan 2007}

Gilligan C, Sanson-Fisher R, Eades S, D'Este C. Antenatal smoking in vulnerable population groups: an area of need. Journal of Obstetrics and Gynaecology 2007;27(7):664-71.

Giovino 2007

Giovino GA. The tobacco epidemic in the United States. American Journal of Preventive Medicine 2007;33(6 Suppl): S318-S326.

\section{Gluckman 2008}

Gluckman PD, Hanson MA, Cooper C, Thornburg KL. Effect of in-utero and early life conditions on adult health and disease. New England Journal of Medicine 2008;359(1): 61-73.

Goniewicz 2014

Goniewicz ML, Knysak J, Gawron M, Kosmider L, Sobczak A, Kurek J, et al. Levels of selected carcinogens and toxicants in vapour from electronic cigarettes. Tobacco Control 2014; 23(2):133-9.

Graham 1976

Graham H. Smoking in pregnancy: the attitudes of pregnant mothers. Social Science and Medicine 1976;10(78):399-405.

Graham 1996

Graham H. Smoking prevalence among women in the European community 1950-1990. Social Science and Medicine 1996;43(2):243-54.

Graham 2010

Graham H, Hawkins SS, Law C. Lifecourse influences on women's smoking before, during and after pregnancy. Social Science and Medicine 2010;70(4):582-7.

Grana 2014

Grana R, Benowitz N, Glantz SA. E-Cigarettes: a scientific review. Circulation 2014;129(19):1972-86.

\section{Grana 2014a}

Grana RA, Popova L, Ling PM. A longitudinal analysis of electronic cigarette use and smoking cessation. JAMA Internal Medicine 2014;174(5):812-3.

\section{Green 2005}

Green NS, Damus K, Simpson JL, Iams J, Reece EA, Hobel CJ, et al. Research agenda for preterm birth: recommendations from the March of the Dimes. American Journal of Obstetrics and Gynecology 2005;193(3 Pt 1): 626-35.

\section{Hammoud 2005}

Hammoud AO, Bujold E, Sorokin Y, Schild C, Krapp $\mathrm{M}$, Baumann P. Smoking in pregnancy revisited: findings from a large population-based study. American Journal of Obstetrics and Gynecology 2005;192(6):1856-63.

\section{Harrell 2014}

Harrell PT, Simmons VN, Correa JB, Padhya TA, Brandon TH. Electronic nicotine delivery systems ("ecigarettes"): review of safety and smoking cessation efficacy. Otolaryngology -- Head and Neck Surgery 2014;151(3): 381-93.

Herrmann 2008

Herrmann M, King K, Weitzman M. Prenatal tobacco smoke and postnatal secondhand smoke exposure and child neurodevelopment. Current Opinion in Pediatrics 2008;20 (2):184-90.

\section{Higgins 2011}

Higgins JPT, Green S, editors. Cochrane Handbook for Systematic Reviews of Interventions Version 5.1.0 [updated March 2011]. The Cochrane Collaboration, 2011. Available from www.cochrane-handbook.org. 


\section{Hitchman 2014}

Hitchman SC, McNeill A, Brose LS. Electronic cigarettes: time for an accurate and evidence-based debate. Addiction 2014;109(6):867-8.

\section{Hughes 2014}

Hughes JR, Stead LF, Hartmann-Boyce J, Cahill K, Lancaster T. Antidepressants for smoking cessation. Cochrane Database of Systematic Reviews 2014, Issue 1. [DOI: 10.1002/14651858.CD000031.pub4]

Hunt 2003

Hunt J. Trying to make a difference: improving pregnancy outcomes, care and services for Australian indigenous women [thesis]. Victoria: LaTrobe University, 2003.

Kaplan 1997

Kaplan SD, Lanier AP, Merritt RK, Siegel PZ. Prevalence of tobacco use among Alaska natives: a review. Preventive Medicine 1997;26(4):460-5.

\section{Kramer 1987}

Kramer MS. Determinants of low birth weight: methodological assessment and meta-analysis. Bulletin of the World Health Organization 1987;65(5):663-737.

\section{Lanting 2012}

Lanting CI, van Wouwe JP, van den Burg I, Segaar D, van der Pal-de Bruin KM. Smoking during pregnancy: trends between 2001 and 2010 [Roken tijdens de zwangerschap: trends in de periode 2001-2010]. Nederlands Tijdschrift Voor Geneeskunde 2012;156(46):A5092.

\section{Maritz 2009}

Maritz GS. Are nicotine replacement therapy, varencline or bupropion options for pregnant mothers to quit smoking? Effects on the respiratory system of the offspring. Therapeutic Advances in Respiratory Disease 2009;3(4): 193-210.

\section{McBride 2003}

McBride CM, Emmons KM, Lipkus IM. Understanding the potential of teachable moments: the case of smoking cessation. Health Education Research 2003;18(2):156-70.

\section{McCowan 2009}

McCowan LME, Dekker GA, Chan E, Stewart A, Chappell LC, Hunter M, et al. Spontaneous preterm birth and small for gestational age infants in women who stop smoking early in pregnancy: prospective cohort study. BMJ 2009; 338:b1081.

\section{McNeill 2014}

McNeill A, Etter J-F, Farsalinos K, Hajek P, le Houezec J, McRobbie H. A critique of a World Health Organizationcommissioned report and associated paper on electronic cigarettes. Addiction 2014;109(12):2128-34.

\section{Murin 2011}

Murin S, Rafii R, Bilello K. Smoking and smoking cessation in pregnancy. Clinics in Chest Medicine 2011;32(1):75-91.

\section{Myung 2012}

Myung SK, Ju W, Jung HS, Park CH, Oh SW, Seo H, et al. Efficacy and safety of pharmacotherapy for smoking cessation among pregnant smokers: a meta-analysis. BJOG: an international journal of obstetrics and gynaecology 2012; 119(9):1029-39.

National Institute for Clinical Excellence 2002

National Institute for Clinical Excellence. Guidance on the use of Nicotine Replacement Therapy (NRT) and Bupropion for Smoking Cessation. Technology Appraisal Guidance No.39. London: National Institute for Clinical Excellence, 2002.

Oncken 2009b

Oncken CA, Kranzler HR. What do we know about the role of pharmacotherapy for smoking cessation before or during pregnancy?. Nicotine and Tobacco Research 2009;11 (11):1265-73.

Oncken 2010

Oncken CA, Dietz PA, Tong VT, Belizan JM, Tolosa JE, Berghella V, et al. Prenatal tobacco prevention and cessation interventions for women in low- and middle- income countries. Acta Obstetricia et Gynecologica Scandinavica 2010;89(4):442-53.

Orr 2014 Orr MS. Electronic cigarettes in the USA: a summary of available toxicology data and suggestions for the future. Tobacco Control 2014;23(Suppl 2):ii18-22.

Osadchy 2009

Osadchy A, Kazmin A, Koren G. Nicotine replacement therapy during pregnancy: recommended or not recommended?. Journal of Obstetrics and Gynaecology Canada 2009;31(8):744-7.

\section{Pickett 2009}

Pickett KE, Wilkinson RG, Wakschlag LS. The psychosocial context of pregnancy smoking and quitting in the Millennium Cohort Study. Journal of Epidemiology and Community Health 2009;63(6):474-80.

\section{Polanska 2005}

Polanska K, Hanke W, Sobala W. Characteristic of the smoking habit among pregnant women on the base of the test "Why am I a smoker?" [Charakterystyka nagogu palenia papierosow wsrod kobiet ciezarnych na podstawie testu Dlaczego pale?]. Przeglad Lekarski 2005;62(10):1095-8.

Potter 1996

Potter A, Lumley J, Watson L. The 'new' risk factors for SIDS: is there an association with ethnic and place of birth differences in incidence in Victoria?. Early Human Development 1996;45:119-31.

\section{Quinn 1991}

Quinn VP, Mullen PD, Ershoff DH. Women who stop smoking spontaneously prior to prenatal care and predictors of relapse before delivery. Addictive Behaviour 1991;16(12):29-40

Regan 2013

Regan AK, Promoff G, Dube SR, Arrazola R. Electronic nicotine delivery systems: adult use and awareness of the 'ecigarette' in the USA. Tobacco Control 2013;22(1):19-23.

\section{RevMan 2014 [Computer program]}

The Nordic Cochrane Centre, The Cochrane Collaboration. Review Manager (RevMan). Version 5.3. Copenhagen: 
The Nordic Cochrane Centre, The Cochrane Collaboration, 2014 .

\section{Richmond 2003}

Richmond R. You've come a long way baby: women and the tobacco epidemic. Addiction 2003;98(5):553-7.

Rore 2008

Rore C, Brace V, Danielian P, Williams D. Smoking cessation in pregnancy. Expert Opinion on Drug Safety 2008; 7(6):727-37.

Ryan 1980

Ryan P, Booth R, Coates D, Chapman A, Healy P. Experiences of Pregnancy. Pregnant Pause Campaign. Sydney: Health Commission of New South Wales, Division of Drug and Alcohol Services, 1980.

\section{Salihu 2007}

Salihu HM, Wilson RE. Epidemiology of prenatal smoking and perinatal outcomes. Early Human Development 2007; 83(11):713-20.

\section{Samet 2001}

Samet JM, Yoon SY. Women and the Tobacco Epidemic: Challenges for the 21st Century. Geneva: World Health Organization, 2001.

\section{Schmidt 2004}

Schmidt S. Nicotine addiction. Journal of Addictive Nursing 2004;15(2):15.

\section{Schneider 2008}

Schneider S, Schutz J. Who smokes during pregnancy? A systematic literature review of population-based surveys conducted in developed countries between 1997 and 2006. European Journal of Contraception and Reproductive Health Care 2008;13(2):138-47.

\section{Slemmer 2000}

Slemmer JE, Martin BR, Damaj MI, Slemmer JE, Martin BR, Damaj MI. Bupropion is a nicotinic antagonist. Journal of Pharmacology \& Experimental Therapeutics 2000;295(1): $321-7$.

Small 2000

Small R. Mothers in a New Country (MINC) [thesis].

Victoria: LaTrobe University, 2000.

\section{Squires 2009}

Squires J, Twombly E, Bricker D, Potter L. ASQ-3 User's Guide for the Ages and Stages Questionnaires Third Edition. Baltimore, MD: Paul H Brookes Publishing Co, 2009.

\section{SRNT2002}

SRNT Subcommittee on Biochemical Verification. Biochemical verification of tobacco use and cessation. Nicotine \& Tobacco Research 2002;4(2):149-59.

\section{Stead 2012}

Stead LF, Perera R, Bullen C, Mant D, HartmannBoyce J, Cahill K, Lancaster T. Nicotine replacement therapy for smoking cessation. Cochrane Database of Systematic Reviews 2012, Issue 11. [DOI: 10.1002/ 14651858.CD000146.pub4]

\section{Stead 2013}

Stead LF, Hartmann-Boyce J, Perera R, Lancaster T. Telephone counselling for smoking cessation. Cochrane Database of Systematic Reviews 2013, Issue 8. [DOI: 10.1002/14651858.CD002850.pub2]

\section{Stedman 1968}

Stedman RL. The chemical composition of tobacco and tobacco smoke. Chemical Reviews 1968;68(2):153-207.

\section{Tappin 1996}

Tappin DM, Ford RP, Nelson KP, Wild CJ. Prevalence of smoking in early pregnancy by census area, measured by anonymous cotinine testing of residual antenatal blood samples. New Zealand Medical Journal 1996;109(1018): $101-3$.

\section{Tappin 2010}

Tappin DM, MacAskill S, Bauld L, Eadie D, Shipton D, Galbraith L. Smoking prevalence and smoking cessation services for pregnant women in Scotland. Substance Abuse: Treatment, Prevention, and Policy 2010;5:doi:10.1186/ 1747-597X-5-1.

\section{The NHS Information Centre 2011}

The NHS Information Centre (IFF Research). Infant feeding survey 2010. Early results. Health Care and Social Care Information Centre. The National Health Service Information Centre for Health and Social Care, 2011:1-22.

Tong 2009

Tong VT, Jones JR, Dietz PM, D'Angelo D, Bombard JM. Trends in smoking before, during, and after pregnancy - Pregnancy risk assessment monitoring system (PRAMS), United States, 31 sites, 2000-2005. Morbidity and Mortality Weekly Report 2009;58:1-29.

Troe 2008

Troe EJ, Raat H, Jaddoe VW, Hofman A, Steegers EA, Verhulst FC, et al. Smoking during pregnancy in ethnic populations: the Generation R study. Nicotine \& tobacco research : official journal of the Society for Research on Nicotine and Tobacco 2008;10(8):1373-84. [PUBMED: 18686185]

\section{Tsoi 2013}

Tsoi DT, Porwal M, Webster AC. Interventions for smoking cessation and reduction in individuals with schizophrenia. Cochrane Database of Systematic Reviews 2013, Issue 2. [DOI: 10.1002/14651858.CD007253.pub3]

\section{US DHHS 2004}

U.S. Department of Health and Human Services. The Health Consequences of Smoking. 2004 Surgeon General's Report. U.S. Department of Health and Human Services, 2004.

\section{Vickerman 2013}

Vickerman KA, Carpenter KM, Altman T, Nash CM, Zbikowski SM. Use of electronic cigarettes among state tobacco cessation quitline callers. Nicotine \& Tobacco Research 2013;15(10):1787-91.

\section{Wanless 2004}

Wanless D. Securing Good Health for the Whole Population. London: TSO, 2004. 


\section{West 2005}

West R, Hajek P, Stead L, Stapleton J, West R, Hajek P, et al. Outcome criteria in smoking cessation trials: proposal for a common standard. Addiction 2005;100(3):299-303.

\section{WHO 2008}

World Health Organization. Report on the Global Tobacco Epidemic 2008 - the mpower package. WHO (http:// www.who.int/tobacco/mpower/en/index.html) (accessed 2008) 2008.

\section{WHO 2013}

Grana R, Benowitz N, Glanz SA. Background paper on e-cigarettes (Electronic Nicotine Delivery Systems): WHO report. Vol. Available at: http:/ /escholarship.org/uc/item/13p2b72n and http:// www.arizonansconcernedaboutsmoking.com/201312ecig report.pdf, Geneva: World Health Organisation, 2013.

\section{Wiemann 1994}

Wiemann CM, Berenson AB, San Miguel VV. Tobacco, alcohol and illicit drug use among pregnant women: age and racial/ethnic differences. Journal of Reproductive Medicine 1994;39(10):769-76.

Woodby 1999

Woodby LL, Windsor RA, Snyder SW, Kohler CL, Diclemente CC. Predictors of smoking cessation during pregnancy. Addiction 1999;94(2):283-92.

\section{Zhu 2014}

Zhu SH, Sun JY, Bonnevie E, Cummins SE, Gamst A, Yin $\mathrm{L}$, et al. Four hundred and sixty brands of e-cigarettes and counting: implications for product regulation. Tobacco Control 2014;23(Suppl 3):iii3-9.

\section{References to other published versions of this review}

\section{Coleman 2012}

Coleman T, Chamberlain C, Davey MA, Cooper SE, Leonardi-Bee J. Pharmacological interventions for promoting smoking cessation during pregnancy. Cochrane Database of Systematic Reviews 2012, Issue 9. [DOI: 10.1002/14651858.CD010078]

\section{Lumley 1995a}

Lumley J. Advice as a strategy for reducing smoking in pregnancy. [revised 02 October 1993]. In: Enkin MW, Keirse MJNC, Renfrew MJ, Neilson JP, Crowther C (eds.) Pregnancy and Childbirth Module. In: The Cochrane Pregnancy and Childbirth Database [database on disk and CDROM] The Cochrane Collaboration; Issue 2, Oxford: Update Software; 1995.

\section{Lumley $1995 b$}

Lumley J. Behavioural strategies for reducing smoking in pregnancy. [revised 27 September 1993]. In: Enkin MW, Keirse MJNC, Renfrew MJ, Neilson JP, Crowther C (eds.) Pregnancy and Childbirth Module. In: The Cochrane Pregnancy and Childbirth Database [database on disk and CDROM] The Cochrane Collaboration; Issue 2, Oxford: Update Software; 1995.

Lumley 1995c

Lumley J. Counselling for reducing smoking in pregnancy. [revised 02 October 1993]. In: Enkin MW, Keirse MJNC, Renfrew MJ, Neilson JP, Crowther C (eds.) Pregnancy and Childbirth Module. In: The Cochrane Pregnancy and Childbirth Database [database on disk and CDROM] The Cochrane Collaboration; Issue 2, Oxford: Update Software; 1995.

\section{Lumley 1995d}

Lumley J. Feedback as a strategy for reducing smoking in pregnancy. [revised 27 September 1993]. In: Enkin MW, Keirse MJNC, Renfrew MJ, Neilson JP, Crowther C (eds.) Pregnancy and Childbirth Module. In: The Cochrane Pregnancy and Childbirth Database [database on disk and CDROM] The Cochrane Collaboration; Issue 2, Oxford: Update Software; 1995.

Lumley 1995e

Lumley J. Strategies for reducing smoking in pregnancy. [revised 02 October 1993]. In: Enkin MW, Keirse MJNC, Renfrew MJ, Neilson JP, Crowther C (eds.) Pregnancy and Childbirth Module. In: The Cochrane Pregnancy and Childbirth Database [database on disk and CDROM] The Cochrane Collaboration; Issue 2, Oxford: Update Software; 1995.

Lumley 1999

Lumley J, Oliver S, Waters E. Interventions for promoting smoking cessation during pregnancy. Cochrane Database of Systematic Reviews 1999, Issue 4. [DOI: 10.1002/ 14651858.CD001055]

Lumley 2004

Lumley J, Oliver S, Chamberlain C, Oakley L. Interventions for promoting smoking cessation in pregnancy. Cochrane Database of Systematic Reviews 2004, Issue 4. [DOI: 10.1002/14651858.CD001055.pub2]

Lumley 2009 Lumley J, Chamberlain C, Dowswell T, Oliver S, Oakley L, Watson L. Interventions for promoting smoking cessation during pregnancy. Cochrane Database of Systematic Reviews 2009, Issue 3. [DOI: 10.1002/ 14651858.CD001055.pub3]

* Indicates the major publication for the study 


\section{CHARACTERISTICS OF STUDIES}

\section{Characteristics of included studies [ordered by study ID]}

\section{Berlin 2014}

Methods Double-blind, placebo-controlled, parallel-group RCT.

Participants

Pregnant women aged $\geq 18$ years, between 9 and 20 weeks' gestation who smoked at least 5 daily cigarettes and scored at least 5 on a scale measuring motivation for quitting smoking (range 0-10)

Interventions

Intervention and control differed only in the provision of active or visually-identical placebo transdermal patches. The intervention patch delivered nicotine as nicotine replacement therapy over a 16-hour period. Both $10 \mathrm{mg}$ and $15 \mathrm{mg}$ patches were used and women's doses does ranged from $10 \mathrm{mg}$ to $30 \mathrm{mg}$ per day. A saliva sample was collected at women's first trial visit/contact with the research team. Between this and a second visit/ contact, which occurred 2 weeks later, women were instructed to either stop smoking or to reduce this to less than 5 daily cigarettes. Women who managed to reduce or stop smoking in this way were, at their second visit, randomised to either placebo or active patch in a 1:1 ratio. The nicotine dose used for women's first prescription of NRT (made at this 2nd trial visit) was based on their saliva cotinine level obtained from the sample given at visit 1 with the aim being to attempt $100 \%$ substitution of nicotine obtained from smoking for that obtained via patches

Women were instructed to use NRT from their quit date until delivery. Smoking and using patches was not encouraged (this is described as a 'safety concern'). However, if women did have a temporary lapse to smoking, they were allowed to remain on NRT afterwards. Both groups received counselling on how to use patches

Outcomes

There were 2 primary outcomes, 1 maternal and 1 relating to infants; these were complete, continuous abstinence from smoking since the quit date and infant birthweight. A positive abstinence outcome was recorded where women self-reported 7 days abstinence from smoking at each study visit and this was confirmed by an exhaled CO reading of 8 ppm or less. There were up to 7 study visits with the final 1 intended for 1 month prior to delivery; no lapses from smoking were permitted

Notes

The cessation outcome used was more stringent than in many studies; often some allowance for temporary lapses to smoking is permitted and many studies assess smoking status as a smaller number of time points in pregnancy

\section{Risk of bias}

\section{Bias}

Random sequence generation (selection Low risk bias)

\section{Support for judgement}

A computer-generated randomisation list (allocation ratio 1:1) in blocks of 4 was prepared and kept double-blinded. 60 randomisation numbers were established by centre. In case of more than 60 randomisations by centre, the next randomisation list 
Berlin 2014 (Continued)

\begin{tabular}{|c|c|c|}
\hline & & $\begin{array}{l}\text { of } 60 \text { was added. The randomisation list by } \\
\text { centre was incorporated into the electronic } \\
\text { case report form, and the randomisation } \\
\text { number was attributed automatically at the } \\
\text { completion of the randomisation visit }\end{array}$ \\
\hline Allocation concealment (selection bias) & Low risk & $\begin{array}{l}\text { A statistician at the clinical research cen- } \\
\text { tre of the Assistance publique-Hôpitaux de } \\
\text { Paris, who was fully independent of the } \\
\text { trial, prepared the random, computer-gen- } \\
\text { erated allocation sequence. The randomi- } \\
\text { sation code was kept in a sealed envelope } \\
\text { in a safe. A copy of the randomisation code } \\
\text { was kept separately in case of a serious ad- } \\
\text { verse event necessitating exposure of a par- } \\
\text { ticipant's group assignment. Investigators, } \\
\text { members of the co-ordination centre, hos- } \\
\text { pital pharmacists, and the study statisti- } \\
\text { cian were kept blinded until the code was } \\
\text { opened before witnesses on } 19 \text { February } \\
2013\end{array}$ \\
\hline
\end{tabular}

Blinding (performance bias and detection Low risk bias)

Women and clinical staff
All study staff (investigators, pharmacists, members of the co-ordination centre and of the drug safety monitoring board, laboratory staff, statistician) were double-blinded to treatment allocation. Placebo patches were identical (visually) to active ones. Determination of saliva cotinine levels were carried out blinded and investigators were not aware of the results

There are similar rates of attendance rates for all trial visits but there are no data presented on attendance at individual trial visits; however, for smoking outcomes all who could not be contacted are assumed to be still smoking so the potentially low followup rates do not affect this. Follow-up rates for birth outcomes are high (e.g. only 3 participants had no delivery data)

All pre-specified outcomes appear to have been reported

Exhaled CO used with cut point of $8 \mathrm{ppm}$ or less used to validate 7 days abstinence from smoking

smoking outcomes)

Low risk

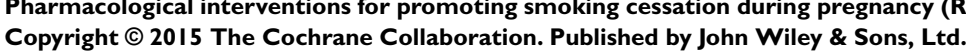


Berlin 2014 (Continued)

Overall assessment of bias risk Low risk

See all of above; no substantial sources of bias identified.

Coleman 2012

Methods

Double-blind placebo-controlled RCT - stratified by trial centre only

Participants

Pregnant women $(\mathrm{n}=1050)$ who agreed to set a quit date, were 16 to 50 years of age, were at 12 to 24 weeks of gestation, smoked 10 or more cigarettes daily before pregnancy, currently smoked 5 or more cigarettes daily, and had an exhaled CO concentration of at least $8 \mathrm{ppm}$

Interventions

Intervention and control conditions differed only in the provision of transdermal patches; the intervention group received active and the control group, placebo patches. Research midwives were trained to provide behavioural support according to national standards, with the use of a manual that included guidance from a British expert trainer of smoking-cessation professionals and behavioural approaches from the Smoking Cessation or Reduction in Pregnancy Treatment trials that were believed to be relevant to British smokers. At enrolment, research midwives provided behavioural support lasting up to $1 \mathrm{hr}$, and participants agreed to a quit date within the following 2 weeks; follow-up was timed from the quit date. Subsequently, participants were randomly assigned to receive a 4-week supply of transdermal patches for nicotine-replacement therapy (at a dose of $15 \mathrm{mg}$ per $16 \mathrm{hrs}$ ) or visually identical placebos, which were started on the quit date (all study treatment was purchased at market rates from United Pharmaceuticals). 1 month after the quit date, women who were not smoking, as validated by an exhaled CO concentration of less than $8 \mathrm{ppm}$, were issued another 4-week supply of patches.

In addition to behavioural support at enrolment, research midwives provided 3 sessions of behavioural support by telephone to participants: 1 session on the quit date, 1 session 3 days afterward, and 1 at 4 weeks. The women who collected a second month's supply of nicotine-replacement or placebo patches also received face-to-face support from the research midwife at the time of collection. Women were offered additional support from local National Health Service smoking cessation services and were encouraged to ask for support from the research midwives or smoking cessation service staff; support was provided according to the manual

Outcomes

Prolonged smoking cessation between a quit date soon after enrolment and delivery, validated by both exhaled $\mathrm{CO}$ monitoring and saliva cotinine estimation. Cut points: exhaled CO, smoking was defined as $>7 \mathrm{ppm}$, saliva cotinine, smoking defined as $>9 \mathrm{ng} /$ dL. Birth outcomes including Apgar score at 5 mins after birth, cord arterial blood $\mathrm{pH}$, intraventricular haemorrhage, neonatal convulsions, congenital abnormalities, necrotising enterocolitis, mechanical ventilation of infant, assisted vaginal delivery, maternal death and caesarean section

For infants: survival to 2 years of age without developmental impairment, reported respiratory symptoms. Maternal: self-reported abstinence from smoking for at least 7 days reported at 6, 12 and 24 months after childbirth, prolonged abstinence from smoking since a quit date set in pregnancy and until 24-month follow-up (defined as having validate abstinence at delivery followed by reported abstinence at all outcome points listed above 
Coleman 2012 (Continued)

Notes

Risk of bias

\begin{tabular}{|c|c|c|}
\hline Bias & Authors' judgement & Support for judgement \\
\hline $\begin{array}{l}\text { Random sequence generation (selection } \\
\text { bias) }\end{array}$ & Low risk & $\begin{array}{l}\text { Computer-generated sequence, in random } \\
\text { permuted blocks of randomly varying size } \\
\text { and with stratification by recruiting site }\end{array}$ \\
\hline Allocation concealment (selection bias) & Low risk & $\begin{array}{l}\text { Allocation and dispensing of treatment/ } \\
\text { placebo packages by external clinical tri- } \\
\text { als unit, with all study staff and partici- } \\
\text { pants unaware of study allocation. "Iden- } \\
\text { tically packaged study patches were dis- } \\
\text { pensed, and all participants and study per- } \\
\text { sonnel were unaware of the study assign- } \\
\text { ments" }\end{array}$ \\
\hline
\end{tabular}

Blinding (performance bias and detection Low risk

bias)

Women and clinical staff

From the text of the paper, it was clear that participants and clinicians were adequately blinded

Although the report does not state the outcome assessor was blinded adequately, this was confirmed in communication with the Chief Investigator who stated that the clinicians acted as outcome assessors and were completely blinded

Incomplete outcome data (attrition bias) Low risk All outcomes

1 participant excluded post randomisation due to accidentally being enrolled twice (control group) and all except this participant were included in intention-to-treat analysis

Intervention: 36 were excluded: (24 were lost to follow-up, 3 withdrew consent, 9 had fetal or infant death)

Control: 33 were excluded: (22 were lost to follow-up, 7 withdrew consent, 4 had fetal or infant death

Also, groups appeared balanced at followup with $60 \%$ follow-up rates for smoking outcomes and much higher for infant ones

Selective reporting (reporting bias) Low risk

Very detailed report of all outcomes and adverse outcomes. 
Coleman 2012 (Continued)

Detection bias (biochemical validation of Low risk smoking outcomes)

Overall assessment of bias risk

Low risk
Biochemical validation of smoking cessation conducted at follow-up points prior to and around childbirth but not afterwards

Only 1 item was independently coded as unclear (and remains as such). However, clarification from the Chief Investigator indicates that this item should be regarded as 'low risk' because outcome assessors were completely blinded

El-Mohandes 2013

Methods

Participants

Interventions

Outcomes
Non-placebo parallel-design RCT.

English speaking pregnant women who smoked and were residents of Washington DC in the United States, of ethnic minority backgrounds, aged at least 18 years and less than 30 weeks' gestation. Women needed to express a, desire to quit and have an expired air CO reading of $8 \mathrm{ppm}$ or less and a salivary cotinine of $20 \mathrm{ng} / \mathrm{mL}$ or less (NB: clincialtrials. gov website says $30 \mathrm{ng} / \mathrm{mL}$ : or less) or a urinary cotinine of $100 \mathrm{ng} / \mathrm{mL}$ or less

1:1 ratio randomisation, stratified by site and initial salivary cotinine levels to either 1) cognitive behavioural therapy (CBT) and NRT transdermal patches or 2) CBT alone NRT: a 10-week course of 24-hour patches was offered, with initial dosing varying with baseline salivary cotinine measurements. Women with levels of $\geq 100 \mathrm{ng} / \mathrm{mL}$ were issued with $21 \mathrm{mg}$ patches for 2 weeks, $14 \mathrm{mg}$ patches for 4 weeks, and finally $7 \mathrm{mg}$ patches for 4 weeks. Women with levels of $\geq 20 \mathrm{ng} / \mathrm{mL}$ and $\leq 100 \mathrm{ng} / \mathrm{mL}$ were issued with $14 \mathrm{mg}$ patches for 6 weeks and $7 \mathrm{mg}$ patches for 4 weeks. The first batch of patches was issued at the second study visit at which salivary cotinine levels were available

Participants were given clear verbal and written instructions on patch use. They were advised never to smoke while using the patch, to remove the patch before going to sleep and not to use other NRT concurrently

CBT: this was the same for both groups.

Smoking cessation outcome: during the study participants made 6 visits to the study team in the antenatal period. At visit 2 (V2), trial interventions were initiated and at each of visits V3-V6 (the last before childbirth), women were asked if they had smoked since their previous clinic visit (e.g. at V3, they were asked if they had smoked since V2) . Participants who reported smoking cessation had this validated using exhaled $\mathrm{CO}$ with abstinence viewed as confirmed by a reading of $<8 \mathrm{ppm}$. The trial manuscript reports point prevalence of abstinence from smoking at each time point and data from V6 are used in analyses. All data were validated (self-report not available), but the period of abstinence which was validated is unclear and varied with the interval between clinic visits

Secondary outcomes reported in the trial manuscript are: premature birth (i.e. at $<37$ weeks' gestation); gestational age at birth; mean birthweight and low birthweight $<2500$ g. Authors have clarified that the following outcomes were collected too: ability to not smoke for 24 hrs or more; longest number of days the woman was able to go without 
El-Mohandes 2013 (Continued)

even a puff of smoking; frequency of smoking at least puff during the last 7 days; number of cigarettes smoked each day; the number of cigarettes smoked during the past $24 \mathrm{hrs}$ and frequency of use of other forms of tobacco

Notes

TItle of paper states it was conducted in 'African-American smokers', but in manuscript participants are described as 'ethnic minority women' and inclusion criteria on clinicaltrials.gov includes Hispanic women

\section{Risk of bias}

\begin{tabular}{|c|c|c|}
\hline Bias & Authors' judgement & Support for judgement \\
\hline $\begin{array}{l}\text { Random sequence generation (selection } \\
\text { bias) }\end{array}$ & Low risk & $\begin{array}{l}\text { Randomisation in a 1:1 ratio was stratified by site } \\
\text { and initial salivary cotinine levels. A web-based } \\
\text { database management system was programmed to } \\
\text { randomise after entering the necessary data to ver- } \\
\text { ify eligibility }\end{array}$ \\
\hline
\end{tabular}

\begin{tabular}{|l|l|l}
\hline Allocation concealment (selection bias) & Low risk & $\begin{array}{l}\text { Randomisation is remote from research staff, so } \\
\text { this seems appropriate (see text from manuscript } \\
\text { above) }\end{array}$
\end{tabular}

Blinding (performance bias and detection High risk bias)

Women and clinical staff
No placebo so participants cannot be blind to treatment allocation; however those delivering behavioural intervention were blind to participants' treatments and the intensity of interventions/contact with participants was standardised in both groups. Those conducting telephone interviews were blind to allocation and smoking behaviour data 'was collected through a self-administered form, completed and sealed by the participant at the end of visits 2-6 and only available to researchers at the end of the study'

Intention-to-treat appears to have been conducted adequately for smoking outcomes and there was relatively little data attrition for infant outcomes, so risk of bias is considered low

Selective reporting (reporting bias) Unclear risk

Adherence data were collected but this is not reported. Some secondary outcomes (regarding smoking) were not reported

Exhaled CO validation using a cut point of $<8$ ppm was used.

Detection bias (biochemical validation of Low risk smoking outcomes)

Overall assessment of bias risk

High risk
In addition to issues highlighted above, 2 women were screened and randomised twice - each pregnancy counted as separate study participation and 
El-Mohandes 2013 (Continued)

both were included in the analysis. Additionally, 1 NRT and CBT group woman received no NRT; given the small size of this trial, both issues could introduce bias

Hotham 2006

\begin{tabular}{ll} 
Methods & Non-placebo parallel-design RCT. \\
\hline Participants & $\begin{array}{l}40 \text { healthy Australian women between } 12 \text { and } 28 \text { weeks pregnant and smoking }>=15 \\
\text { cigarettes daily with an exhaled breath CO reading of }>8 \text { ppm }\end{array}$ \\
\hline Interventions & $\begin{array}{l}\text { Control group: } 5 \text {-minute counselling at baseline and further brief counselling }(<2 \text {-minte } \\
\text { duration) at follow-up visits. } \\
\text { Intervention: counselling as above plus an element concerning correct use of NRT plus } \\
15 \text { mg/16-hour patches for a maximum of } 12 \text { weeks. }\end{array}$ \\
\hline Outcomes & $\begin{array}{l}\text { Smoking cessation (point prevalence) at final antenatal visit } \\
\text { Women seen 'at least monthly during gestation'; also seen within } 48 \text { hrs of delivery when } \\
\text { exhaled CO and saliva sample (for cotinine) taken and by telephone at } 6 \text { weeks and } 3 \\
\text { months }\end{array}$ \\
\hline Notes & $\begin{array}{l}\text { Exhaled CO readings used to validate point prevalence cessation at final antenatal visit. } \\
\text { Cut point }=8 \text { ppm CO. Author clarification used to obtain this information as not } \\
\text { clear in research report. No data on smoking outcomes after childbirth are reported in } \\
\text { the manuscript }\end{array}$ \\
\hline
\end{tabular}

\section{Risk of bias}

$\begin{array}{ll}\text { Bias } & \text { Authors' judgement }\end{array}$

Random sequence generation (selection Low risk bias)

Allocation concealment (selection bias) Unclear risk

Blinding (performance bias and detection High risk

bias)

Women and clinical staff

Incomplete outcome data (attrition bias) Low risk All outcomes

Selective reporting (reporting bias)

\section{Support for judgement}

Computer-generated sequence.

Described as "sealed envelope system". Unclear whether envelopes opaque

No placebo was used. Unclear if assessors blinded to allocation of treatments

$14 / 40$ withdrew from the study (35\% attrition). All withdrawals included in this analysis as continuing smokers

Author confirmed that the following outcomes collected: mode of delivery, labour interventions (if any), birthweight, Apgar scores at 1 and 5 mins, re- 
Hotham 2006 (Continued)

sults of cord-blood analysis for $\mathrm{pH}$ and base excess and also for carboxyhaemoglobin and cotinine Author asked to provide birthweight data to inform safety analyses

Detection bias (biochemical validation of Low risk

Exhaled $\mathrm{CO}$ and salivary samples. smoking outcomes)

Overall assessment of bias risk

High risk

A trial at greater risk of bias.

Kapur 2001

Methods

Parallel-design RCT with active and placebo patches and clinicians/researchers and participants unaware of allocation

Participants

30 healthy Canadian women between 12 and 24 weeks pregnant and smoking >= 15 cigarettes daily who want to quit smoking and could not do so in $1^{\text {st }}$ trimester.

Interventions

12 week course of NRT or identical placebo patches: $15 \mathrm{mg} / 18$ hour patch for 8 weeks, then $10 \mathrm{mg} / 18$-hour for 2 weeks and finally $5 \mathrm{mg} / 18$-hour for 2 weeks. Behavioural counselling at baseline and all follow-up points. Counselling at baseline including a video explaining how to use patch; also counselling at all follow-ups. Weekly telephone contact with women

Intervention $=$ active patch, control $=$ placebo.

Outcomes

Smoking cessation (unclear if point prevalence or continuous cessation measured) 8 weeks into programme (20-32 weeks into pregnancy)

Follow-up also at weeks 1 and 4 into programme with saliva and serum cotinine measured at all time points

Notes Primary outcome validated at 8 weeks into programme. Cotinine cut point not stated but paper states that 'in no case was smoking cessation associate with thiocyanate levels of $>1 \mathrm{ug} / \mathrm{ml}^{\prime}$

\section{Risk of bias}

\begin{tabular}{|c|c|c|}
\hline Bias & Authors' judgement & Support for judgement \\
\hline $\begin{array}{l}\text { Random sequence generation (selection } \\
\text { bias) }\end{array}$ & Low risk & $\begin{array}{l}\text { Random number sequence - confirmed by } \\
\text { authors. }\end{array}$ \\
\hline
\end{tabular}

Allocation concealment (selection bias) Low risk

Placebo or active patches packed remotely as per the randomisation sequence - confirmation via contact with author

Blinding (performance bias and detection Low risk bias)

Women and clinical staff

Described as participants and researchers or clinicians unaware of treatment allocation with identical active and placebo

Pharmacological interventions for promoting smoking cessation during pregnancy (Review)

Copyright $\odot 2015$ The Cochrane Collaboration. Published by John Wiley \& Sons, Ltd. 
Kapur 2001 (Continued)

NRT patches, although most women in the placebo group did not complete the programme

Incomplete outcome data (attrition bias) Low risk All outcomes

Selective reporting (reporting bias)

Unclear risk

Detection bias (biochemical validation of Low risk smoking outcomes)

Overall assessment of bias risk

Low risk
Biochemical validation missing for approximately a third of the sample. All dropouts and missing data treated as continuing smokers in this analysis

No birth outcomes reported.

Biochemical validation by serum thiocyanate and salivary cotinine

At lower risk of bias.

Oncken 2008

Methods

Participants

Interventions
Parallel-design RCT with active and placebo NRT gum and clinicians/researchers and participants unaware of allocation

194 healthy, US English/Spanish-speaking women <= 26 weeks pregnant, smoking >= 1 cigarette daily and aged $>=16$ years

12 weeks treatment with either $2 \mathrm{mg}$ NRT gum or identical placebo. 6 weeks full treatment was followed by 6 weeks tapering of treatment. Instructed not to chew > 20 pieces daily and to use 1 piece of gum for each substituted cigarette. Additionally, all participants received individual counselling at baseline and all 8 follow-ups - 2, 35minute counselling sessions at baseline and within 1 week of quit date and shorter sessions at other follow-ups

Intervention = active gum, control = placebo.

Outcomes

Self-reported 7-day point prevalence abstinence at 6 weeks after treatment commenced, at 32-35 weeks of pregnancy and at 6-12 weeks after delivery. Exhaled CO of less than $8 \mathrm{ppm}$ used for validation all time points

\section{Notes}

\section{Risk of bias}

\begin{tabular}{|c|c|c|}
\hline Bias & Authors' judgement & Support for judgement \\
\hline $\begin{array}{l}\text { Random sequence generation (selection } \\
\text { bias) }\end{array}$ & Low risk & $\begin{array}{l}\text { Computerised randomisation program to } \\
\text { balance participant assignment into treat- } \\
\text { ment groups based on variables of maternal } \\
\text { age, gestational age at study entry, number } \\
\text { of cigarettes smoked per day, health insur- } \\
\text { ance (public or private) and use of metha- }\end{array}$ \\
\hline
\end{tabular}


Oncken 2008 (Continued)

done maintenance

\begin{tabular}{|c|c|c|}
\hline Allocation concealment (selection bias) & Low risk & Computerised allocation. \\
\hline $\begin{array}{l}\text { Blinding (performance bias and detection } \\
\text { bias) } \\
\text { Women and clinical staff }\end{array}$ & Low risk & $\begin{array}{l}\text { Placebo-controlled trial with placebo and } \\
\text { treatment packaged in same blister packets }\end{array}$ \\
\hline $\begin{array}{l}\text { Incomplete outcome data (attrition bias) } \\
\text { All outcomes }\end{array}$ & Low risk & $\begin{array}{l}\text { Perinatal outcomes for } 95 \% \text { control group } \\
\text { and } 97 \% \text { intervention group (excluding } 1 \\
\text { from each group who withdrew consent } \\
\text { and others lost to follow-up). } \\
\text { Smoking outcomes/participation at end of } \\
\text { pregnancy for } 64 \% \text { control group and } 78 \% \\
\text { intervention group } \\
\text { All participants with missing data counted } \\
\text { as smokers in this analysis }\end{array}$ \\
\hline Selective reporting (reporting bias) & Low risk & All adverse events reported. \\
\hline $\begin{array}{l}\text { Detection bias (biochemical validation of } \\
\text { smoking outcomes) }\end{array}$ & Low risk & $\begin{array}{l}\text { Urine anabasine/anatabine alkaloids from } \\
\text { tobacco which are not altered by NRT }\end{array}$ \\
\hline Overall assessment of bias risk & Low risk & At lower risk of bias. \\
\hline
\end{tabular}

Pollak 2007

\begin{tabular}{ll}
\hline Methods & Non-placebo parallel-design RCT. \\
\hline Participants & $\begin{array}{l}181 \text { healthy, US English-speaking women between } 13 \text { and } 25 \text { weeks pregnant, smoking } \\
>=5 \text { cigarettes daily and aged }>=18 \text { years. Must have smoked }>100 \text { cigarettes in lifetime }\end{array}$ \\
\hline Interventions & $\begin{array}{l}\text { Control group: } 5 \text { face-to-face and } 1 \text { telephone behavioural counselling sessions with } \\
\text { booklet and support materials. } \\
\text { Intervention group: counselling as above but with additional focus on use of NRT. } \\
\text { Women permitted choice of NRT from patch, gum or lozenge. Patch dose depended } \\
\text { on CPD: }<10 \text { CPD, } 7 \text { mg/16 hr, } 10 \text { to } 14 \text { CPD } 14 \text { mg/16 hr and }>=15 \text { CPD } 21 \text { mg/ } \\
16 \text { hr. Where gum or lozenge used, one } 2 \text { mg piece was used for each cigarette smoked } \\
\text { daily. Maximum of } 6 \text { weeks NRT provided and no NRT provided when women return } \\
\text { to smoking }\end{array}$ \\
\hline $\begin{array}{l}\text { Self-reported } 7 \text {-day point prevalence abstinence at } 38 \text { weeks. } \\
\text { Also follow-up at } 7 \text { weeks after randomisation and } 3 \text { months postpartum using self- } \\
\text { report data } \\
\text { Saliva samples for cotinine validation were collected at the intervention session that } \\
\text { coincided with each telephone survey from all women regardless of smoking status. Cut } \\
\text { point for primary outcome }<=10 \text { ng/mL. Validation data were collected at all } 3 \text { time } \\
\text { points but is only reported for the } 2 \text { data collection points within pregnancy }\end{array}$
\end{tabular}

Pharmacological interventions for promoting smoking cessation during pregnancy (Review) 
Pollak 2007 (Continued)

$\begin{array}{ll}\text { Notes } & \text { Choices of NRT: } 72 / 122 \text { patch }=59 \%, 32 / 122 \text { gum }=26.2 \% \text { and } 12 / 122 \text { lozenge }=9 . \\ & \begin{array}{l}\text { 8\%. } 19 \text { women chose another formulation as they could not quit with initial selection } \\ \text { (changes not recorded) }\end{array}\end{array}$

\section{Risk of bias}

\begin{tabular}{|c|c|c|}
\hline Bias & Authors' judgement & Support for judgement \\
\hline $\begin{array}{l}\text { Random sequence generation (selection } \\
\text { bias) }\end{array}$ & Low risk & Computerised random number generation. \\
\hline Allocation concealment (selection bias) & Low risk & $\begin{array}{l}\text { Staff responsible for randomising participants used } \\
\text { handheld computer devices which kept allocation } \\
\text { sequence from them until the point of delivering } \\
\text { interventions }\end{array}$ \\
\hline
\end{tabular}

Blinding (performance bias and detection High risk bias)

No placebo used - an open-label trial. Assessors blinded to allocation

Women and clinical staff

Incomplete outcome data (attrition bias) Low risk All outcomes
Loss to follow-up low for perinatal outcomes (10/ 181 births) but more than $30 \%$ attrition for assessment of smoking status at the postnatal follow-up Women lost to follow-up were included as continuing smokers in this analysis

All adverse outcomes reported.

Biochemical validation using salivary cotinine.

Detection bias (biochemical validation of Low risk smoking outcomes)

Overall assessment of bias risk

High risk

At higher risk of bias.

Stotts 2015

Methods

Participants
Placebo-controlled, RCT with parallel group design.

Pregnant women who were at least 18 years old; 14-26 weeks' gestation and currently smoking at least 1 daily cigarette. Wome were excluded if they had abnormal LFTs; history of or current seizure disorder or closed head injury with loss of consciousness; hypersensitivity to bupropion; any psychiatric disorder requiring psychotropic medication; current anorexia or bulimia; MAO use in the past 2 weeks; major depression or risk of suicide; illicit substance use in the past 30 days; > 1 alcoholic drink/week; unstable medical problems; multiple pregnancy; fetal structural anomaly; planned birth at a nonaffiliated hospital; communication problems or lack of transport/phone or current use of NRT, bupropion or varenicline 
Stotts 2015 (Continued)

Interventions
$\begin{aligned} & \text { Bupropion, SR or matching placebo; Bupropion SR was dosed at } 150 \mathrm{mg} / \mathrm{day} \text { for the } \\ & \text { first } 3 \text { days and } 300 \mathrm{mg} / \mathrm{d} \text { thereafter (150 mg twice a day). Placebo appearance, taste, } \\ & \text { and dosing instructions were identical. Patients and providers were masked to treatment } \\ & \text { group. Both the groups received 4, weekly, 15-minute smoking cessation counselling } \\ & \text { sessions based on Clinical Practice Guidelines delivered by a research nurse }\end{aligned}$

Outcomes

The primary smoking outcome was self-reported total abstinence in the prior 7 days (7day point prevalence) with saliva cotinine validation at the EOT. Saliva cotinine assays used a cut point of $>20 \mathrm{ng} / \mathrm{mL}$ indicating regular smoking. Exhaled CO concentration in ppm was measured at each assessment time point using the EC-50 (Vitalograph, Inc., Lenexa, KS), to indicate recent exposure to tobacco smoke in ppm. Maternal, perinatal, and neonatal outcomes assessed included intrauterine fetal death, spontaneous abortion, placental abruption, preterm birth (<37 weeks, 0 days), pre-eclampsia, maternal weight gain, birthweight, umbilical artery $\mathrm{pH}$, gestational age at delivery, fetal growth restriction (birthweight $<10$ th percentile), neonatal intensive care unit admission, respiratory complications (per physician notes)

Notes

The cut point for saliva cotinine is higher than the current standard

\section{Risk of bias}

\begin{tabular}{|c|c|c|}
\hline Bias & Authors' judgement & Support for judgement \\
\hline $\begin{array}{l}\text { Random sequence generation (selection } \\
\text { bias) }\end{array}$ & Low risk & $\begin{array}{l}\text { Randomly assigned using permuted block } \\
\text { design. }\end{array}$ \\
\hline
\end{tabular}

Allocation concealment (selection bias) Unclear risk

There is no description of how randomisation was operationalised, so this is not clear

Blinding (performance bias and detection Low risk bias)

Women and clinical staff

Incomplete outcome data (attrition bias) Low risk All outcomes
As this trial uses visually identical placebos, participants and those delivering the intervention were blind to treatment. It is not explicitly stated that the assessor of outcomes was blinded, but this is likely to be an omission as with placebo control and randomisation, it seems unlikely that the assessor would not be blinded. Consequently, the risk of bias has been assessed as 'low'

It is not specifically reported that an intention-to-treat analysis was used (this would effectively mean that there was no loss of data); however at the main outcome point for smoking cessation, outcome data on all 11 participants are reported within the groups to which these were randomised 


\section{Stotts 2015 (Continued)}

\begin{tabular}{l|l|l}
\hline Selective reporting (reporting bias) & High risk & $\begin{array}{l}\text { A number of outcomes mentioned in study } \\
\text { methods but are not reported in the results } \\
\text { section }\end{array}$ \\
\hline $\begin{array}{l}\text { Detection bias (biochemical validation of } \\
\text { smoking outcomes) }\end{array}$ & Low risk & $\begin{array}{l}\text { There are validated data presented from } \\
\text { cessation outcomes and although this uses } \\
\text { a high cut point }(20 \text { ng/mL for saliva), indi- } \\
\text { vidual participant saliva cotinine readings } \\
\text { are reported and these could be used to eval- } \\
\text { uate findings against a lower cut point, if } \\
\text { desired }\end{array}$ \\
\hline Overall assessment of bias risk & Unclear risk & $\begin{array}{l}\text { This has been allocated an unclear risk of } \\
\text { bias; for smoking cessation outcomes, is- } \\
\text { sues highlighted may be problems with de- } \\
\text { scription rather than design or conduct of } \\
\text { the trial }\end{array}$ \\
\hline
\end{tabular}

Wisborg 2000

\section{Methods}

Parallel-design RCT with active and placebo patches and clinicians/researchers and participants unaware of allocation

Participants

250 healthy Danish women $<22$ weeks pregnant and smoking $>=10$ cigarettes daily

Interventions

11 week course of NRT or identical placebo patches: $15 \mathrm{mg} / 16 \mathrm{hr}$ for 8 weeks then 10 $\mathrm{mg} / 16 \mathrm{hr}$ for 3 weeks plus behavioural counselling and information pamphlet Intervention $=$ active patch, control = placebo.

Outcomes

Self-reported abstinence of $>=7$ days at $2^{\text {nd }}, 3^{\text {rd }}$ and $4^{\text {th }}$ prenatal visits ( 4 weeks prior to delivery).

Follow-ups at times above and also by telephone at 3 months and 1 year after delivery

Notes

Saliva cotinine level $<26 \mathrm{ng} / \mathrm{mL}$ at the 4 th visit ( 4 weeks prior to expected delivery date) used to validate reported smoking cessation. The test used could not detect lower than $20 \mathrm{ng} / \mathrm{mL}$ (data verified by communication with author). Only self-report data were collected after childbirth

\section{Risk of bias}

\begin{tabular}{l|l|l}
\hline Bias & Authors' judgement & Support for judgement \\
\hline $\begin{array}{l}\text { Random sequence generation (selection } \\
\text { bias) }\end{array}$ & Low risk & Randomised list in balanced blocks. \\
\hline Allocation concealment (selection bias) & Low risk & $\begin{array}{l}\text { Placebo-controlled trial with allocation } \\
\text { coded until the end of data collection }\end{array}$
\end{tabular}


Wisborg 2000 (Continued)

\begin{tabular}{|c|c|c|}
\hline $\begin{array}{l}\text { Blinding (performance bias and detection } \\
\text { bias) } \\
\text { Women and clinical staff }\end{array}$ & Low risk & $\begin{array}{l}\text { Placebo-controlled trial with allocation } \\
\text { coded until the end of data collection }\end{array}$ \\
\hline $\begin{array}{l}\text { Incomplete outcome data (attrition bias) } \\
\text { All outcomes }\end{array}$ & Unclear risk & $\begin{array}{l}\text { The treatment allocation of } 7 \text { miscarriages } \\
\text { could not be determined. Small loss to fol- } \\
\text { low-up but missing data treated as contin- } \\
\text { uing smokers in this analysis }\end{array}$ \\
\hline Selective reporting (reporting bias) & Low risk & Adverse outcomes reported. \\
\hline $\begin{array}{l}\text { Detection bias (biochemical validation of } \\
\text { smoking outcomes) }\end{array}$ & Unclear risk & $\begin{array}{l}\text { Used cut point which is higher than cur- } \\
\text { rently accepted and biochemical test which } \\
\text { could not detect levels of cotinine of }<20 \\
\mathrm{ng} / \mathrm{mL} \text { (data obtained from authors). Some } \\
\text { respondents reporting smoking cessation } \\
\text { may have actually been still smoking and } \\
\text { the biochemical test would not detect this. } \\
\text { In analyses we dealt with this by using self- } \\
\text { report data in primary analyses and inves- } \\
\text { tigating the impact of using biochemically } \\
\text { validated data in a sensitivity analysis }\end{array}$ \\
\hline Overall assessment of bias risk & Low risk & At lower risk of bias. \\
\hline
\end{tabular}

CO: carbon monoxide

CPD: cigarettes per day

hr(s): hour(s)

LFTs: liver function tests

mg: milligrams

$\mathrm{mg} / \mathrm{hr}$ : milligrams per hour

Monoamine oxidase $\min (\mathrm{s})$ : minute(s)

ng/mL: nanograms per millilitre

NRT: nicotine replacement therapy

ppm: parts per million

RCT: randomised controlled trial

Characteristics of excluded studies [ordered by study ID]

Study Reason for exclusion

Eades 2012 This was a pilot trial of a smoking cessation intervention developed specially for Aboriginal and Torres Strait Islander women. It was quasi-randomised as women were allocated to intervention or control in 'control' or 'intervention' weeks with the nature of individual weeks determined by random allocation (but outcomes being monitored at the level of individual women). It was not judged possible to attribute treatment effects in the intervention arm to NRT

Pharmacological interventions for promoting smoking cessation during pregnancy (Review)

Copyright $\odot 2015$ The Cochrane Collaboration. Published by John Wiley \& Sons, Ltd. 
because NRT was offered as part of a multi-modal intervention which offered more behavioural support (in addition to the NRT) to participants in the intervention group. Additionally, NRT was only offered to those intervention group women who made 2 failed quit attempts after receiving behavioural components of the intervention and, in the presentation of outcomes from the study, women who accepted the offer of NRT at this stage could not be differentiated from other intervention group women. Components of the intervention delivered in addition to the offer of NRT detailed above were:

i) the use of a 'buddy' to provide 'lay' support for women trying to quit,

ii) signing a 'partnership agreement' with health professionals as evidence of commitment to try quitting,

iii) a high intensity behavioural intervention in early pregnancy and ongoing support

Hegaard 2003 Quasi-random allocation/sequence generation of participants (by their birth dates)

Also, it was not judged possible to attribute treatment effects in the intervention arm to NRT because:

NRT was offered as part of a multi-modal intervention which differed between trial arms, with the intervention group receiving counselling by specially trained staff on "intervention days" and the control group receiving only routine advice from their usual midwife

At randomisation, participants did not have to agree to use NRT; of 327 women randomised to the intervention group only 75 accepted and offer of NRT. Smoking outcomes were not reported within the subgroup of those using NRT so it was not clear if NRT was responsible for smoking outcomes. Also this post-randomisation self-selection of participants for NRT use introduces unknown biases into the study. This is not the same as other trials in which all participants agreed to use and were randomised to potentially receiving NRT

Oncken 2009a This was not an RCT but was a cohort study in which the impacts of nicotine patches or nasal spray on nicotine exposure in pregnant women were investigated. It was excluded at the stage of abstract scrutiny

NRT: nicotine replacement therapy

RCT: randomised controlled trial

\section{Characteristics of ongoing studies [ordered by study ID]}

\section{Hankins 2011}

\begin{tabular}{ll}
\hline Trial name or title & Bupropion for smoking cessation during pregnancy \\
\hline Methods & Placebo-randomised, double-blind, controlled trial. \\
\hline Participants & $\begin{array}{l}\text { Pregnant women aged } 18 \text { and over who are smoked at least } 10 \text { daily cigarettes prior to pregnancy (and in } \\
\text { pregnancy smoke at least } 5 \text { daily cigarettes) and who are between } 13 \text { and } 26 \text { weeks' gestation }\end{array}$ \\
\hline Interventions & $\begin{array}{l}\text { Bupropion (slow release) } 150 \text { mg twice daily (after gradual build up in dose) for } 12 \text { weeks, dispensed for } 30 \\
\text { days at a time }\end{array}$ \\
\hline Outcomes & $\begin{array}{l}\text { Primary outcome: change in withdrawal symptoms from the quit date (onset of smoking cessation }+ \text { after } 1 \\
\text { week of treatment) to that at the completion of study therapy (status post } 12 \text { weeks of study treatment, } 11 \\
\text { weeks post quit date) measured by Minnesota Nicotine Withdrawal Scale. Other outcomes include: } 7 \text {-day } \\
\text { point prevalence of smoking abstinence as } 3 \text { weeks after a quit date and 7-day point prevalence of smoking } \\
\text { abstinence at } 36 \text { to } 38 \text { weeks' gestation }\end{array}$
\end{tabular}

Pharmacological interventions for promoting smoking cessation during pregnancy (Review)

Copyright $\odot 2015$ The Cochrane Collaboration. Published by John Wiley \& Sons, Ltd. 
Hankins 2011 (Continued)

\begin{tabular}{l|l}
\hline Starting date & July 2011. \\
\hline Contact information & mlzimmer@utmb.edu or jbrando@utmb.edu \\
\hline Notes & Aims to recruit 150 participants and to be completed by October 2015 \\
\hline
\end{tabular}

\section{Koren 2008}

\begin{tabular}{l|l}
\hline Trial name or title & Study of nicotine replacement therapy in pregnancy \\
\hline Methods & Randomised, controlled open-label study. \\
\hline $\begin{array}{l}\text { Participants } \\
\text { - Wregnant women after } 12 \text { weeks' gestation, confirmed by ultrasound. } \\
\bullet\end{array}$ & On the day of the recruitment, women will be at least 18 years old and no older than 40 years old. \\
\hline Interventions & Smoking cessation. \\
\hline Outcomes & August 2008. \\
\hline Starting date & gideon.koren@sickkids.ca \\
\hline Contact information & $\begin{array}{l}\text { This study has been withdrawn due to recruitment difficulties. I have left it here so readers have an audit trail } 14 \mathrm{mg} / \text { day or } 21 \mathrm{mg} / \text { day. } \\
\text { for study outcomes }\end{array}$ \\
\hline Notes
\end{tabular}

\section{Kranzler 2014}

\begin{tabular}{|c|c|}
\hline Trial name or title & Placebo-controlled trial of Bupropion for smoking cessation in pregnant women (BIBS) \\
\hline Methods & Placebo-randomised, parallel-group, controlled trial. \\
\hline Participants & $\begin{array}{l}\text { Pregnant at } 13-24 \text { weeks' gestation and > } 18 \text { years of age; currently smoking at least } 5 \text { cigarettes per day for the } \\
\text { preceding } 7 \text { days and want to quit smoking; able to speak and read English at a 6th grade level or higher, using } \\
\text { the Slosson Oral Reading Test (SORT); committed to remaining in the geographic area for at least } 3 \text { months } \\
\text { postpartum; able to sign written informed consent and commit to completing the procedures involved in the } \\
\text { study }\end{array}$ \\
\hline Interventions & Bupropion $150 \mathrm{mg}$ twice daily for 10 weeks or a visually identical placebo \\
\hline Outcomes & $\begin{array}{l}\text { 7-day point prevalence abstinence from smoking; number of cigarettes smoked; frequency of moderate or } \\
\text { severe side effects; birth outcomes; smoking frequency after } 10 \text { weeks treatment phase }\end{array}$ \\
\hline Starting date & 014. \\
\hline
\end{tabular}




\section{Kranzler 2014 (Continued)}

\begin{tabular}{l|l} 
Contact information & $\begin{array}{l}\text { Henry Kranzler, M.D., University of Pennsylvania } \\
\text { timpond@mail.med.upenn.edu }\end{array}$ \\
\hline Notes & \\
\hline
\end{tabular}

\section{Oncken 2009c}

\begin{tabular}{ll}
\hline Trial name or title & Pilot study of nicotine replacement for smoking cessation during pregnancy \\
\hline Methods & Open-label, single group cohort study (non-randomised). \\
\hline Participants & Healthy women $13-26$ weeks pregnant, smoking 5 daily cigarettes in previous 7 days \\
\hline Interventions & Nicotrol inhaler with behavioural counselling. Inhaler intended to be used for 4 weeks \\
\hline Outcomes & Abstinence from smoking at 2 and 4 weeks after quit date. \\
\hline Starting date & April 27 2009. \\
\hline Contact information & oncken@nso2.uchc.edu \\
\hline Notes & $\begin{array}{l}\text { Estimated closing date was November 2010; still listed on clinicaltrials.gov but of “unknown" status as no } \\
\text { data uploaded for over } 2 \text { years }\end{array}$ \\
\hline
\end{tabular}

\section{Oncken 2012}

\begin{tabular}{l|l}
\hline Trial name or title & Nicotine replacement for smoking cessation during pregnancy \\
\hline Methods & Placebo-randomised, double-blind, controlled trial. \\
\hline Participants & $\begin{array}{l}\text { Pregnant women aged } 16 \text { years or over; } 13-26 \text { weeks' gestation; smoke at least } 5 \text { daily cigarettes in previous } \\
\text { 7 days and report a previous attempt to stop smoking during this pregnancy }\end{array}$ \\
\hline Interventions & Nicotrol Inhaler; using up to 2 cartridges per day, for 6 weeks with a 6 week taper \\
\hline Outcomes & 7-day point prevalence of smoking cessation at 32-34 weeks' gestation \\
\hline Starting date & December 2010. \\
\hline Contact information & Sheila D Thurlowthurlow@uchc.edu \\
\hline Notes & Aims to recruit 360 participants and to be completed by November 2015 \\
\hline
\end{tabular}

NRT: nicotine replacement therapy

ng/mL: nanograms per millilitre 
mg/day:milligrams per day

Pharmacological interventions for promoting smoking cessation during pregnancy (Review)

Copyright $\odot 2015$ The Cochrane Collaboration. Published by John Wiley \& Sons, Ltd. 
DATA AND ANALYSES

Comparison 1. Nicotine replacement therapy versus control (Primary outcome - efficacy)

\begin{tabular}{|c|c|c|c|c|}
\hline Outcome or subgroup title & $\begin{array}{l}\text { No. of } \\
\text { studies }\end{array}$ & $\begin{array}{c}\text { No. of } \\
\text { participants }\end{array}$ & Statistical method & Effect size \\
\hline $\begin{array}{l}1 \text { Validated cessation in later } \\
\text { pregnancy }\end{array}$ & 8 & 2199 & Risk Ratio (M-H, Random, 95\% CI) & $1.41[1.03,1.93]$ \\
\hline 1.1 Placebo-controlled trials & 5 & 1926 & Risk Ratio (M-H, Random, 95\% CI) & $1.28[0.99,1.66]$ \\
\hline $\begin{array}{l}1.2 \text { Non placebo-controlled } \\
\text { trials }\end{array}$ & 3 & 273 & Risk Ratio (M-H, Random, 95\% CI) & $8.51[2.05,35.28]$ \\
\hline $\begin{array}{l}2 \text { Self-report cessation at } 3 \text { or } 6 \\
\text { months after childbirth }\end{array}$ & 3 & 625 & Risk Ratio (M-H, Random, 95\% CI) & $1.22[0.84,1.77]$ \\
\hline 2.1 Placebo-controlled trials & 2 & 444 & Risk Ratio (M-H, Random, 95\% CI) & $1.15[0.75,1.77]$ \\
\hline $\begin{array}{l}2.2 \text { Non placebo-controlled } \\
\text { trials }\end{array}$ & 1 & 181 & Risk Ratio (M-H, Random, 95\% CI) & $1.45[0.69,3.03]$ \\
\hline $\begin{array}{l}3 \text { Self-report cessation at } 12 \\
\text { months after childbirth }\end{array}$ & 1 & 246 & Risk Ratio (M-H, Random, 95\% CI) & $1.04[0.57,1.88]$ \\
\hline
\end{tabular}

Comparison 2. Nicotine replacement therapy versus control (Secondary outcomes - safety)

\begin{tabular}{|c|c|c|c|c|}
\hline Outcome or subgroup title & $\begin{array}{l}\text { No. of } \\
\text { studies }\end{array}$ & $\begin{array}{c}\text { No. of } \\
\text { participants }\end{array}$ & Statistical method & Effect size \\
\hline $\begin{array}{l}1 \text { Miscarriage and spontaneous } \\
\text { abortion }\end{array}$ & 4 & 1782 & Risk Ratio (M-H, Random, 95\% CI) & $1.47[0.45,4.77]$ \\
\hline 2 Stillbirth & 4 & 1777 & Risk Ratio (M-H, Random, 95\% CI) & $1.24[0.54,2.84]$ \\
\hline 3 Mean birthweight (g) & 6 & 2068 & Mean Difference (IV, Random, 95\% CI) & $\begin{array}{l}100.54[-20.84,221 . \\
91]\end{array}$ \\
\hline 3.1 Placebo-controlled trials & 4 & 1852 & Mean Difference (IV, Random, 95\% CI) & $\begin{array}{l}124.63[-22.21,271 . \\
47]\end{array}$ \\
\hline $\begin{array}{l}3.2 \text { Non-placebo controlled } \\
\text { trials }\end{array}$ & 2 & 216 & Mean Difference (IV, Random, 95\% CI) & $\begin{array}{l}36.39[-256.19,328 . \\
98]\end{array}$ \\
\hline 4 Low birthweight $(<2500 \mathrm{~g})$ & 6 & 2037 & Risk Ratio (M-H, Random, 95\% CI) & $0.74[0.41,1.34]$ \\
\hline 4.1 Placebo-controlled trials & 4 & 1821 & Risk Ratio (M-H, Random, 95\% CI) & $0.58[0.27,1.26]$ \\
\hline $\begin{array}{l}4.2 \text { Non-placebo controlled } \\
\text { trials }\end{array}$ & 2 & 216 & Risk Ratio (M-H, Random, 95\% CI) & $1.35[0.61,2.98]$ \\
\hline 5 Preterm birth (birth < 37 weeks) & 6 & 2048 & Risk Ratio (M-H, Random, 95\% CI) & $0.87[0.67,1.14]$ \\
\hline 5.1 Placebo-controlled trials & 4 & 1821 & Risk Ratio (M-H, Random, 95\% CI) & $0.81[0.60,1.11]$ \\
\hline $\begin{array}{l}5.2 \text { Non-placebo controlled } \\
\text { trials }\end{array}$ & 2 & 227 & Risk Ratio (M-H, Random, 95\% CI) & $1.20[0.62,2.35]$ \\
\hline $\begin{array}{l}6 \text { Neonatal intensive care unit } \\
\text { admissions }\end{array}$ & 4 & 1756 & Risk Ratio (M-H, Random, 95\% CI) & $0.90[0.64,1.27]$ \\
\hline 7 Neonatal death & 4 & 1746 & Risk Ratio (M-H, Random, 95\% CI) & $0.66[0.17,2.62]$ \\
\hline 8 Congenital abnormalities & 2 & 1401 & Risk Ratio (M-H, Random, 95\% CI) & $0.73[0.36,1.48]$ \\
\hline
\end{tabular}




\section{Analysis I.I. Comparison I Nicotine replacement therapy versus control (Primary outcome - efficacy), Outcome I Validated cessation in later pregnancy.}

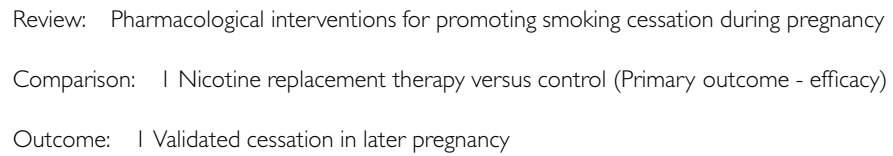

I Placebo-controlled trials

\section{Oncken 2008}

Coleman 2012

$18 / 100$

14/94

Berlin 2014

$49 / 521$

$40 / 529$

Wisborg 2000

$25 / 203$

$19 / 199$

Kapur 200I

$22 / 124$

$17 / 126$

$4 / 17$

$0 / 13$

Subtotal $(95 \% \mathrm{CI})$

965

961

Total events: I I8 (NRT), 90 (Control)

Heterogeneity: $\mathrm{Tau}^{2}=0.0 ; \mathrm{Chi}^{2}=1.45, \mathrm{df}=4(\mathrm{P}=0.84) ; \mathrm{I}^{2}=0.0 \%$

Test for overall effect: $Z=1.87(P=0.062)$

2 Non placebo-controlled trials

Hotham 2006

$3 / 20$

$0 / 20$

Pollak 2007

$17 / 122$

$1 / 59$

El-Mohandes 2013

$$
5 / 26
$$

$0 / 26$

Subtotal (95\% CI)

168

105

Total events: 25 (NRT), I (Control)

Heterogeneity: $\mathrm{Tau}^{2}=0.0 ; \mathrm{Chi}^{2}=0.05, \mathrm{df}=2(\mathrm{P}=0.98) ; \mathrm{I}^{2}=0.0 \%$

Test for overall effect: $Z=2.95(P=0.0032)$

Total (95\% CI) 1133

1066

Total events: 143 (NRT), 91 (Control)

Heterogeneity: $\mathrm{Tau}^{2}=0.03 ; \mathrm{Chi}^{2}=8.5 \mathrm{I}, \mathrm{df}=7(\mathrm{P}=0.29) ; \mathrm{I}^{2}=18 \%$

Test for overall effect: $Z=2.15(P=0.031)$

Test for subgroup differences: $\mathrm{Chi}^{2}=6.59, \mathrm{df}=\mathrm{I}(\mathrm{P}=0.0 \mathrm{I}), \mathrm{I}^{2}=85 \%$

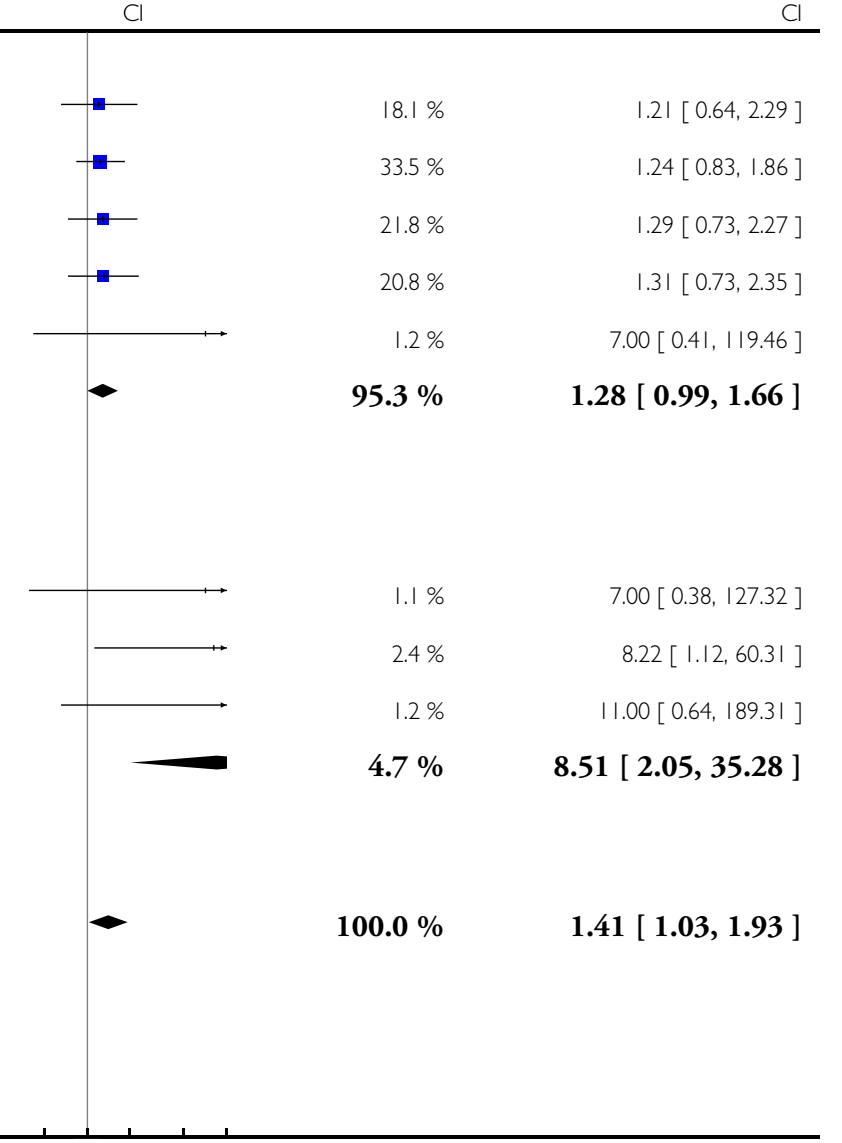

$\begin{array}{lllllll}0.1 & 0.2 & 0.5 & 1 & 2 & 5 & 10\end{array}$

Favours control Favours NRT 


\section{Analysis I.2. Comparison I Nicotine replacement therapy versus control (Primary outcome - efficacy), Outcome 2 Self-report cessation at 3 or 6 months after childbirth.}

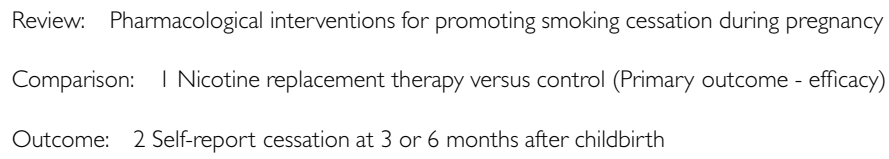

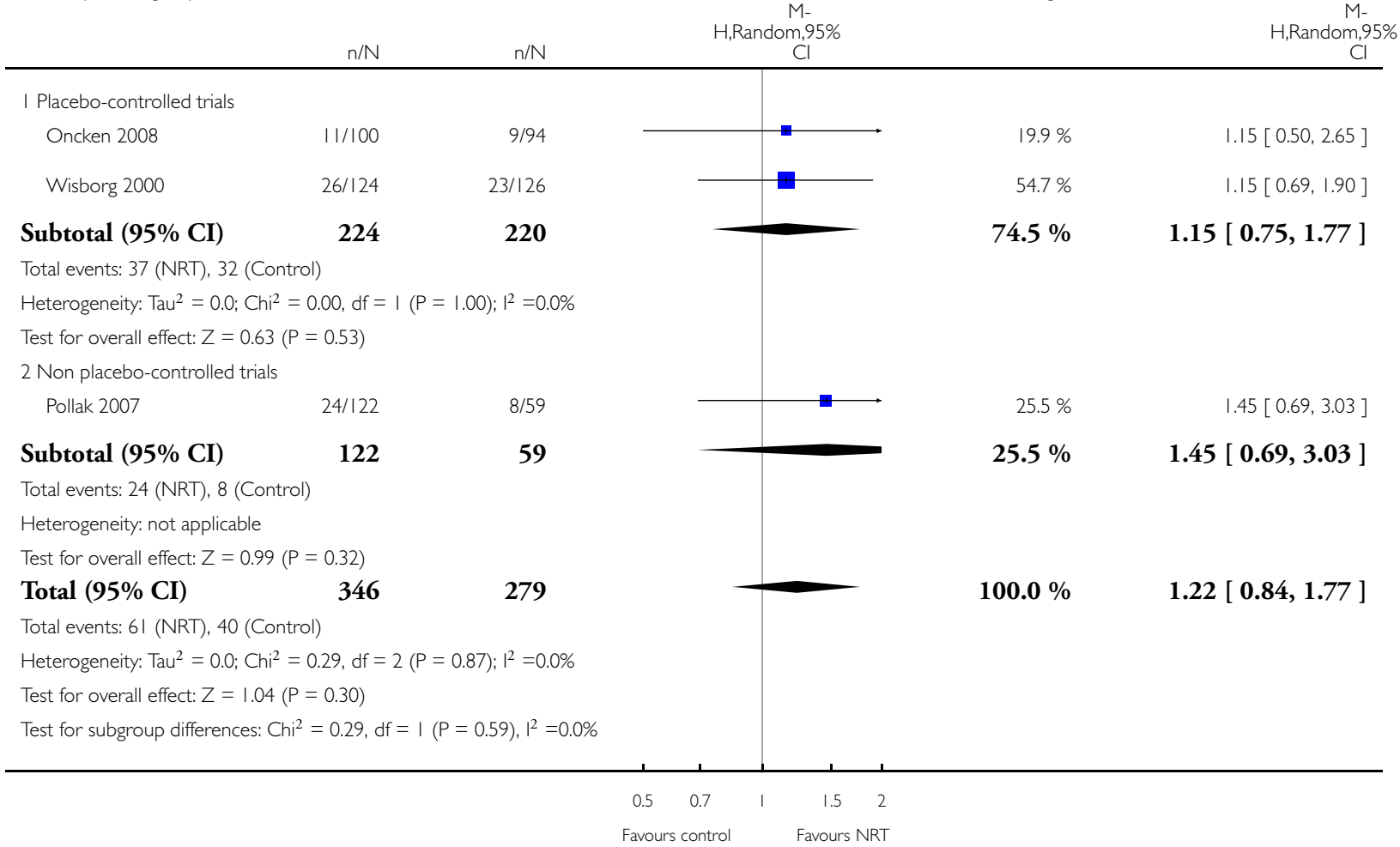




\section{Analysis I.3. Comparison I Nicotine replacement therapy versus control (Primary outcome - efficacy),}

Outcome 3 Self-report cessation at 12 months after childbirth.

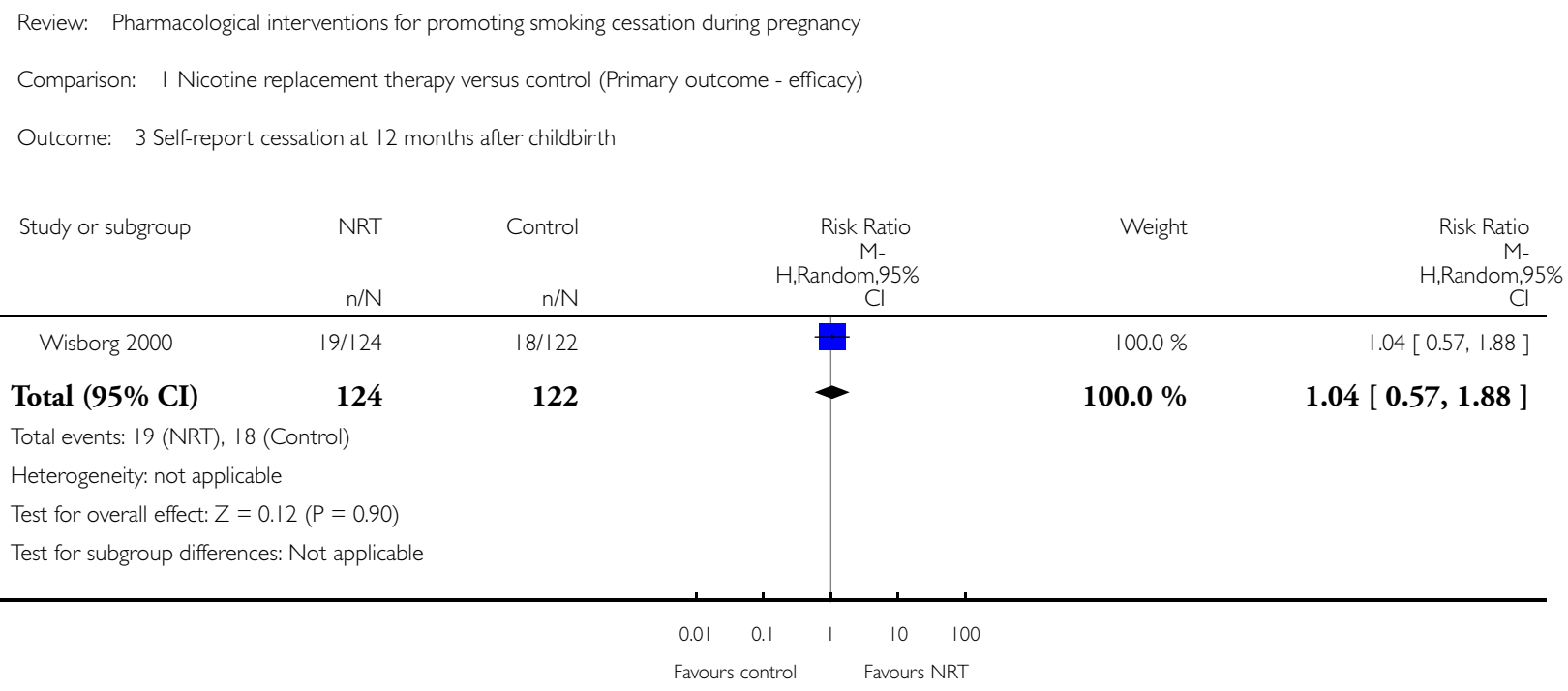


Analysis 2.I. Comparison 2 Nicotine replacement therapy versus control (Secondary outcomes - safety), Outcome I Miscarriage and spontaneous abortion.

Review: Pharmacological interventions for promoting smoking cessation during pregnancy

Comparison: 2 Nicotine replacement therapy versus control (Secondary outcomes - safety)

Outcome: I Miscarriage and spontaneous abortion

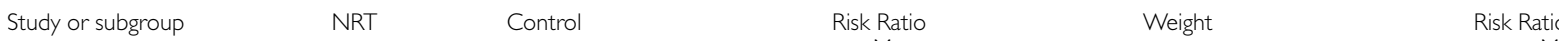
M-
H.Random,95\%

\begin{tabular}{|c|c|c|c|c|c|}
\hline & $\mathrm{n} / \mathrm{N}$ & $\mathrm{n} / \mathrm{N}$ & $\begin{array}{c}\text { H,Random,95\% } \\
\mathrm{Cl} \\
\end{array}$ & & $\begin{array}{r}\text { H,Random,95 } \\
\mathrm{Cl}\end{array}$ \\
\hline Berlin 2014 & 1//89 & 1//88 & $\longrightarrow$ & $18.2 \%$ & $0.99[0.06,15.79]$ \\
\hline Coleman 2012 & $3 / 515$ & $2 / 521$ & & $43.6 \%$ & $1.52[0.25,9.04]$ \\
\hline Oncken 2008 & $2 / 100$ & $|/ 9|$ & \pm & $24.5 \%$ & $1.82[0.17,19.74]$ \\
\hline Pollak 2007 & $1 / 119$ & $0 / 59$ & 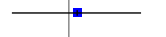 & $13.7 \%$ & I.50 [0.06, 36.27 ] \\
\hline
\end{tabular}

Total $(95 \% \mathrm{CI})$

923

859

$100.0 \%$

1.47 [ $0.45,4.77$ ]

Total events: 7 (NRT), 4 (Control)

Heterogeneity: $\mathrm{Tau}^{2}=0.0 ; \mathrm{Chi}^{2}=0.1 \mathrm{l}, \mathrm{df}=3(\mathrm{P}=0.99) ; \mathrm{I}^{2}=0.0 \%$

Test for overall effect: $Z=0.64(P=0.52)$

Test for subgroup differences: Not applicable 
Analysis 2.2. Comparison 2 Nicotine replacement therapy versus control (Secondary outcomes - safety), Outcome 2 Stillbirth.

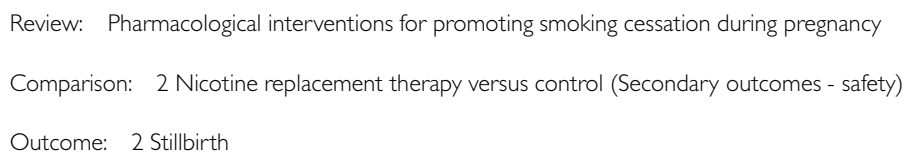

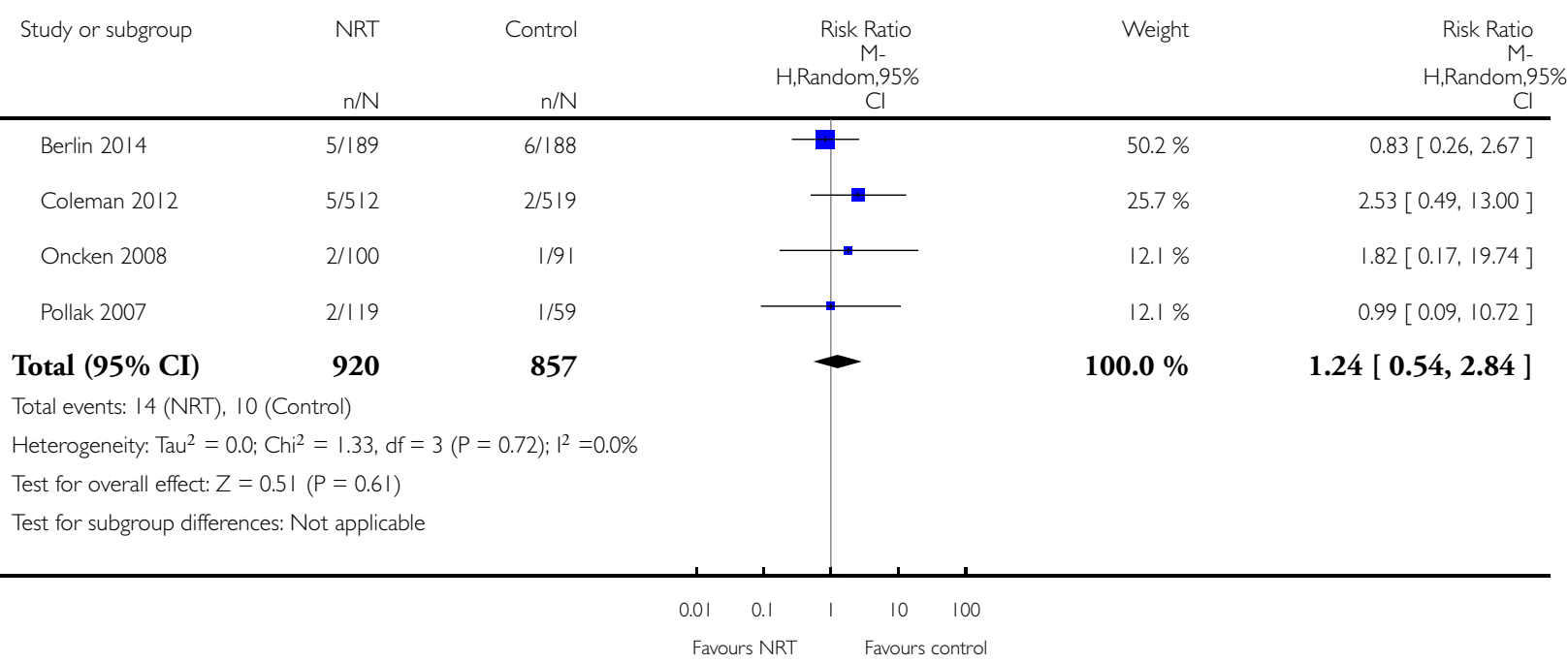


Analysis 2.3. Comparison 2 Nicotine replacement therapy versus control (Secondary outcomes - safety), Outcome 3 Mean birthweight (g).

Review: Pharmacological interventions for promoting smoking cessation during pregnancy

Comparison: 2 Nicotine replacement therapy versus control (Secondary outcomes - safety)

Outcome: 3 Mean birthweight $(g)$

Study or subgroup MRT Mean Mean

N Mean(SD) N Mean(SD) IV,Random,95\% Cl IV,Random,95\% Cl

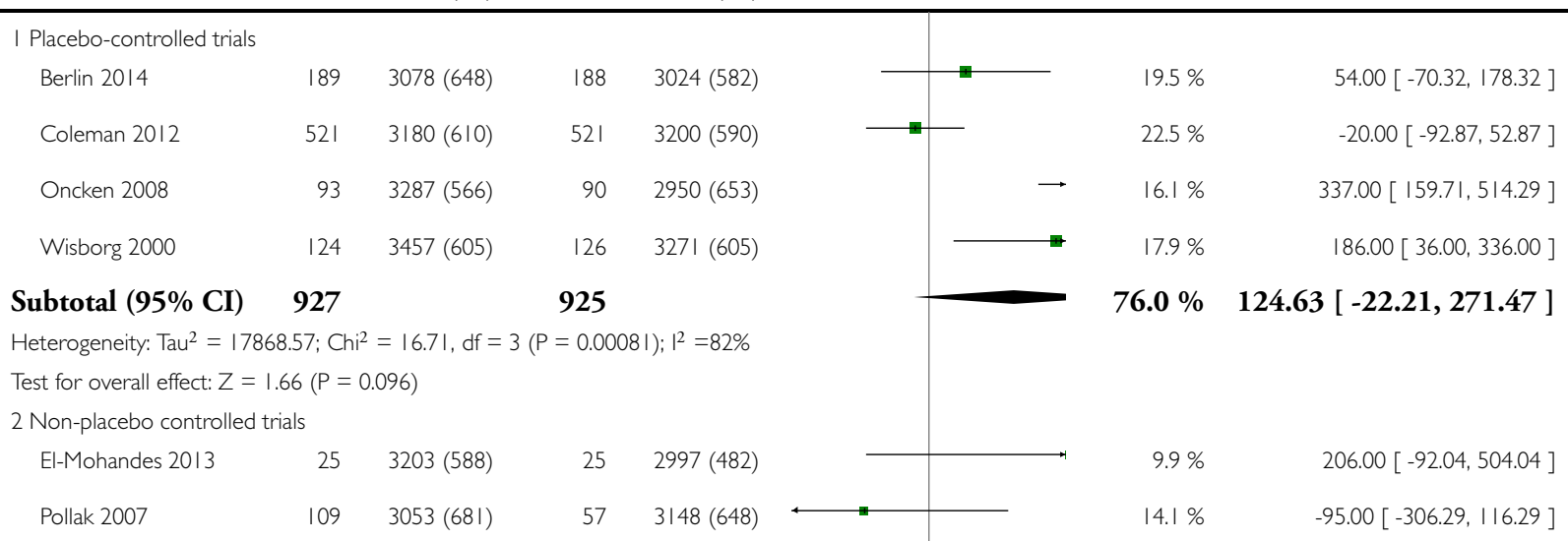

Subtotal (95\% CI) 134

82

$24.0 \% 36.39[-256.19,328.98]$

Heterogeneity: $\operatorname{Tau}^{2}=27928.43 ; \mathrm{Chi}^{2}=2.61, \mathrm{df}=1(\mathrm{P}=0.1 \mathrm{I}) ; \mathrm{I}^{2}=62 \%$

Test for overall effect: $Z=0.24(P=0.81)$

Total (95\% CI) 1061

$100.0 \% \quad 100.54[-20.84,221.91]$

Heterogeneity: Tau $^{2}=15624.49 ; \mathrm{Chi}^{2}=19.63, \mathrm{df}=5(\mathrm{P}=0.00 \mathrm{I}) ;\left.\right|^{2}=75 \%$

Test for overall effect: $Z=1.62(P=0.10)$

Test for subgroup differences: $\mathrm{Chi}^{2}=0.28, \mathrm{df}=\mathrm{I}(\mathrm{P}=0.60), \mathrm{I}^{2}=0.0 \%$

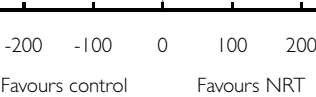


Analysis 2.4. Comparison 2 Nicotine replacement therapy versus control (Secondary outcomes - safety), Outcome 4 Low birthweight (<2500 g).

Review: Pharmacological interventions for promoting smoking cessation during pregnancy

Comparison: 2 Nicotine replacement therapy versus control (Secondary outcomes - safety)

Outcome: 4 Low birthweight $(<2500 \mathrm{~g})$

\begin{tabular}{|c|c|c|c|c|c|}
\hline Study or subgroup & $\begin{array}{l}\text { NRT } \\
\mathrm{n} / \mathrm{N}\end{array}$ & Control & $\begin{array}{c}\text { Risk Ratio } \\
\text { M- } \\
\text { H,Random,95\% } \\
\text { Cl }\end{array}$ & Weight & $\begin{array}{c}\text { Risk Ratio } \\
\text { M- } \\
\text { H,Random,95\% } \\
\text { Cl }\end{array}$ \\
\hline \multicolumn{6}{|l|}{ I Placebo-controlled trials } \\
\hline Berlin 2014 & $25 / 189$ & $33 / 188$ & $\rightarrow$ & $23.4 \%$ & $0.75[0.47,1.22]$ \\
\hline Coleman 2012 & $56 / 507$ & $43 / 517$ & + & $24.8 \%$ & $1.33[0.91,1.94]$ \\
\hline Oncken 2008 & $2 / 93$ & $16 / 85$ & - & $10.5 \%$ & $0.11[0.03,0.48]$ \\
\hline Wisborg 2000 & $4 / 120$ & $11 / 122$ & & $14.0 \%$ & $0.37[0.12,1.13]$ \\
\hline Subtotal (95\% CI) & 909 & 912 & & $72.7 \%$ & $0.58[0.27,1.26]$ \\
\hline \multicolumn{6}{|c|}{ Total events: 87 (NRT), I03 (Control) } \\
\hline \multicolumn{6}{|c|}{ Heterogeneity: $\operatorname{Tau}^{2}=0.44 ; \mathrm{Chi}^{2}=15.22, \mathrm{df}=3(\mathrm{P}=0.002) ;\left.\right|^{2}=80 \%$} \\
\hline \multicolumn{6}{|c|}{ Test for overall effect: $Z=1.38(P=0.17)$} \\
\hline \multicolumn{6}{|c|}{2 Non-placebo controlled trials } \\
\hline El-Mohandes 2013 & $3 / 25$ & $4 / 25$ & - & $11.0 \%$ & $0.75[0.19,3.01]$ \\
\hline Pollak 2007 & $17 / 109$ & $5 / 57$ & - & $16.3 \%$ & $1.78[0.69,4.57]$ \\
\hline Subtotal (95\% CI) & 134 & 82 & & $27.3 \%$ & $1.35[0.61,2.98]$ \\
\hline \multicolumn{6}{|c|}{ Total events: 20 (NRT), 9 (Control) } \\
\hline \multicolumn{6}{|c|}{ Heterogeneity: $\operatorname{Tau}^{2}=0.01 ; \mathrm{Chi}^{2}=1.02, \mathrm{df}=\mathrm{I}(\mathrm{P}=0.31) ; \mathrm{I}^{2}=2 \%$} \\
\hline \multicolumn{6}{|c|}{ Test for overall effect: $Z=0.75(P=0.46)$} \\
\hline Total (95\% CI) & 1043 & 994 & & $100.0 \%$ & $0.74[0.41,1.34]$ \\
\hline \multicolumn{6}{|c|}{ Total events: I07 (NRT), I 12 (Control) } \\
\hline \multicolumn{6}{|c|}{ Heterogeneity: $\mathrm{Tau}^{2}=0.33 ; \mathrm{Chi}^{2}=17.02, \mathrm{df}=5(\mathrm{P}=0.004) ;\left.\right|^{2}=71 \%$} \\
\hline \multicolumn{6}{|c|}{ Test for overall effect: $Z=0.99(P=0.32)$} \\
\hline Test for subgroup differen & $=2.23, \mathrm{df}$ & $0.13),\left.\right|^{2}=55 \%$ & & & \\
\hline
\end{tabular}

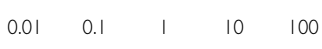

Favours NRT Favours control 
Analysis 2.5. Comparison 2 Nicotine replacement therapy versus control (Secondary outcomes - safety), Outcome 5 Preterm birth (birth $<37$ weeks).

Review: Pharmacological interventions for promoting smoking cessation during pregnancy

Comparison: 2 Nicotine replacement therapy versus control (Secondary outcomes - safety)

Outcome: 5 Preterm birth (birth $<37$ weeks)

\begin{tabular}{|c|c|c|c|c|c|}
\hline Study or subgroup & $\begin{array}{l}\text { NRT } \\
n / N\end{array}$ & Control & $\begin{array}{c}\text { Risk Ratio } \\
\text { M- } \\
\text { H,Random,95\% } \\
\text { Cl }\end{array}$ & Weight & $\begin{array}{c}\text { Risk Ratio } \\
\text { M- } \\
\text { H,Random,95\% } \\
\text { Cl }\end{array}$ \\
\hline \multicolumn{6}{|l|}{ I Placebo-controlled trials } \\
\hline Berlin 2014 & $19 / 189$ & $20 / 188$ & & $20.1 \%$ & $0.94[0.52,1.71]$ \\
\hline Coleman 2012 & $40 / 507$ & $45 / 517$ & & $42.8 \%$ & $0.91[0.60,1.36]$ \\
\hline Oncken 2008 & $7 / 93$ & $16 / 85$ & $\rightarrow$ & $10.1 \%$ & $0.40[0.17,0.92]$ \\
\hline Wisborg 2000 & $10 / 120$ & $12 / 122$ & & $11.1 \%$ & $0.85[0.38,1.89]$ \\
\hline Subtotal (95\% CI) & 909 & 912 & $\bullet$ & $84.1 \%$ & $0.81[0.60,1.11]$ \\
\hline \multicolumn{6}{|c|}{ Total events: 76 (NRT), 93 (Control) } \\
\hline \multicolumn{6}{|c|}{ Heterogeneity: $\mathrm{Tau}^{2}=0.0 \mathrm{I} ; \mathrm{Chi}^{2}=3.28, \mathrm{df}=3(\mathrm{P}=0.35) ; \mathrm{I}^{2}=9 \%$} \\
\hline \multicolumn{6}{|c|}{ Test for overall effect: $Z=1.29(P=0.20)$} \\
\hline \multicolumn{6}{|c|}{2 Non-placebo controlled trials } \\
\hline El-Mohandes 2013 & $1 / 25$ & $2 / 25$ & & $1.3 \%$ & $0.50[0.05,5.17]$ \\
\hline Pollak 2007 & $24 / 119$ & $9 / 58$ & - & $14.6 \%$ & $1.30[0.65,2.61]$ \\
\hline Subtotal (95\% CI) & 144 & 83 & & $15.9 \%$ & $1.20[0.62,2.35]$ \\
\hline \multicolumn{6}{|c|}{ Total events: 25 (NRT), I I (Control) } \\
\hline \multicolumn{6}{|c|}{ Heterogeneity: $\operatorname{Tau}^{2}=0.0 ; \mathrm{Chi}^{2}=0.59, \mathrm{df}=\mathrm{I}(\mathrm{P}=0.44) ; \mathrm{I}^{2}=0.0 \%$} \\
\hline \multicolumn{6}{|c|}{ Test for overall effect: $Z=0.54(P=0.59)$} \\
\hline Total (95\% CI) & 1053 & 995 & 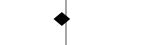 & $100.0 \%$ & $0.87[0.67,1.14]$ \\
\hline \multicolumn{6}{|c|}{ Total events: I0I (NRT), 104 (Control) } \\
\hline \multicolumn{6}{|c|}{ Heterogeneity: $\operatorname{Tau}^{2}=0.0 ; \mathrm{Chi}^{2}=4.91, \mathrm{df}=5(P=0.43) ;\left.\right|^{2}=0.0 \%$} \\
\hline \multicolumn{6}{|c|}{ Test for overall effect: $Z=1.00(P=0.32)$} \\
\hline Test for subgroup differen & $=1.06, \mathrm{~d}$ & $0.30),\left.\right|^{2}=6 \%$ & & & \\
\hline
\end{tabular}

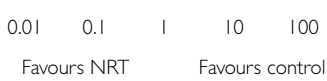

Pharmacological interventions for promoting smoking cessation during pregnancy (Review) 
Analysis 2.6. Comparison 2 Nicotine replacement therapy versus control (Secondary outcomes - safety), Outcome 6 Neonatal intensive care unit admissions.

Review: Pharmacological interventions for promoting smoking cessation during pregnancy

Comparison: 2 Nicotine replacement therapy versus control (Secondary outcomes - safety)

Outcome: 6 Neonatal intensive care unit admissions

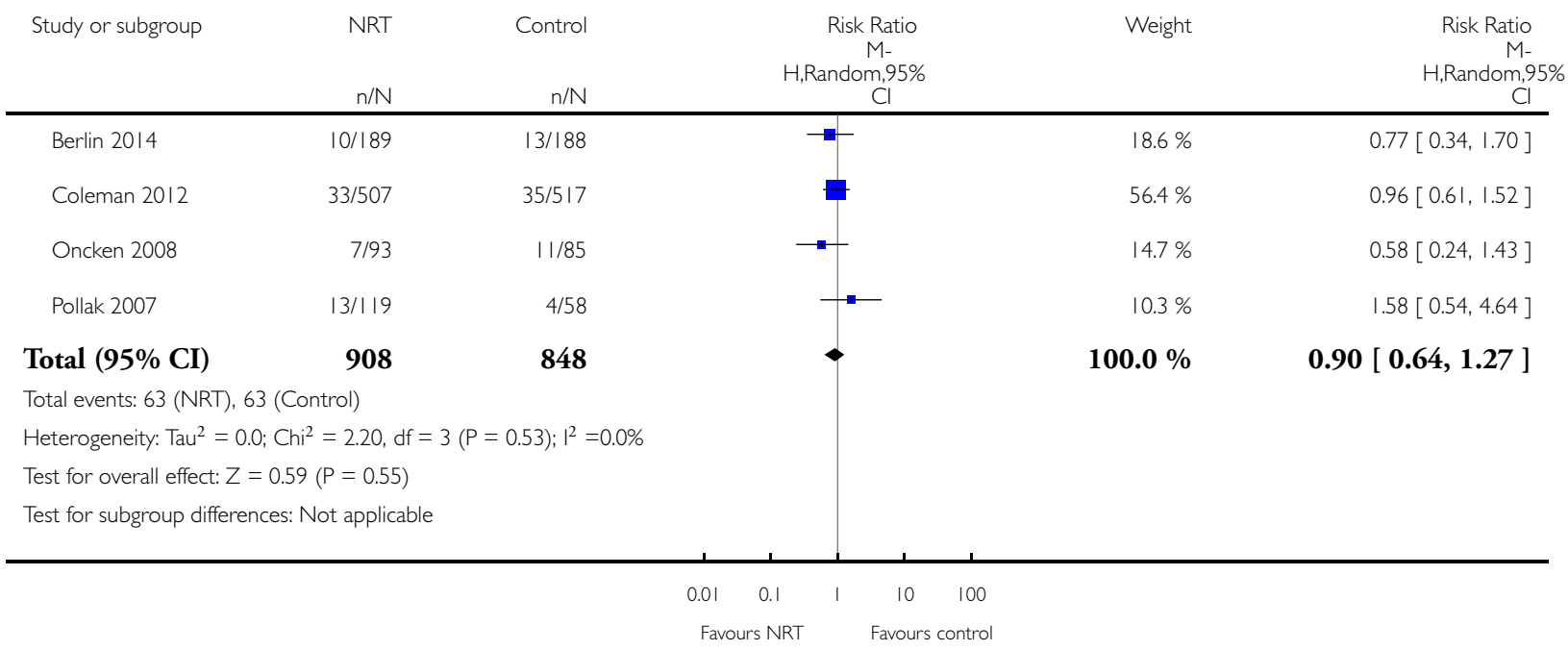


Analysis 2.7. Comparison 2 Nicotine replacement therapy versus control (Secondary outcomes - safety), Outcome 7 Neonatal death.

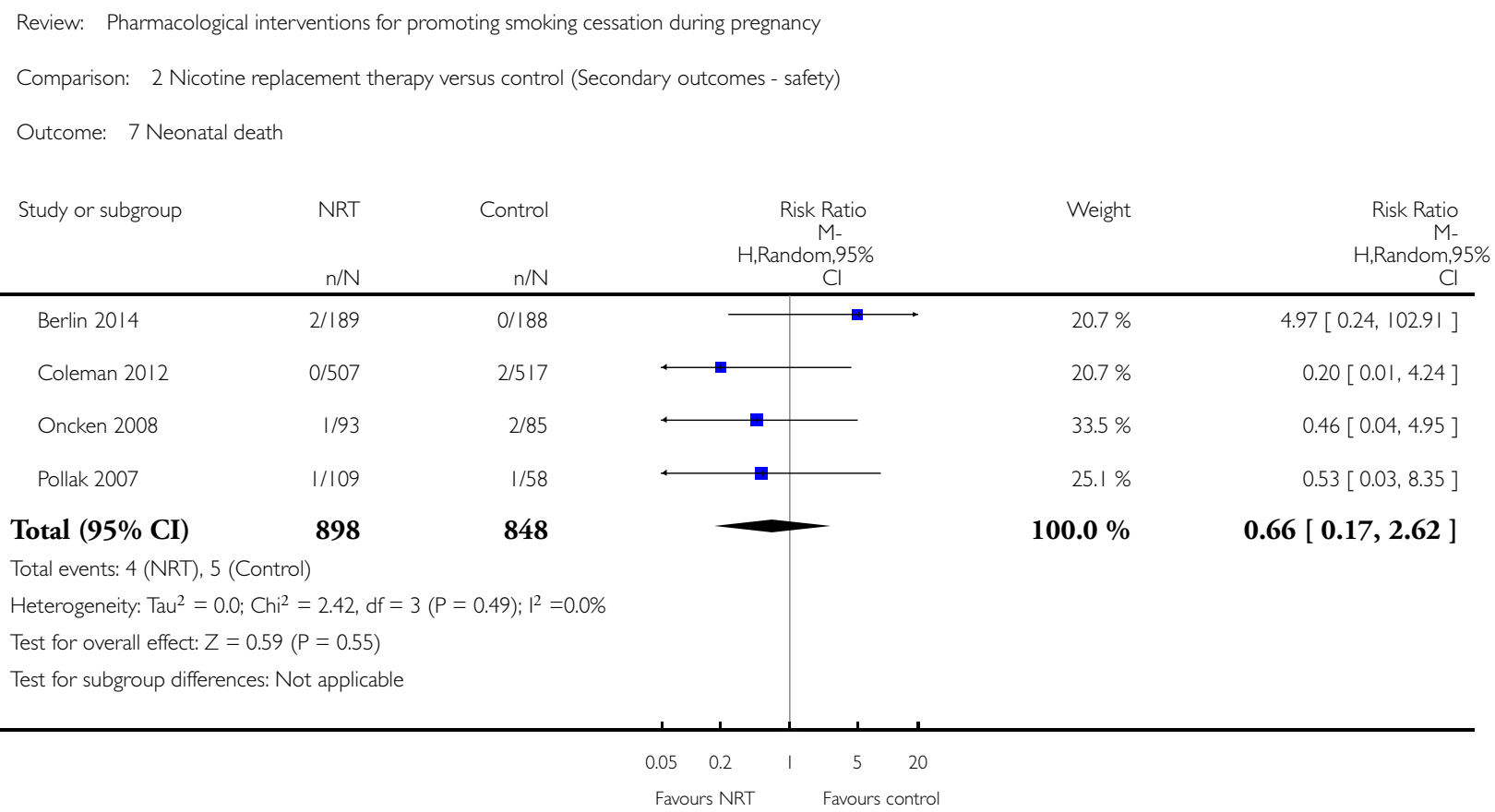


Analysis 2.8. Comparison 2 Nicotine replacement therapy versus control (Secondary outcomes - safety), Outcome 8 Congenital abnormalities.

Review: Pharmacological interventions for promoting smoking cessation during pregnancy

Comparison: 2 Nicotine replacement therapy versus control (Secondary outcomes - safety)

Outcome: 8 Congenital abnormalities

$\begin{array}{llll}\text { Study or subgroup } & \text { NRT } & \text { Control } & \text { Risk Ratio }\end{array}$ Weight H.Random, $95 \%$ H.

\begin{tabular}{|c|c|c|c|c|c|}
\hline & $\mathrm{n} / \mathrm{N}$ & $\mathrm{n} / \mathrm{N}$ & $\begin{array}{c}\mathrm{H}, \text { Random,95\% } \\
\mathrm{Cl}\end{array}$ & & $\begin{array}{r}\mathrm{H} \text {,Random,9 } \\
\mathrm{Cl}\end{array}$ \\
\hline Berlin 2014 & $4 / 189$ & $5 / 188$ & $\longrightarrow$ & $29.5 \%$ & $0.80[0.22,2.92]$ \\
\hline Coleman 2012 & $9 / 507$ & $13 / 517$ & - & $70.5 \%$ & $0.71[0.30,1.64]$ \\
\hline
\end{tabular}

Total $(95 \% \mathrm{CI}) \quad 696 \quad 705$

Total events: 13 (NRT), 18 (Control)

Heterogeneity: Tau $^{2}=0.0 ; \mathrm{Chi}^{2}=0.02, \mathrm{df}=\mathrm{I}(\mathrm{P}=0.88) ; \mathrm{I}^{2}=0.0 \%$

Test for overall effect: $Z=0.87(P=0.39)$

Test for subgroup differences: Not applicable

$100.0 \%$

0.73 [ $0.36,1.48$ ] 
Analysis 2.9. Comparison 2 Nicotine replacement therapy versus control (Secondary outcomes - safety), Outcome 9 Caesarean section.

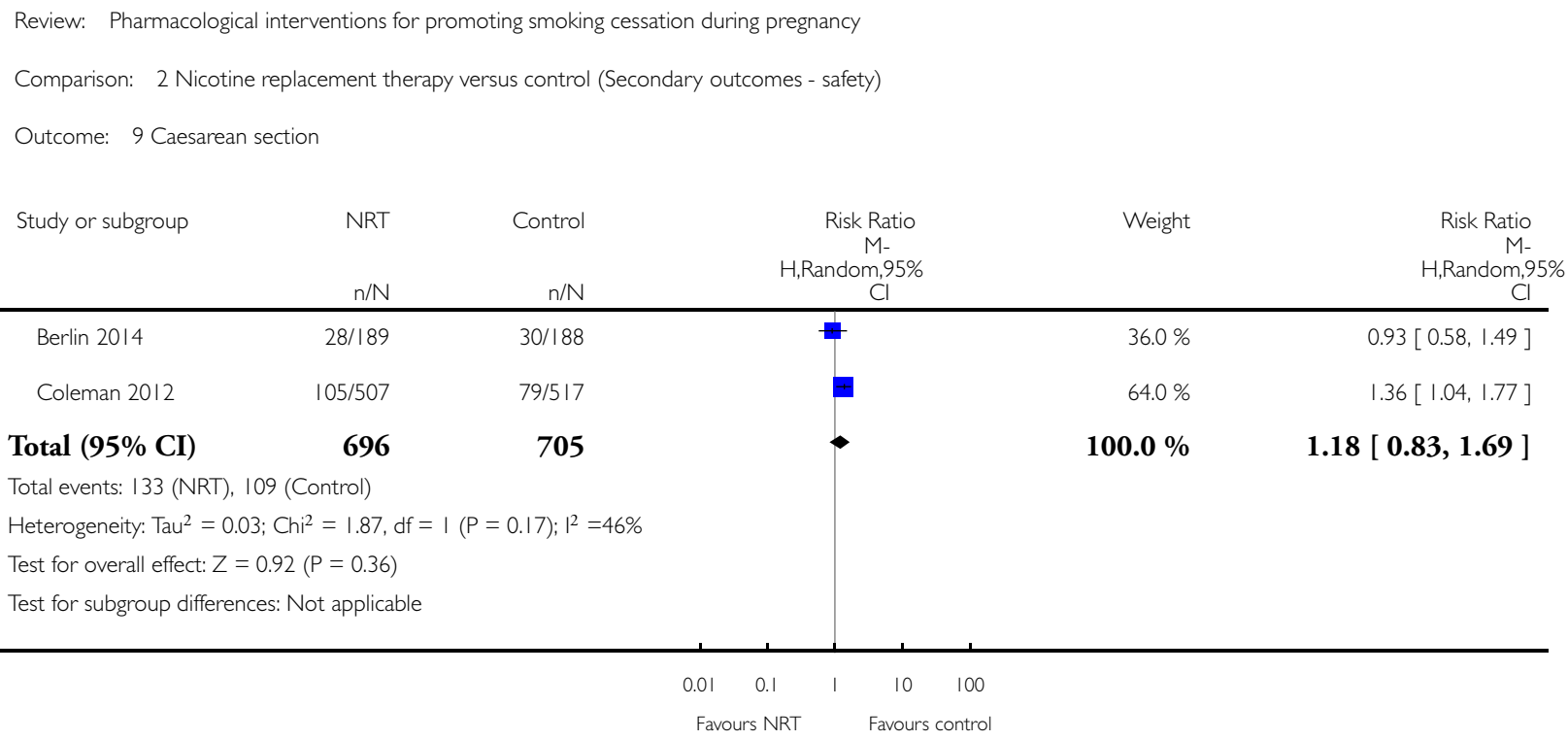

\section{ADDITIONAL TABLES}

Table 1. Distribution of twin births and fetal losses within singleton pregnancies in NRT and control groups

\begin{tabular}{|c|c|c|c|c|c|c|c|c|c|c|c|c|c|c|}
\hline & \multicolumn{2}{|c|}{$\begin{array}{l}\text { Twin pregnan- } \\
\text { cies, } n\end{array}$} & \multicolumn{2}{|c|}{ Miscarriage, $\mathrm{n}$} & \multicolumn{2}{|c|}{ Stillbirth, n } & \multicolumn{2}{|c|}{ Termination, $\mathrm{n}$} & \multicolumn{2}{|c|}{$\begin{array}{l}\text { Miss- } \\
\text { ing data: birth } \\
\text { outcomes/ } \\
\text { whether } \\
\text { birth occurred } \\
\text { not known }\end{array}$} & \multicolumn{2}{|c|}{$\begin{array}{l}\text { Non-viable } \\
\text { pregnancy } \\
\text { at randomisa- } \\
\text { tion, } n\end{array}$} & \multicolumn{2}{|c|}{$\begin{array}{l}\text { Known live } \\
\text { births } \\
\text { from singleton } \\
\text { pregnancies, } n\end{array}$} \\
\hline & NRT & $\begin{array}{l}\text { Con- } \\
\text { trol }\end{array}$ & NRT & $\begin{array}{l}\text { Con- } \\
\text { trol }\end{array}$ & NRT & $\begin{array}{l}\text { Con- } \\
\text { trol }\end{array}$ & NRT & $\begin{array}{l}\text { Con- } \\
\text { trol }\end{array}$ & NRT & $\begin{array}{l}\text { Con- } \\
\text { trol }\end{array}$ & NRT & $\begin{array}{l}\text { Con- } \\
\text { trol }\end{array}$ & NRT & $\begin{array}{l}\text { Con- } \\
\text { trol }\end{array}$ \\
\hline $\begin{array}{l}\text { Wis- } \\
\text { borg } \\
2000\end{array}$ & $1^{*}$ & & $7^{*}$ & & & & & & & & & & 120 & 122 \\
\hline $\begin{array}{l}\text { Pollak } \\
2007\end{array}$ & 2 & 0 & 1 & 0 & 2 & 1 & 0 & 0 & 8 & 1 & 1 & 0 & 109 & 57 \\
\hline $\begin{array}{l}\text { On- } \\
\text { cken } \\
2008\end{array}$ & $\begin{array}{l}\text { Wome } \\
\text { multip } \\
\text { births }\end{array}$ & $\begin{array}{l}\text { with } \\
\text { vere ex- }\end{array}$ & 2 & 1 & 2 & 1 & 0 & $3^{* *}$ & 3 & 4 & 0 & 0 & 93 & 85 \\
\hline
\end{tabular}

Pharmacological interventions for promoting smoking cessation during pregnancy (Review)

Copyright $\odot 2015$ The Cochrane Collaboration. Published by John Wiley \& Sons, Ltd. 
Table 1. Distribution of twin births and fetal losses within singleton pregnancies in NRT and control groups

\begin{tabular}{|c|c|c|c|c|c|c|c|c|c|c|c|c|c|c|}
\hline & $\mathrm{clu}$ & & & & & & & & & & & & & \\
\hline $\begin{array}{l}\text { Cole- } \\
\text { man } \\
2012\end{array}$ & 4 & 8 & 3 & 2 & 5 & 2 & 1 & 0 & 4 & 10 & 1 & 0 & 503 & 507 \\
\hline $\begin{array}{l}\text { Berlin } \\
2014\end{array}$ & 3 & 4 & 1 & 1 & 4 & 5 & $1^{* * *}$ & $1^{* * *}$ & 3 & 0 & 0 & 0 & $189^{* * * *}$ & 188 \\
\hline $\begin{array}{l}\text { El- } \\
\text { Mo- } \\
\text { han- } \\
\text { des } \\
2013\end{array}$ & 0 & 0 & 0 & 0 & 0 & 0 & 0 & 0 & 1 & 1 & 0 & 0 & 25 & 25 \\
\hline
\end{tabular}

* the treatment allocation of the twin pregnancy and miscarriages are not known

** authors confirmed that all terminations were done for social reasons and fetus thought to be normal

*** done for medical problems judged incompatible with birth survival

**** includes 2 infants who died during childbirth

Table 2. Adherence with nicotine replacement therapy regimens

\begin{tabular}{|c|c|c|}
\hline Study & $\begin{array}{l}\text { Adherence with offered regimen as a percentage of } \\
\text { complete course }\end{array}$ & $\begin{array}{l}\text { Adherence with offered regimen in terms of period of } \\
\text { use }\end{array}$ \\
\hline Wisborg 2000 & $\begin{array}{l}\text { Complete adherence with } 11 \text { weeks course: nicotine } \\
\text { group }=11 \% \text {, placebo }=7 \% \text {. Partial adherence (up to } 8 \\
\text { weeks use): nicotine group }=17 \% \text {, placebo }=8 \%\end{array}$ & $\begin{array}{l}\text { Median number patches (ranges): nicotine group }=14 \\
(0-77)-\text { median }=\text { approximately } 2 \text { weeks, placebo }=7 \\
(0-77)-\text { median approximately } 1 \text { week }\end{array}$ \\
\hline Kapur 2001 & $\begin{array}{l}\text { In the nicotine group, } 4 / 17(23.5 \%) \text { completed the } 14- \\
\text { week programme. In the placebo group, no participants } \\
\text { completed the programme }\end{array}$ & $\begin{array}{l}\text { In the nicotine group, } 4 / 17(23.5 \%) \text { completed the } 14- \\
\text { week programme, } 3 / 17(17.6 \%) \text { - used patch for at least } \\
3 \text { weeks and } 10 / 17(58.8 \%) \text { - used patch for less than } 1 \\
\text { week } \\
\text { In the placebo group, no participants completed the pro- } \\
\text { gramme, } 3 / 13(23 \%) \text { used patch for between } 4 \text { and } 5 \\
\text { weeks and } 10 / 13(76.9 \%) \text { used patch for }<1 \text { week }\end{array}$ \\
\hline Hotham 2006 & $\begin{array}{l}25 \%(5) \text { participants complied fully with protocol: 'con- } \\
\text { tinuous patch use till } 12 \text { weeks or confident that abstinence } \\
\text { achieved or adverse reaction experienced. }\end{array}$ & $50 \%$ (10) of participants used NRT for 6 or less weeks. \\
\hline Pollak 2007 & $\begin{array}{l}\text { Difficult to ascertain from this manuscript. A secondary } \\
\text { publication reported that } 29 \% \text { of participants used NRT } \\
\text { as directed for intended 6-week programme (Fish 2009) }\end{array}$ & $\begin{array}{l}\text { Means of reported periods of use: } \\
\text { Patch }=23.4 \text { patches }=3.3 \text { weeks } \\
\text { Gum }=8 \text { days } \\
\text { Lozenge }=4 \text { days }\end{array}$ \\
\hline
\end{tabular}

Pharmacological interventions for promoting smoking cessation during pregnancy (Review) 
Oncken 2008 Not clearly reported.

\begin{tabular}{|c|c|}
\hline Coleman 2012 & $\begin{array}{l}\text { Limited compliance with the intervention. Only } 7.2 \% \\
\text { of women ( } 35 \text { of } 485) \text { assigned to receive NRT and } 2 \text {. } \\
8 \% \text { ( } 14 \text { of } 496) \text { assigned to receive placebo reported us- } \\
\text { ing trial medications for more than } 1 \text { month ( } 2 \text { months } \\
\text { represented a complete course); rates of use of non-study } \\
\text { nicotine-replacement therapy were very low. Most partic- } \\
\text { ipants had no additional contact, either face-to-face or by } \\
\text { text message, with smoking-cessation advisors; among } \\
\text { those who did, the frequency of contact was similar in } \\
\text { the } 2 \text { groups }\end{array}$ \\
\hline
\end{tabular}

Berlin 2014 In contrast to other studies, women were issued with a much longer course of transdermal patches; these were issued from women's quit dates to their delivery Compliance was measured using self-reported data on patches used between study visits and was obtained at 1016 study visits from 307 (76\%) participants; 164 (84\%) in NRT and 143 (72\%) in placebo groups Median (IQR) reported patch use in NRT group was $85 \%$ (56\% to $99 \%)$ and $83 \%(56 \%$ to $95 \%)$ in placebo. However, it is not clear how these figures relate to the rate with which participants discontinued the intervention. Overall, 225 (60.0\%) of participants stopped using trial treatments; $105(51.7 \%)$ in the NRT group and $60.3 \%$ in placebo
The nicotine group used gum for a mean (standard deviation) of 37.8 (3.8) days (i.e. just > 5 weeks). The placebo group reported using gum for a mean (standard deviation) of 29.9 (3.4) days (i.e. just $>4$ weeks)

Most participants discontinued patches after only short usage periods: in the nicotine group $60.1 \%$ of participants used patches for no longer than 2 weeks and in the placebo patch group this figure was $76.8 \%$

This was not reported but has less meaning for this RCT as women started using patches at different points in pregnancy and continued until childbirth

IQR: interquartile range

NRT: nicotine replacement therapy

RCT: randomised controlled trial

\section{WHAT'S NEW}

Last assessed as up-to-date: 11 July 2015.

\begin{tabular}{lll} 
Date & Event & Description \\
\hline 11 July 2015 & New search has been performed & $\begin{array}{l}\text { Search updated. Three new trials included in this update } \\
\text { (Berlin 2014; El-Mohandes 2013; Stotts 2015). }\end{array}$
\end{tabular}

Pharmacological interventions for promoting smoking cessation during pregnancy (Review) 
This update looked for both trials of pharmacotherapies and also of Electronic Nicotine Delivery Systems (ENDS) used for smoking cessation in pregnancy; it found mainly nicotine replacement therapy (NRT) trials with one bupropion trial which randomised only 11 pregnant smokers. A total of nine trials are included in this update

The conclusions are largely the same, although there is now more evidence to suggest that NRT used in pregnancy increases smoking cessation rates measured in late pregnancy by approximately $40 \%$. There is evidence, suggesting that when potentially-biased, non-placebo RCTs are excluded from analyses, NRT is no more effective than placebo

\section{CONTRIBUTIONSOFAUTHORS}

Review authors Tim Coleman (TC) and Catherine Chamberlain (CC) independently inspected search results and selected papers for inclusion in the review with disagreements resolved by discussion with Sue Cooper (SC). Jo Leonardi-Bee (JLB) extracted data from three papers, TC from two (excluding one authored by him, from which CC extracted data) and Mary-Ann Davey (MD), from one. Discussion with SC was used to resolve disagreements. TC contacted study authors as appropriate and he also entered data into Revman software. TC and SC assessed the risk of bias for two studies and the third (authored by SC and TC) was assessed by JLB and CC. All authors commented on the final draft of the updated review after TC had produced an initial draft and TC finalised the text.

\section{DECLARATIONSOF INTEREST}

Within the last five years, Tim Coleman has once been paid for speaking at two meetings arranged by Pierre Fabre Laboratories (manufacturers of nicotine replacement therapy). Tim Coleman was Chief Investigator and Sue Cooper Trial Manager for a UK-based, placebo-randomised controlled trial of NRT in pregnancy which was funded by public monies and used nicotine replacement products which are not available on prescription or 'over the counter' in any country (Coleman 2012). This trial is included in this review but neither Tim nor Sue undertook data extraction from or quality assessment of either paper reporting this study.

Catherine Chamberlain is lead author of the Cochrane review on Psychosocial interventions for supporting women to stop smoking in pregnancy (Chamberlain 2013); earlier versions of this included a subgroup analysis of trials involving provision of NRT as part their intervention strategy (Lumley 2009). Catherine works for the Indigenous Health Equity Unit, which receives some funding from VicHealth, which in turn is partly government funded from tobacco revenue to reduce tobacco harm, and is governed by the Tobacco Act. CC does not have any other conflicts of interest to declare.

Jo Leonardi-Bee receives an educational grant from Roche which is unrelated to any smoking cessation treatments.

Mary-Ann Davey does not have any conflicts of interest to declare.

Pharmacological interventions for promoting smoking cessation during pregnancy (Review) 


\section{SOURCES OF SUPPORT}

\section{Internal sources}

- La Trobe University 1996 to date, Australia.

- UK Centre for Tobacco Control Studies: a Public Health Centre of Research Excellence, UK.

- NIHR National School For Primary Care Research, UK.

\section{External sources}

- Victorian Health Promotion Foundation, Australia.

- Department of Health, UK funding for EPI-Centre, London University, UK.

- Public Health Branch Victorian Department of Human Services, Australia.

- (TC, SC and JLB) National Institute for Health Research (NIHR), Programme Grant for Applied Research programme (grant number RP-PG 0109-10020), UK.

\section{DIFFERENCES BETWEEN PROTOCOLANDREVIEW}

A protocol for this (pharmacological interventions) review was submitted prior to initiating this work; however, there were two differences between the protocol and the first version of this review and further minor changes were made for this first review update. These are described below with explanations of why changes were made.

Types of studies: in the protocol we planned to search for only nicotine replacement therapy (NRT) studies but realised that if studies using other smoking cessation drugs had been conducted, these should be included. Consequently, for the first version of this review we altered criteria to potentially include all trials of smoking cessation pharmacotherapies conducted in pregnancy. Additionally, in the period between publication of the review and the first update, the use of 'e cigarettes' increased substantially and at least one smoking cessation trial (non-pregnant smokers) has been published. Consequently, we believed it was important to search for any studies investigating the use of e-cigarettes (now called Electronic Nicotine Delivery Systems (ENDS)) for smoking cessation in pregnancy and, if any such studies which met review eligibility criteria were found, to include these in the review update.

Changes to outcomes: this review has slightly different pregnancy and birth outcomes compared to those listed in the protocol. The differences between the protocol and first version were: miscarriage and spontaneous abortion, stillbirth and neonatal deaths and caesarean section. At the protocol stage, we had planned to report perinatal death, post-randomisation fetal death and fetal demise, but as the use of these terms made the review less amenable to comprehension and so these were dropped and replaced with more standard terms. We also decided to use the term 'adherence' rather than compliance as this is more appropriate to describe medication taking and we also realised that, should any trials document the long-term effects of pharmacotherapies, this would be important to document and this was added as an outcome.

For the update, we have added maternal hypertension, infant respiratory symptoms and infant development to listed, named safety outcomes that were investigated. This was because more than one trial has now recorded data on hypertension, so there was now potential for meta-analysis of this outcome and, for the first time, we identified a trial that had monitored infant outcomes after the perinatal period and these seemed important to include for comprehensiveness.

Clarification of subgroup and sensitivity analyses: the protocol was rather vague regarding subgroup and sensitivity analyses, so prior to undertaking the review we made these explicit.

The only planned subgroup analysis was: i) a comparison of placebo-randomised controlled trials with trials that did not use a placebo. The two planned sensitivity analyses were i) including only trials with biochemical validation and ii) excluding those which reported substantially lower adherence.

For the previous version of the review we took the decision to use self-reported data from Wisborg 2000 in primary analyses and to report analyses using biochemically-validated data from this study alongside the primary analysis as a sensitivity analysis. This was a post hoc sensitivity analysis and was not specified in the protocol.

We have now reconsidered this issue and, in retrospect, the decision to use self-report rather than validated data from Wisborg 2000 in primary analyses seems flawed. Possibly, the most important issue to affect ascertainment bias in smoking cessation studies is that

Pharmacological interventions for promoting smoking cessation during pregnancy (Review)

Copyright $\Subset 2015$ The Cochrane Collaboration. Published by John Wiley \& Sons, Ltd. 
of participants reporting abstinence when they are in fact still smoking. The converse, in which participants falsely report that they are smoking is not generally considered likely to occur frequently. Consequently, biochemical validation usually detects some false reports of abstinence and lower cut points for biochemical tests are likely to detect more of these. A higher than usual cut point will still detect some false reports of abstinence; in particular, false reports made by participants who are still smoking heavily are more likely to be detected. This means that even when validation uses a higher than standard cut point, validated rather than self-report data should be used in primary analyses.

This issue is described in detail in the 'Blinding (performance and detection bias)' under the sub-heading 'Detection bias'.

Given the above, the review now reports a primary 'efficacy' analysis using validated data only (all studies provided this) and text has been altered to reflect this fact. The updated review now includes no post hoc sensitivity analyses.

\section{INDEX TERMS}

\section{Medical Subject Headings (MeSH)}

*Tobacco Use Cessation Products; Pregnancy Complications [*drug therapy]; Pregnancy Outcome; Randomized Controlled Trials as Topic; Smoking Cessation [* methods]

\section{MeSH check words}

Female; Humans; Pregnancy 


\section{University Library}

\section{- M M N E R VA A gateway to Melbourne's research publications}

Minerva Access is the Institutional Repository of The University of Melbourne

Author/s:

Coleman, T;Chamberlain, C;Davey, M-A;Cooper, SE;Leonardi-Bee, J

Title:

Pharmacological interventions for promoting smoking cessation during pregnancy

Date:

2015-01-01

Citation:

Coleman, T., Chamberlain, C., Davey, M. -A., Cooper, S. E. \& Leonardi-Bee, J. (2015). Pharmacological interventions for promoting smoking cessation during pregnancy. COCHRANE DATABASE OF SYSTEMATIC REVIEWS, 2015 (12), https:// doi.org/10.1002/14651858.CD010078.pub2.

Persistent Link:

http://hdl.handle.net/11343/57346 